\title{
REEL COPS: EXPLORING THE REPRESENTATION OF POLICING ON POLICE
} TEN 7

\author{
By \\ Gabrielle Margaret Podvoiskis
}

\begin{abstract}
A thesis
submitted to the Victoria University of Wellington

in fulfilment of the requirements for the degree of

Master of Arts

In Criminology
\end{abstract}

School of Social and Cultural Studies

Victoria University of Wellington 


\begin{abstract}
Cop shows have been a perennial on prime time television for the past fifty years ${ }^{1}$. Over the past two decades, however, the increasing popularity of reality television means that it is now competing for ascendency with traditional police-centered "soap operas". For example, at the time of writing a search of the television scheduling by genre on TVNZ on demand reveals 92 reality television programmes compared to 65 dramas, 36 comedies and 22 news programmes. New Zealand, despite its limited production capacity has also cashed in on reality television with recent New Zealand offerings including Motorway Patrol, Illegal NZ, Drug Bust and Emergency 111. The most popular, award winning ${ }^{2}$ reality crime programme currently screening on New Zealand television, now in its $20^{\text {th }}$ season, is Police Ten 7. The principle research question driving this thesis is: "To what extent does Police Ten 7 reflect the actual reality of contemporary policing in New Zealand?"
\end{abstract}

This research question was explored through a content analysis of the entire 2010 season of Police Ten 7, consisting of 15 episodes. To assess the extent to which Police Ten 7 reflects the known realities of policing, the content analysis was broken into three main components. The first examined the demographic makeup of police. The second explored types of offences and offenders featured and the third explored the types of police activities depicted on Police Ten 7. These were then contrasted against the known realities of police, offenders and offending patterns in New Zealand. In short, the focus was on who was featured on Police Ten 7, what were they portrayed as doing and how this compares to what we actually know about crime and policing in New Zealand.

The main findings were that while some aspects of policing and offending were depicted reasonably accurately, for example gender and ethnicity of police, other aspects were significantly skewed. Police Ten 7 consistently misrepresents the types of offences most commonly committed in New Zealand, over-representing traditional "street" crime such as drug and antisocial offending and violence and under-representing and even ignoring

1 For example, in the UK The Dixon of Dock Green first aired in 1955 followed by Z-Cars in 1962, The Sweeney in 1975, The Bill in 1984, Law and Order (1990).

2 Police Ten 7 was voted best reality series on the Best on the Box TV Guide viewers' choice awards in 2007, 2010 and 2011 (TVNZ, 2011a) 
completely other common offences such as dishonesty crimes. Similarly, white individuals depicted in Police Ten 7 are much more likely to be police than offenders, while the opposite is true for non-white individuals who are also depicted more commonly as being involved in violent offending than their white counterparts. As a vehicle for the presentation of the reality of policing Police Ten 7 was found to significantly misrepresent the work undertaken by the typical police officer, over-emphasising the exciting and action-packed aspects of the job and under-emphasising the service and administrative functions of police.

The conclusion reached as a result of this research is that Police Ten 7 does not in fact show audiences "a glimpse into the real working lives of New Zealand police" (TVNZ, 2011b). Instead it creates a specific, pro-police vision of policing and crime in New Zealand which features real police and offenders but as a result of the symbiotic relationship between the producers and the police combines to misrepresent the reality of both policing and offending for the majority of police and offenders. 


\section{Acknowledgments}

The existence of this thesis is thanks to the assistance, patience and support of many people. My supervisor, Trevor Bradley, has been an enormous help throughout this process, guiding me academically and providing much appreciated support when the entire thing seemed almost too much. Your humour and enthusiasm made the entire process more enjoyable and I have learnt more about writing and researching from you than I can express. The kindness and support given to me from the entire criminology department during the year has been amazing and I cannot thank everyone enough for their help.

I would like to thank my family who have supported me along the way and without whom I could not have finished this thesis. It would have been impossible to attempt without you and I owe you more than I can say (or ever repay). Finally, thank you T.J.B for your support, encouragement, patience and love. 


\section{Table of contents}

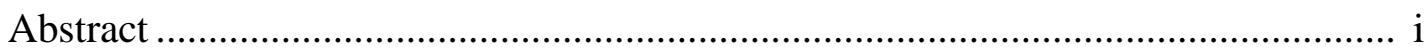

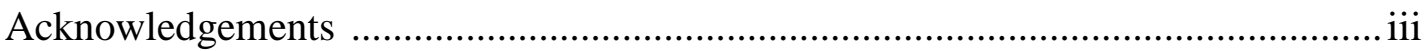

List of figures, tables and images....................................................................... vii

Chapter One: Introduction to research ............................................................................... 1

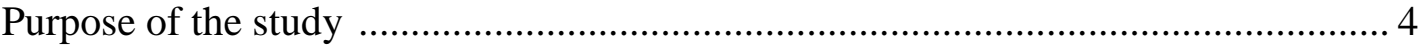

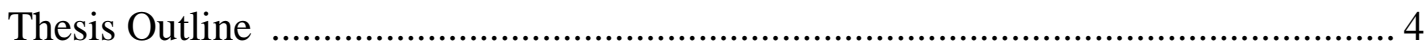

Chapter Two: Literature review..................................................................... 7

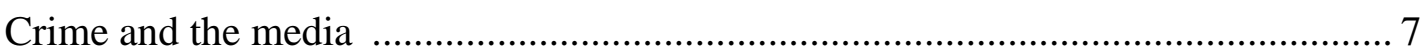

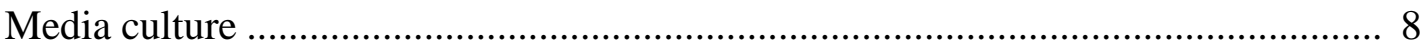

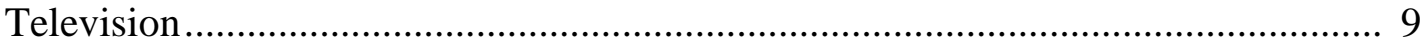

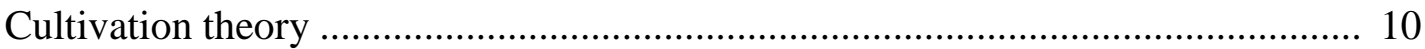

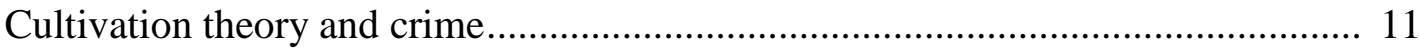

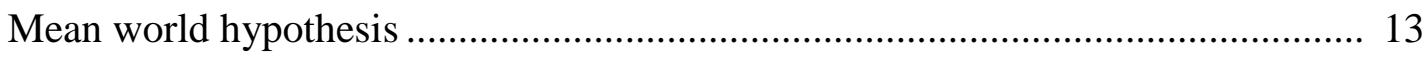

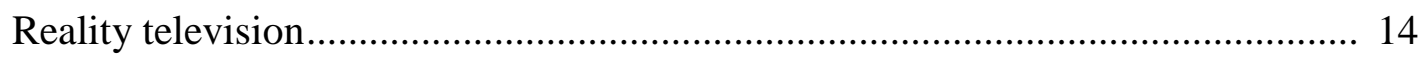

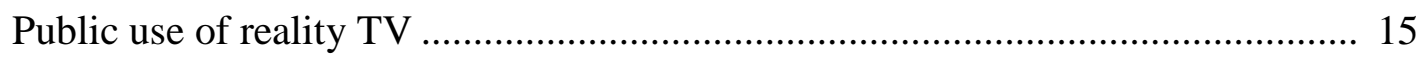

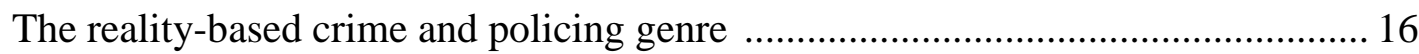

The producers and the police: an uneasy alliance ............................................. 18

Police promotion and the creation of "good" publicity .......................................... 20

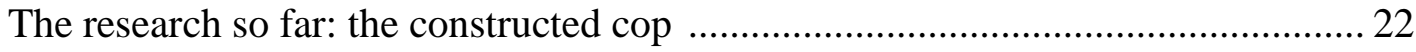

Chapter Three: Research design and methodology ............................................. 29

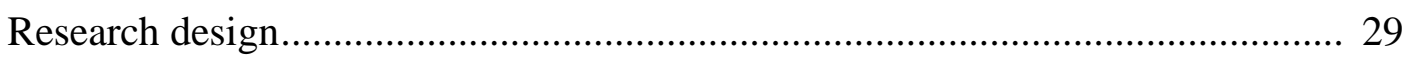

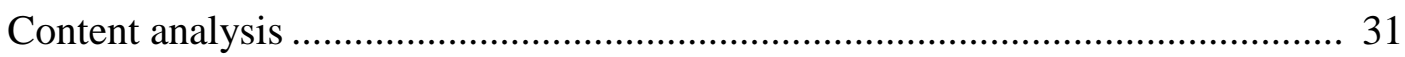

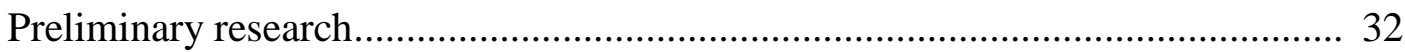

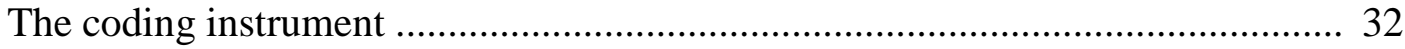

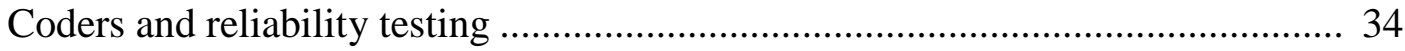

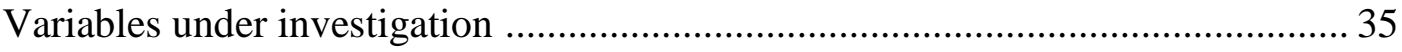

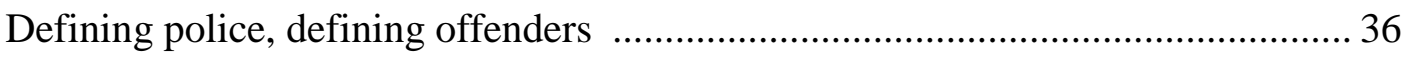

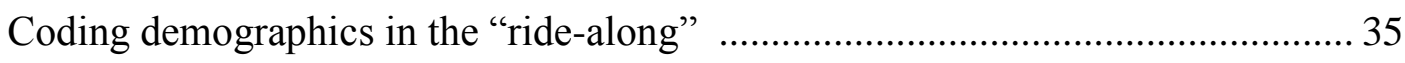

Coding gender, coding ethnicity, coding age .................................................. 37

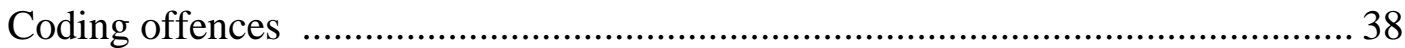

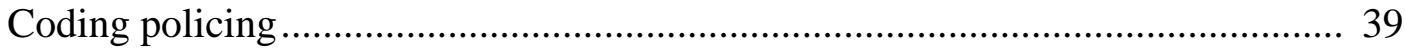

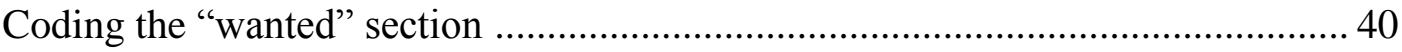

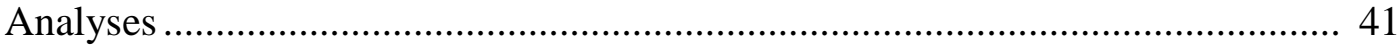

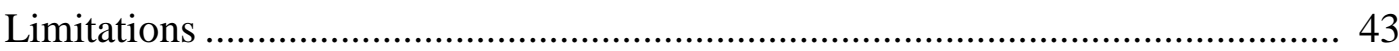


Chapter Four: Findings $\quad$.......................................................................................................... 45

Section one: the police "ride-along" section …................................................... 46

Representing the police: Demographics: gender............................................. 46

Representing the police: ethnicity .............................................................. 47

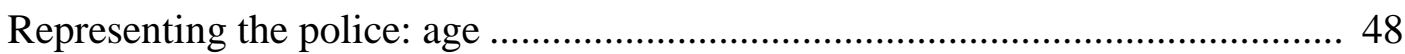

Representing offenders: Demographics, character portrayal and offence type .....50

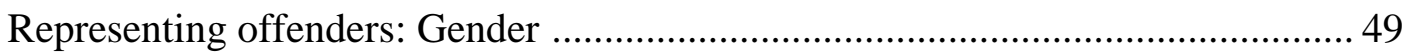

Representing offenders: Age ................................................................. 51

Representing offenders: Ethnicity ............................................................ 52

Representing offenders: Character portrayal …............................................... 53

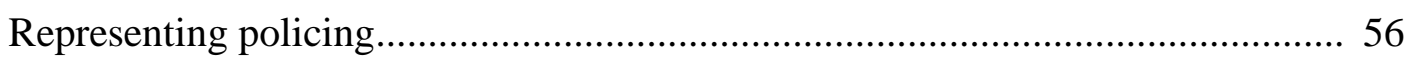

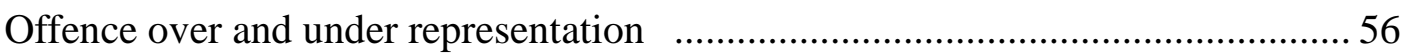

Temporal and geographical settings of policing ............................................. 58

Proactive and reactive policing .................................................................... 58

Policing resolution/clearance rates ...................................................................5 59

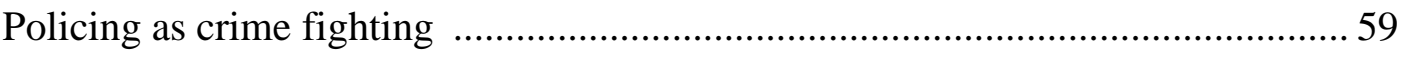

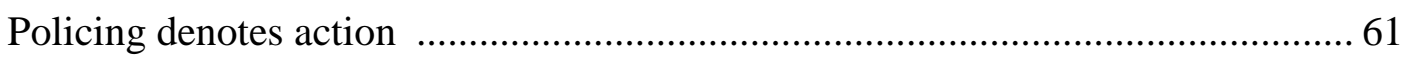

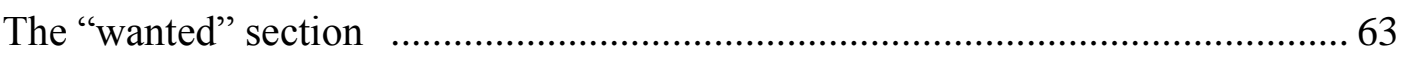

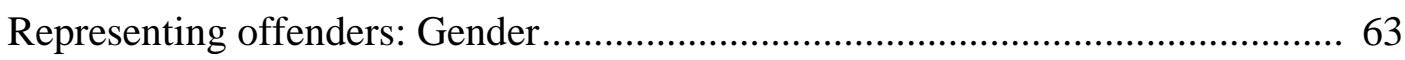

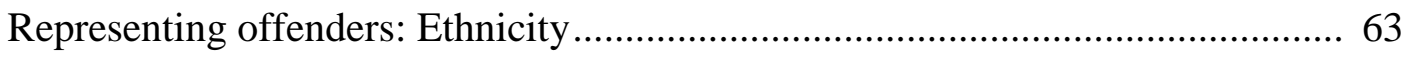

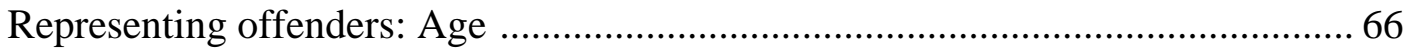

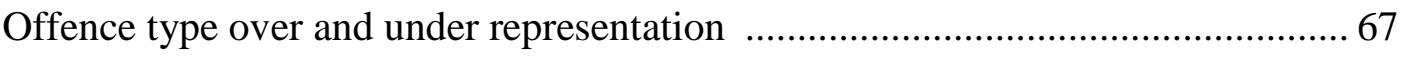

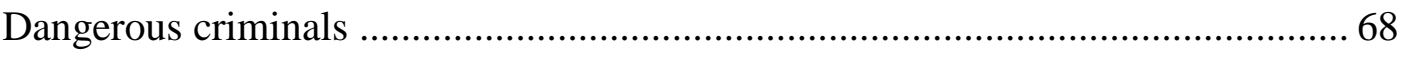

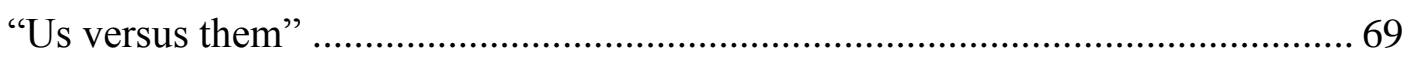

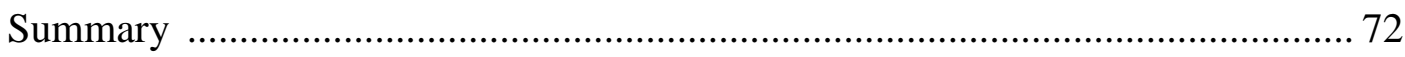

Chapter Five: Discussion ................................................................................ 74

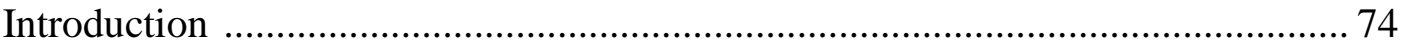

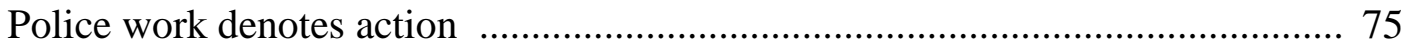

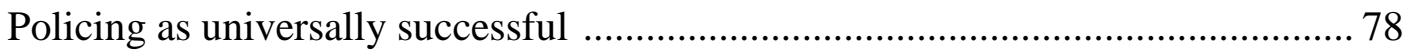

Policing as a young, white, male profession ..................................................... 79

Recruitment: Young recruits seeking action? ................................................. 80

Recruitment: Attracting a diverse police service ........................................... 82

Recruitment: The boys in blue? Women in the police ........................................ 83

Police Ten 7 as a vehicle for the promotion of police culture ............................ 86

Could too much success lead to unrealistic expectations? ................................. 87

The portrayal of crime and criminals: Ethnicity ................................................. 88 
Crime as public, inter-personal and violent 90

Dangerous predators and moron criminals 93

Offenders as individually deficient and out of control...................................... 95

Fear of crime and the assessment of risk ..................................................... 96

Giving voice to police, silencing offenders..................................................... 99

Police Ten 7 as a vehicle for the advancement of pro-police sentiment............. 100

The promotional power of Police Ten 7 ......................................................... 101

Reality TV: Issues for consideration .............................................................. 104

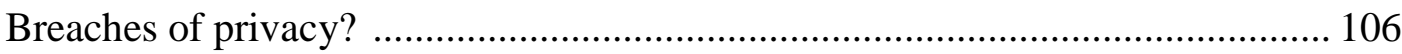

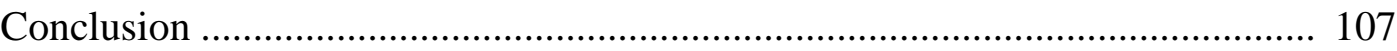

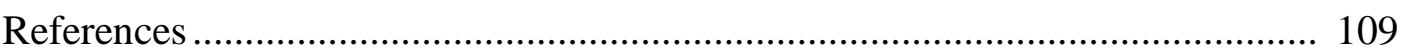

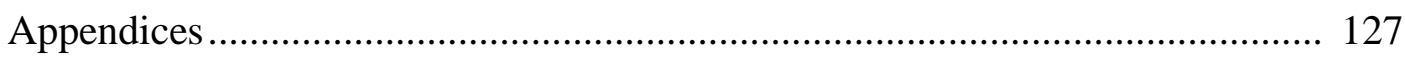

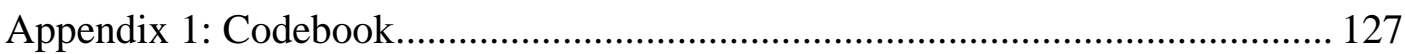

Appendix 2:Ethical approval.................................................................... 149 


\section{List of figures, images and tables}

Figure One: Ethnicity of police officers on Police Ten 7 and ethnicity of New Zealand Police

Figure Two: Police age as depicted on Police Ten 7 and actual distribution of police age in the Census (2006)

Figure Three: Police age curve as of 2008

Figure Four: Ethnicity of offenders on Police Ten 7 and National Annual Apprehensions (2010)

Figure Five: Character portrayal on Police Ten 7

Figure Six: Violent offences and ethnicity on Police Ten 7 and in National Annual Apprehensions (2010) 54

Figure Seven: Offender ethnicity and offence type on Police Ten 7

Figure Eight: Ethnicity and offence type in National Annual Apprehensions (2010) .56

Figure Nine: Offence distribution: Police Ten 7 and National Recorded Offences (2010)

Figure Ten: Ethnicity in the "wanted" section and in 2010 National Annual Apprehensions (2010)

Figure Eleven: Ethnicity in the "wanted" section and National Annual Apprehensions (2010) White and non-white

Figure Twelve: Custodial sentences by ethnicity 2010

Figure Thirteen: Offence type distribution in "ride-along", "wanted" and National Annual Recorded Offences(2010)

Table One: New Zealand Police resolution rates (2009) and coverage per offence type on Police Ten 7. 


\section{Chapter One: Introduction to research}

Over the past two decades a particularly significant development in broadcast television has been the advent and subsequent explosion of reality-based TV. Such is its popularity that reality-based programmes have achieved top ratings in most years since 2000 (Strenger, 2011). Moreover, according to Strenger (2011:43), the four national networks in the United States (ABC, CBS, NBC and Fox) have since 2008 planned for at least one "prime-time" reality show a year. Reality TV ostensibly offers viewers "a glimpse into the life" of an endless variety of individuals and professions ${ }^{1}$. Out of the wide variety of professions and interests which feature in reality TV one of the most popular and prolific subsets follows the work of law enforcement ${ }^{2}$. The early success of genre forerunners Cops in the United States of America and Crimewatch in the United Kingdom has spawned multiple localised versions across the Western world, including Police Ten 7 in New Zealand.

Police Ten 7 is New Zealand's answer to Cops and Crimewatch, hybridising both popular formats into one high-rating, half-hour weekly "home-grown crime-fighting series" (TVNZ, 2011b). The show has been on air for more than a decade, is widely acclaimed and is regularly named "best reality show" by viewers (TVNZ, 2011a). Police Ten 7 is advertised as presenting "a gritty unflinching look at the day-to-day working lives of police in New Zealand" (TVNZ, 2011b) and as providing "a behindthe-scenes glimpse into the real working lives of New Zealand police" (TVNZ, 2011b). Similar claims of reality have been the focus of extensive international research that has investigated the "reality" depicted in reality TV and its correspondence to the known realities of crime, policing and offending as evidenced in official crime statistics. International researchers (see Oliver \& Armstrong, 1998, Doyle, 2003, Oliver, 2003) have repeatedly concluded that the picture of policing,

\footnotetext{
In New Zealand a small sample of some of the reality TV shows broadcast include shows that follow the work of auctioneers, SPCA staff, property managers, MAF staff, lifeguards, ambulance officers, police college recruits as well as the exploits of "DIY dads", people sitting their drivers' licences, neighbours at war, teenagers deemed "delinquent", university students training to be vets and staff working at Auckland Zoo.

2 For example, Motorway Patrol, Crime Scene, Crimewatch, Border Patrol, Customs and Police Ten 7
} 
crime and offending in reality TV is significantly different from the actual known realities of policing, crime and offending.

This divergence between the claimed reality of these television shows and the actual unreality of the action presented has been identified by researchers as a matter of concern due to the potentially significant influence reality TV can have on public conceptions and perceptions of criminal justice related issues. The influence of the media in general, and television in particular, has long been debated by criminologists with cultivation theorists arguing that media depictions can "shape how the audience perceives the real world" (Chong Ho Shon \& Arrigo, 2006:63) through repeated exposure to media products (Gerbner \& Gross, 1976). The rise of reality TV has raised further questions due to the very explicit claims to reality made by these media products. It has been argued that the media has an increased influence when audiences believe the source to be true, as opposed to explicitly fictional shows, and even more so when the content is related to an area of interest about which audiences have limited personal experience (Cavender, Bond-Maupin \& Jurik, 1999, Surrette, 1992, Oliver \& Armstrong, 1998).

The 2009 New Zealand Crime and Safety Survey (NZCASS) revealed that in 2008 $64 \%$ of New Zealanders did not experience any criminal victimisation (Ministry of Justice, 2010). Furthermore, this survey confirmed that victimisation is unevenly distributed with $6 \%$ of respondents experiencing $54 \%$ of all offending captured by the survey (Ministry of Justice, 2010). Assuming we can generalise the findings of such surveys to the wider population most people do not directly experience victimisation, offending or policing. Law and order issues nonetheless remain at the forefront of public concern (TVNZ, 2008). Theorists have argued that reality TV can provide a "magic window" (Potter, 1986) for the public into the world of crime where little first-hand knowledge is the norm (Surrette, 1992, Oliver \& Armstrong, 1998; Oliver, 2003; Doyle, 2003) and where mediated reality TV experiences function as "vicarious police contacts" (Escholtz, Blackwell; Gertz \& Chiricos 2002:1) 
If Police Ten 7 provides audiences with a kind of second-hand policing experience then questions arise about the content and rationale for the show. Police Ten 7 is a collaboration between the New Zealand Police and Screentime, the producers of the programme $^{3}$. The premise of Police Ten 7 necessitates mutual co-operation between the police and media, resulting in a symbiotic and mutually beneficial relationship (Leishman \& Mason, 2003; Bradley \& Walters, 2011). This collaboration, based on the divergent aims of the media and the police means that it is necessary to question the representations subsequently created and presented to the public.

Despite the importance of media influences on public understandings and perceptions of crime and policing and extensive research internationally, empirical research into the ways in which crime and policing are represented in the New Zealand broadcast media is conspicuous by its absence. There has been no empirical research exploring the depiction of crime and policing on reality TV in the New Zealand context despite Police Ten 7's high profile status, free-to-air accessibility, longevity and popularity. This research addresses this gap in criminological knowledge and for the first time presents an empirical exploratory study of this important and increasingly popular form of public information about crime and policing.

Research by the Broadcasting Standards Authority (BSA) concluded that viewers of reality TV in New Zealand generally trust the depictions presented to them in reality TV to accurately reflect events as they actually occurred. Moreover, viewers confirm that they watch reality TV both for its entertainment and educational value (BSA, 2011). Given that New Zealand viewers believe reality TV to provide real, unfiltered and informative content it is necessary to systematically examine the content of such media constructions of policing, in particular the recurring images created and the selection of behaviours and actions presented which are claimed to accurately represent policing in contemporary New Zealand society.

\footnotetext{
As well as producing several reality television shows including "Illegal NZ" "The Missing" and "Marae DIY" Screentime also produces corporate television and commercials for business such as Air New Zealand, Mighty River Power and New Zealand Trade and Enterprise (Screentime, 2011).
} 


\section{Purpose of the Study}

Because the public is increasingly reliant on media depictions of crime and policing the portrayal of policing broadcast on Police Ten 7 has the potential to have a multitude of implications. The primary goal of this research is to provide an exploratory insight into representations of crime and policing in Police Ten 7. This is achieved through a content analysis of the entire 15 episodes of the 2010 Police Ten 7 season. More specifically, the key research question underlying the thesis is "How are police, policing, offenders and crime depicted in Police Ten 7, how does this compare to the known realities and what are the implications of any unrealistic depictions for public understandings of crime, policing and punishment?". To address the last part of the research question, if the realities depicted on Police Ten 7 diverge from those suggested by official crime statistics and other sources, this thesis seeks to explore and critically discuss the possible implications of such representations on public understandings of offenders and attitudes towards policing and punishment.

\section{Thesis Outline}

Chapter Two begins by discussing the media's long-standing fascination with crime and policing, exploring the idea that contemporary Western society is characterised by "media culture" (Downing, Mohammadi \& Mohammadi, 1990). The influential role the media plays in informing viewers is discussed; with particular reference to the power of the media when depicting realities about which viewers have limited personal experience and knowledge. The accessibility and wide-ranging influence of television in particular is then explored with reference to cultivation theory and crime (Gerbner \& Gross, 1976). Following this the discussion focuses on the rise of reality TV before discussing the history and format of Police Ten 7. An important aspect to this discussion is the symbiotic nature of the relationship between the police and the producers who create reality TV. The chapter then moves on to introduce and explore the utilisation of reality TV for the promotion of good police-public relations. The chapter ends with a review of similar international research discussing common findings and implications. 
Chapter Three describes the methodology employed by this research. First the basic format of Police Ten 7 is described before qualitative and quantitative elements of the research are introduced and discussed. The chapter then briefly describes the methodology of content analysis and the various limitations involved in undertaking such research. It is important to note at this point that this research does not attempt to state with certainty what the individual interpretations of Police Ten 7 would be for the public, this is beyond its scope and it is accepted that individual interpretations will be coloured by personal experiences and beliefs about crime and policing (Reiner, 2007; Neuendorf, 2002). While it is accepted that content analysis itself cannot be used to predict audience perceptions or interpretations of the content, this research is undertaken with the acknowledgment that this research will provide “one reading” of the content which Reiner (2007:304) suggests can "yield valuable insights and questions about the significance of patterns and trends".

Chapter Three then presents the coding instrument used in the content analysis and details the preliminary research and reliability testing measures. The remainder of the chapter describes and briefly discusses the key variables under investigation, providing detailed information about those variables that proved challenging to consistently and reliably code including ethnicity and age. Finally the chapter discusses the various analyses which were undertaken to make sense of the data and provides details on the "interreality" (Dixon \& Linz, 2000) measures utilised to compare the reality presented on Police Ten 7 with the known realities of policing as depicted in official crime statistics and through other relevant sources.

Chapter Four presents the findings of the content analysis of the 2010 Police Ten 7 season. The portrayal of police, offenders, policing and crime is described and comparisons are made between these portrayals and the known realities of crime and policing using official crime statistics, unpublished HR reports (2010), The New Zealand Police Annual Report (2010), The New Zealand Police Strategic Plan to 2010 (2005), National Annual Apprehensions (2010), National Annual Recorded Crime Offences (2010) Convicted Offenders by ANZOC (2010), The New Zealand 
Crime and Safety Survey 2009 (Ministry of Justice, 2010) and UK Home Office report Diary of a Police Officer $(2001)^{4}$.

Chapter Five further explores the findings presented in Chapter Four and discusses the potential implications of those depictions of policing and crime which are unrepresentative of the known reality. The promotional power of Police Ten 7 is discussed along with the use of the show by the New Zealand Police as a recruitment and public relations tool. The question of how skewed depictions of police work might impact police and public expectations of policing is also explored. Chapter Five provides discussion on the show's representation of ethnicity both for police and offenders and makes use of international studies which have raised concerns with the way white and non-white characters are portrayed in reality TV. Other implications such as the potential for increased fear of crime as a result of unrepresentative offence type distribution and the way Police Ten 7 could function to legitimise certain stereotypes of crime and victimisation at the expense of others are explored with specific reference to sexual violence. Finally the morality or propriety of the concept of reality crime and policing as entertainment is discussed with reference to New Zealand and international complaints and concerns.

\footnotetext{
${ }^{4}$ The Diary of a Police Officer, commissioned by the Home Office (2001) is utilised as a comparison source in this research because of the lack of New Zealand based research on the day-to-day routines of police and because of the similarities between the UK and New Zealand. An illustration of the broad similarities between the UK and NZ are the large scale recruitment campaigns by the NZ Police which saw entire wings of UK police immigrating to NZ. Similarly, as reported in the NZ Police 2010 Annual Report, the NZ police have a full time liason officer stationed in London.
} 


\section{Chapter Two: Literature review}

\section{Crime and the media}

The public has long been fascinated with the world of crime and policing. From early broadsheet coverage of offences and pre-execution confessions in the $17^{\text {th }}$ and $18^{\text {th }}$ centuries (Reiner, 2007; Carrabine, 2008) to the modern police television procedural drama, the media have consistently sought to capitalise on the public's fascination with crime.

This long-standing media obsession has resulted in a contemporary popular culture replete with images of crime and policing (Schlesinger \& Tumber, 1994; Marsh \& Melville, 2009). Crime and the detection of crime remain popular, high profile subjects in books and films. Moreover, interest in "real life" crime and policing does not seem to be dissipating as demonstrated by McGregor and Comrie (2002:35) who report that "crime news constitutes a constant and significant portion of television news in New Zealand" adding that the percentage of crime stories as hard news has been increasing since 1985 and in 2001. Bradley \& Walters (2011) point out that crime news on New Zealand television news has continued to rise despite a steady decline in officially recorded crime during the same period. More recent research reports that in 2008 across four free to air New Zealand news programmes "crime stories made up the greatest percentage of stories across the four programmes combined" (MacDonald, 2008:59). Research by Rose (2008 cited in Bradley \& Walters, 2011) revealed that New Zealand news sites Stuff.co.nz and The New Zealand Herald featured more news relating to violence and death than The Boston Globe and Israeli site Haaretz despite both countries experiencing significantly more violent crime than New Zealand. It seems that the adage "if it bleeds it leads" still functions to prioritise violent offending in the news (McGregor, 1993). High crime content, combined with the "events orientation" of crime news reporting (McGregor, 1993), results in a picture of crime that is unrepresentative of official statistics and which is divorced from the context of offending (McGregor \& Comrie, 1995; Bradley \& Walters, 2011). 
Crime is a constant feature of television and print news and this pattern is replicated in fictional depictions on television and film. Fictional tales about crime and policing abound across both mediums. A cursory examination of the weekly TV schedules on free to air New Zealand television illustrates the popularity that crime currently enjoys. Prime time TV is dominated by programmes such as City Homicide, Criminal Minds, NCIS, Special Victims Unit and dozens more which regularly receive high viewership rating highly with audiences ${ }^{5}$.

Crime is a "pervasive, constant and systematic feature" (Bradley \& Walters, 2011:63) of print, film and television and, as a result, has been a topic of inquiry by academics for decades. The large majority of research in this area has focused on newspaper coverage of crime, television news reports and fictional film and television crime depictions (Reiner, 2007). Of key concern to early researchers was the criminogenic potential for such media to incite criminal impulses amongst the viewing audience and to inspire so called "copy-cat" crimes (Carrabine, 2008). As a result early media effects studies focused on the influential power of films and television to produce negative imitative behaviour in children and in the possibility that the constant barrage of criminal acts broadcast might result in a desensitisation of viewers to crime (Carrabine, 2008). This early research also focused on the role of the news media in creating and sustaining crime waves and moral panics and informed some of the influential radical criminology texts (Carrabine, 2008). Further study concerned the depiction of crime and justice related issues in the media, the latter is the concern of this research.

\section{Media culture}

Lovell (2003:45) argues that one of the central features of post modernity is the "prominence of mediated experiences in our daily lives", an assertion echoed by Downing, Mohammadi and Mohammadi (1990) who contend that life in Western society in the $21^{\text {st }}$ century is marked by a "media culture". This refers to the fact that

For example, overnight reports for $1^{\text {st }}$ August 2011 show the five "most watched" shows in the 7:30 $11 \mathrm{pm}$ time slot consisting of Dog Squad, The Force, My Kitchen Rules, The Mentalist and Kalgoorie Cops, four of which are crime and policing based shows and four of which are reality based television shows (Kreft, 2011). 
for the majority of us our lives' experiences are mediated ones, experienced through second-hand exposure in newspapers, film, television or the internet. Mason (2003:1) argues that "factual, fictional and factional representations of media representations of policing are a crucial, and for a great many citizens, probably the sole influence in shaping their perceptions about criminality and community safety and criminal justice".

In a similar vein others have argued that in post modernity the media function as one of the key sources of information about social realities which the majority of people have little personal experience (Surrette, 1992; Leishman \& Mason, 2003; Marsh \& Melville, 2009; Gillsepie \& McLaughlin, 2003; McGovern \& Lee, 2010; Pratt, 2007). The New Zealand Crime and Safety Survey (NZCASS 2009) for example, showed that $64 \%$ of people surveyed had no personal experience with crime in 2008 (Ministry of Justice, 2010). While the majority of people do not personally experience crime, policing or victimisation first-hand they do experience a secondhand mediated experience through the myriad of media produced narratives (Pratt, 2007). Research in the UK revealed that $96 \%$ of those sampled view crime programmes weekly (Gillespie \& McLaughlin, 2003) and the British Crime Survey (2000) found that nearly three quarters of those surveyed said that the media, particularly television and radio, were the most influential sources of information about crime and the criminal justice system (cited in Marsh \& Melville, 2009). In New Zealand too Bradley, Rowe and Sedgwick (2010) found that the majority of participants in their study almost always relied on the news media for information about crime beyond their own local communities. In this way it is argued that the media have a powerful influence by filling in knowledge gaps by completing "the half-formed picture" (Mawby, 2003) and are in a position to construct meaning (Hall, 1973) through both fictional and factual depictions of crime and policing.

\section{Television}

While print, radio, film and the internet are important mediums through which audiences become familiar with crime and policing, television is arguably the most widely available and popular. Television is an almost inescapable feature of life in 
modern Western society (Bradley \& Walters, 2011, Reiner, 2007, Mastro \& Robinson, 2000). In New Zealand, for example, 98.8\% of households own at least one television (New Zealand Television Broadcasters Council, 2009). Television acts as a key source of entertainment and education for viewers (Oliver \& Armstrong, 1998; Gerbner et al, 2002). The proverbial "seeing is believing" is particularly apt, so great is the power of television (Doyle, 2003). Gerbner et al (2002:43) argue that despite the rise and popularity of new media formats television remains the source for "the most broadly shared images and messages in history".

\section{Cultivation Theory}

Media effects research has presented several theoretical frameworks to explain the influence and impact of watching television. These include the hypodermic needle analogy which sees audiences as empty vessels waiting to be filled by potentially negative and dangerous ideas (Reiner, 2007). This idea lay behind the campaign for the removal or control of "video nasties" in the 1980s and 1990s (Reiner, 2007). Gerber et al (2002:47) also contend, however, that traditional "effects" research does not sufficiently explore the ways television produces "mass distributed and repetitive systems of stories" to the public. Traditional effects studies tend to focus on one-off selected exposure to a specific message, measured by before and after attitudinal or behaviour tests (Gerbner et al, 2002). Reception studies have argued that audiences are not merely empty vessels waiting to be filled by whatever they view on television and the idea of a monolithic message being broadcast and absorbed into audiences has been questioned (Reiner, 2007, Gerbner et al, 2002). Cultivation theory instead advances the idea that television influence occurs as the result of multiple exposures across time (Gerbner et al, 2002; Mastro \& Robinson, 2000). While effects can be altered by circumstances such as selective viewing and different audience understandings of the message, cultivation theory argues that, despite potential differences in perceptions of the myriad of messages, there exist "important commonalities and consistencies" (Gerbner et al, 2002:48) across media representations. 
Cavender and Deutsch (2007:68) contend that television can "provide the interpretive frameworks through which we are encouraged to understand aspects of our culture" primarily via presenting myths, stories and tropes which, "cloaked in the form of entertainment ... serve to define the world and legitimise a particular social order" (Gerbner et al 2002:44). Cultivation theorists accept that different audiences, bringing different experiences and assumptions to the viewing, will "read" the same text differently (Gerbner et al, 2002; Neuendorf, 2002; Reiner, 2007). Gerbner et al (2002:49) contend that the avalanche of messages which audiences are exposed to across a lifetime functions to reinforce consistent and systematic values and myths which are repeatedly presented as "the aggregate messages embedded in television as a system". Audience influence is felt through "massive, long-term and common exposure of large and heterogeneous publics to centrally produced, mass-distributed and repetitive systems of stories" (Gerbner \& Gross, 1976; Gerbner et al, 2002:47). This long-term exposure to repetitive images and messages results in "the cultivation of shared conceptions of reality among otherwise diverse publics" (Gerbner et al, 2002:44). Variations in levels of television watching are assumed, within this viewpoint, to be linked with varying degrees of belief that the realities depicted on television are consistent with the real world (Gerbner et al, 2002; Mastro and Robinson, 2000, Reiner, 2007). Cultivation theory posits that these common and repetitive conceptions presented by multiple media exposures across time form a framework for viewing the world, providing a mass produced structure on which to hang real life events.

These common shortcuts or repeated conventions contain and back up the "facts, norms and values of society" (Gerbner \& Gross, 1976:182) and shape the way content is understood (Cavender \& Deutsch, 2007). Under this theory meaning is understood through these commonly depicted frameworks and carried over to inform the way audiences respond in their actual lives (Chong Ho Shon \& Arrigo, 2006).

\section{Cultivation theory and crime}

Cultivation theory suggests that exposure to repeated types of representations, for example the repeated depiction of the typical offender belonging to an ethnic 
minority group, can go on to "shape how the audience perceives the real world" (Chong Ho Shon \& Arrigo, 2006:63). Cavender \& Deutsch (2007:68) argue that if viewers are provided with certain repeated images about crime and policing through the mass media they may view real life crime and police through this mediated lens. This thesis aims to explore the tinted lens through which crime and policing is depicted on Police Ten 7 with the goal of uncovering how real life understandings of crime and policing issues might be influenced.

Crime is most commonly a mediated experience as opposed to a first-hand experience (Surrette, 1992, Pratt, 2007) but remains a highly salient and emotive topic in public opinion. The New Zealand public is, however, commonly misinformed about the workings of the criminal justice system (Paulin, Searle \& Knaggs, 2003). Surrette (1998) contends that the media not only present particular images of crime and policing but also promote the appropriate response, suggesting that media images can support certain societal responses to crime and discourage others. The influence of the media, then, is conceptualised less as a simple cause and effect paradigm focused on behavioural mimicking in encouraging or facilitating criminal behaviour and more as agenda-setting where the media "cannot tell you what to think, but it can tell you what to think about" (Bradley \& Walters, 2011:59; Leishman \& Mason, 2003).

The concept of agenda-setting is one of the key ways the media are argued to influence audiences. Cultivation theorists argue that media productions' content selections are highly influenced by organisational pressure to produce "newsworthy" copy (Chibnall, 1977; Reiner, 2007). This allows for the parameters of debate to be set by media decisions over what is newsworthy; in essence amounting to audiences being fed media deigned "suitable" topics (Bradley \& Walters, 2011). Furthermore, Hall, Critchley, Jefferson, Clarke and Roberts (1978) argue that the media's dependence on official police sources prioritises the official interpretation of events which they argue constructs the stage upon which all further public debate is set. 


\section{Mean world hypothesis}

Gerbner et al (1980) assert that the end result of viewing television is the cultivation, in the mind of the audience, of a world which matches that presented on television (Kooistra et al, 1998). Because television so often presents unrealistically high levels of crime and violence as staples of entertainment Gerbner and Gross (1976) reason that such exposure could translate to audiences perceiving the real world around them as like that of television. In short, the cultivation of a view of the world as "mean", full of violence, crime and danger (Kooistra, Mahoney \& Westervelt, 1998; Signorielli, 1990). In other words, a world much more violent and dangerous than official statistics suggest.

However it would be bold to argue that audiences are merely passive receptacles of information, incapable of discerning for themselves what is fact and what is fiction. Research suggests (Kooistra et al, 1998; Oliver \& Armstrong, 1998) that audiences are influenced differently based on whether the television content is judged by audiences to be reflective of reality or purely fictional. This is referred to as “perceived reality" (Kooistra et al, 1998; Oliver \& Armstrong, 1998). The suspension of belief which is encouraged in the act of viewing crime and police fiction does not apply to representations which are purported to be real. Through the representation of crime and justice issues, filtered via the mediated lens of the television camera, audiences may be provided with misinformation which may act to shape and define how viewers make sense of and respond to crime (Soulliere, 2003). This variable is important in a discussion of media effects and influence. As Kooistra et al (1998) suggest, the more realistic a depiction is presented and accepted by an audience, the more potential for influencing conceptions of the world. The mean world hypothesis, combined with the important concept of perceived reality, suggests that exposure to supposedly "true-to life" but in actuality unrealistic portrayals of crime and policing may also result in an increased fear of crime and furthermore an unrealistic estimation of risk (Reiner, 2007). Kooistra et al (1998) suggest that inaccurate perceptions of high crime and danger could, in turn, be linked to an increase in public support for more punitive "anti-crime" strategies, as well as increased support for 
potentially restrictive or controversial police strategies (Prosise \& Johnson, 2004; Kooistra et al, 1998; Cavender, 1998, Reiner, 2007).

\section{Reality television}

If traditional fictional television can influence viewers' perceptions of crime and policing it pales in comparison with reality television, a genre of TV programming which has risen to prominence in the past two decades.

Reality-based, "infotainment" or "factional" television is a hybrid form of television which combines the reality of documentaries with the pacing, entertainment value and dramatic elements of fictional entertainment (Mason, 2002). It is "reality-based" in that it uses real people, as opposed to paid actors and that the events depicted purportedly occurred in reality. Reality-based television has been usefully described as "blurring the boundaries" (Mason, 2003:1) between fictional and factual ${ }^{6}$ television because while it presents events that did occur in reality, it presents them in a way which often resembles fictional television, as opposed to documentaries which also depict real people and real occurrences (Friedman, 2002; Cavender \& Bond-Maupin, 1993).

Reality-based television is a relatively recent phenomenon which experienced a surge of popularity beginning in the 1980s and continued into the 1990s and the new millennium (Friedman, 2002). The genre has become a mainstay across networks and countries proving popular with viewers and producers alike due to its relatively low cost of production (Friedman, 2002; Jermyn, 2007). The main point of difference which sets reality-based television apart from other television genres, like fiction or documentary, is the explicit claim to reality combined with the overarching goal of providing entertainment (Friedman, 2002; Leishman \& Mason, 2003). Both documentary and reality programmes claim to be realistic representations of events however the two have divergent aims. Where documentaries are primarily educational or informative, reality-based television is aimed at providing informative

\footnotetext{
${ }^{6}$ This blurring of the boundaries can be seen in the Arizona reality police TV show Steven Seagal: Lawman, which features the action movie star working as a volunteer police officer alongside Sheriff Joe Arpaio (Adams, 2011).
} 
content using entertainment techniques (Leishman \& Mason, 2003; Cavender \& Fishman, 1998; Corner 2000). The primary aim of reality-based television is to entertain the audience (BSA, 2011; Corner, 2000) or, as Corner (2000:1) argues, to provide "pleasurable diversion".

There are many different subsets of reality-based television. These include "docusoaps" which typically consist of groups of people whose work and lives are chronicled on film and "biovision" gameshows where contestants are placed in contrived environments and face various tasks such as the Big Brother franchise (Mason, 2002). Finally there are reality-based shows which focus on emergency services or law enforcement agencies including police, customs officers, airport staff, ambulance response or fire-fighters (Mason, 2002). It is the latter subset which is the subject of exploration in this study in part because this subset makes the most explicit claims to authenticity ${ }^{7}$ (Mason, 2002).

Advances in technology, and the expansion of television networks in the past two to three decades have altered the face of television and aided the rise of reality-based television (Fetviet, 1999). The development of lighter, more portable filming equipment has allowed film crews to capture events faster, more easily and with much smaller budgets (Fetviet, 1999; Friedman, 2002). The cost in writing, hiring actors, creating a set and filming a traditional procedural drama is substantially more than the cost of essentially sending out a small camera crew to film individuals and then pay post production staff to edit, cut and put together the final cohesive product (Seagal, 1993). Reality television makes financial sense and has proven to be popular with both viewers and networks (Friedman, 2002).

\section{Public use of reality TV}

One of the key motivations for this and similar research is the repeated finding that the media, and in particular television, functions as an important source of

For example, Police Ten 7 claims to present "a behind the scenes glimpse into the real working lives of the New Zealand Police" (TVNZ, 2011b) and Cops producer John Langley refers to Cops as "about real people, real events, real life" and "a genuine ride-along" (Langley, 2001) 
information for many members of the public (Mason, 2002; Oliver, 1994; Oliver, 2003). Mason (2002) notes that the British public is uninformed about the workings of the criminal justice system, and use the media as key sources of information. Moreover, $94 \%$ of those surveyed by Levenson (2001) believed media sources to be accurate. In New Zealand, reality television is also undoubtedly popular where nine out of the top ten highest rating television shows across all networks in 2010 were reality-based programmes (Knowsley, 2011). There is also recent evidence supporting the idea that viewers understand such television to be authentic. Research by the New Zealand Broadcasting Standards Authority (BSA) reported that viewers believe reality television to depict events as they actually occur. Among other things participants in this research stated that reality television "shows people as they really are, it's not dramatised" (BSA, 2011:16) and that the whole point of reality TV is that “it's entertaining but it's real" (BSA, 2011:9). The BSA research also reported that viewers believed reality television to be informative and that it provided learning experiences for viewers in terms of demonstrating acceptable and unacceptable behaviour (BSA, 2011). It appears, then, that in New Zealand reality television is not only popular but is widely viewed as an accurate depiction of real life events. With this in mind the educational and entertainment role of reality TV in New Zealand is of prime importance to public understandings of crime and policing. The degree to which these representations reflect the known realities of crime and policing in New Zealand is currently unknown but the potential for these depictions influencing public conceptions is significant. This research aims to explore the ways police and crime are presented to audiences through Police Ten 7 and to contrast these mediated images with the realities of policing in New Zealand, and to discuss the potential implications of this on the viewing public.

Conversely, critics have argued that "television cannot bring reality to viewers; it can only provide a representation of an event" (Friedman 2002:5) which Andersen (1994:8) argues "masquerades as reality" while actually depicting situations which are "contrived" and "protagonists who are handpicked" (Greer, 2001:2). As a result researchers have sought to explore the actual accuracy of television portrayals. The goal of this research is to explore the accuracy of, and degree of convergence between the realities of policing, and by extension crime, and the mediated 
representations of it on New Zealand's award winning reality TV show Police Ten 7. The accuracy of these representations affords scrutiny because of public perceptions of reality, that is viewers of reality shows in New Zealand report high levels of belief in the truthfulness and reliability of such reality programmes (BSA,2012). Given this degree of trust and acceptance of the reality television medium as a way for viewers to understand and make sense of issues as complex as crime and justice the degree of accuracy of these depictions, or lack thereof, is a significant aspect of this research.

\section{The reality-based crime and policing genre}

One of the most popular subsets of the reality-based genre is reality crime and policing. This sub-genre first became popular with Cops in the USA and Crimewatch in the UK in the 1980s and 1990s. These programmes spawned numerous versions on the same theme and subsequently sparked a new generation of crime based entertainment (Friedman, 2002; Jermyn, 2007). Generally speaking, reality based crime and policing shows conform to two primary formats. The first is the police "ride-along" which depicts a "day in the life" of a police officer and is typically filmed inside the police car following the police as they attend incidents. This is the format used in Cops and in the first part of Police Ten 7. The aim is to allow the audience to see the world through the eyes of the police and experience what it is like to be a police officer from the safety of their couch. The second format consists of the reconstruction of a crime and interviews with victims, their families, police and detectives and usually includes a description of the suspect and a request for public assistance (Cavender \& Fishman, 1998). Police Ten 7 uses both of these formats, the "ride-along" and the reconstruction.

The police reality-based genre uses specific techniques to imply authenticity (Fetviet, 1999). These include the use of maps, CCTV footage and reconstructions which allow the viewer to see themselves as a fellow detective, privileged enough to see this usually hidden aspect of the police work (Ibid, 1999). To emphasise the reality of reality-based crime and policing television techniques are employed to enhance the sounds and sights and include radio static and jumpy and haphazard camera work (Fetveit, 1999; Cavender \& Fishman, 1998; Prosise \& Johnson, 2004). Such 
techniques "testif[y] to the authenticity of the recordings" (Fetveit, 1999:792) and imply a level of raw unfiltered reality. As Fetveit (1999) notes, the footage presented to the audience may not be edited to make sense, further implying raw, untouched footage. This problem is solved by narration, through which voice-overs explain the action and police officers on the scene provide extra information from their point of view. The untouched or raw realism implied by the haphazard filming belies the reality in which hours of filming are edited and enhanced with sound bites or stock footage to create crime "stories". Seagal (1993:52), a story analyst on American Detective, a reality-based programme from the 1990s, explains "although American Detective and its competitors seem a long way from ... all the famous old cop shows, they follow the same formula, the same dramatic arc, because that is what the viewers and the advertisers have come to expect". The resulting product fuses together documentary techniques to imply authenticity and realism while employing entertainment values which are more commonly found in fictional representations of crime and police (Mason, 2002; Leishman \& Mason, 2003; Seagal, 1993, Cavender \& Bond-Maupin, 1993) to create one construction of crime and policing. Crime and policing reality-based television requires the cooperation of both the producers of reality-based crime and policing programmes and the police therefore it is important to discuss this collaboration in more detail.

\section{The producers and the police: an uneasy alliance}

Reality-based television which depicts crime and policing must be understood in the context of meeting several divergent goals for the key stakeholders. For the producers of such shows the content must be exciting and sellable, given that one main aim of creating television is to entice viewers who can then be exposed to advertising (Friedman, 2002). Reality-based television is a profitable way of gaining viewers while operating under a substantially smaller budget than traditional fictional television products (Seagal, 1993; Kooistra et al, 1998).

The reduced budget, however, comes at a price. Traditionally the media have performed an adversarial function "exposing malpractice and misconduct" (Andersen, 1994:8; Mawby, 2001). However new police-media collaborations, such 
as reality- based television, alter the dynamics of this relationship and require the media to dispense with journalistic objectivity and independence (Andersen, 1994; Mason, 2002; Mawby, 2001; McGovern, 2009) in exchange for mutually beneficial co-dependence. Because the police consent to their cooperation they presumably have the ability to veto any footage which would not reflect well on the police. This is certainly the case with the American reality policing show Cops which enjoys a friendly relationship with police through mutual cooperation. The following quote by a police officer who was involved in the filming illustrates the point:

"Most officers would be apprehensive to have the media ride with them ... but these guys proved themselves to us. They said that they wouldn't do anything to undermine us and that we'd have final discretion about what ran" (Zoglin, 1992:62).

This requires the media to reposition themselves as, at best, collaborators and at worst, colluders in the creation of these media products (Mason, 2002, McGovern, 2009). Seagal (1993) describes how the producers of reality show American Detectives self-censored potentially damaging (for the police) footage, leading her to conclude that "this was clearly a case of too-much reality for reality-based TV" (Seagal, 1993:55). The abandonment of traditional media goals of objectivity is seen in what Doyle (2003) describes as the internalisation of pro-police values by the production team. This claim is supported by Seagal (1993). She pointed out that the executive producer of reality show American Detective commonly wore a police badge on his belt-buckle and camera operators wore jackets with "POLICE" on the back while filming, carrying in one hand a camera and the other a pistol and stated “the police don't seem to care about [the cameraman's] blurred role" (Seagal, 1993:55). The benefit of this reliance on police for the producers is the provision of ready-made "newsworthy"8 stories at low costs (Bradley \& Walters, 2011; Reiner, 2007; Corner, 2000).

It is easy to see why the media cooperate in this joint production given the popularity of the genre and the relatively low production costs (Seagal, 1993; McGovern, 2009).

In the sense of adhering to Chibnall's (1977) list: immediacy, novelty, structured access, dramatic tension and personalization. 
However while access to easy "copy" and low production costs may explain the attraction of media companies to reality TV this cannot be the attraction for the police. The benefits that accrue to the police via collaboration with reality TV producers thus require a little more thought. This is especially so when seen in the light of the traditional suspicion of the police toward the media and their reluctance to collaborate with those outside of the strong police culture (Waddington, 1999).

There are several benefits for the police in their involvement with the media. First, the police are provided with free publicity and exposure to the public (Bradley \& Walters, 2011). This publicity provides police with the ability to reach large numbers of potential witnesses who may be able to offer assistance by providing information on unsolved cases. It also provides publicity for the police organisation in the general sense. According to the police themselves a key benefit of involvement in reality shows, such as Crimewatch, America's Most wanted and Police Ten 7 is the ability to reach a wide-group of people in order to obtain information on a wanted offender. Detective Inspector Sue Schwalger of the New Zealand police states that "It's always been a consideration to use Police Ten 7 as another means of eliciting information ... you look at ways you can reach different audiences" (New Zealand Herald, 2010b). So while the crime-fighting aspect of the show is commonly used as justification for its existence (Dobash et al. 1998) as in the case with many shows including Police Ten 7 , the majority of the show is focused on the police "ride-along" section, as opposed to the requests for public assistance and the benefits for police involvement here are more complex.

\section{Police promotion and the creation of "good" publicity}

Police have long been aware of the potential for the media to both blemish and bolster their image (Hanke, 2005; Mawby, 2001). Reiner (2007:259) argues that "policing is as much a matter of symbolism as much as substance" and Marsh and Melville (2009) have highlighted the importance of image control for police since the inception of the modern police force. Mawby (2001:44) asserts that the police are in the business of "promoting, projecting and protecting" their image and argues that contemporary policing "operates in an increasingly mediated world" in which not 
only must police achieve their crime reduction and prevention goals but must also perform effective reassurance policing and effective (and visible) engagement with diverse communities (Mawby, 2001:1). Mawby (2001:5) describes “image work" as "all the activities in which police forces engage and which construct and project images and meanings of policing". This image work has arguably become a key concern for the New Zealand Police which has gone through what Leishman and Mason (2003) describe as a "professionalisation" of the police-media relationship. This refers to the situation whereby communications and media professionals have become more active in shaping and controlling the image of police and policing in the eyes of the public. The relationship between the media and the police has long been referred to as "symbiotic" (McGovern \& Lee, 2010) or mutually beneficial. This is even more pronounced in reality-based crime and policing television where the reliance on each other is much more obvious.

Policing has always relied on the cooperation and consent of the public to function (Reiner, 2000). Efficient police services require public input in the form of information and intelligence (Reiner, 2000). Given that the public commonly learn about the police from the media as opposed to through direct contact (Surrette, 1992; Lovell, 2003; Oliver \& Armstrong, 1998) one of the key necessities of policing in contemporary society therefore revolves around developing positive media relations (Chermak \& Weiss, 2006; McGovern \& Lee, 2010). The New Zealand Police is clearly aware of the need to maintain a positive image on television as evidenced by the statement in the Strategic Plan to 2010 "policing is very public and highly scrutinised and perceptions of policing can be influenced by television" (NZ Police, 2005b:9). This awareness of the potential influence of television specifically, and media in general, combined with the repeated finding that policing is most often experienced through second-hand and mass mediated experience (Lovell, 2003; Pratt, 2007), suggests that police may view reality-based programmes as an effective way of providing symbolic reassurance to the public. This is typically achieved by demonstrating the visibility and effectiveness of police and importantly, by serving as a vehicle for the presentation of a controlled image (Mawby 2001; Mason, 2002; McGovern \& Lee, 20101 Leishman \& Mason, 2003). 
In Australia the trend towards the "professionalisation" of police/media interactions is visible in the cooperation of police and media in the creation of a multitude of television products which have reportedly netted the New South Wales police with more than \$1 million in revenue (Lawrence \& Bissett, 2009 cited in McGovern, 2009; Mawby, 2001; Mason 2002; McGovern \& Lee, 2010). McGovern and Lee (2010:447) state that the professionalisation of the police-media relationship represents an important change from police simply providing information to "framing and constructing crime narratives". They further describe the public relations departments of police as actively attempting to present both a positive, controlled public image as well as muzzling negative or problematic media content. Doyle (2003) also agrees that media-police collaborative productions such as Cops, Crimewatch or Police Ten 7 perform ideological functions by airing only material which reflects positively on the police. This is, he argues, a result of the dependence of TV producers on the police to create the show, the internalised "pro-police values" of the producers and the belief that the public do not want to see police as anything but effective.

McGovern \& Lee (2010:61) further suggest that media-police collaboration attempt to reinforce the process of "responsibilisation" through which "citizens can be governed at a distance" as well as promoting punitive law and order rhetoric. In this way the public become responsible for and involved in the prevention of crime as well as supportive of the punitive actions of police, which for McGovern and Lee (2010) links up with the climate of fear that is commonly communicated in police media relations.

It follows, then, that involvement in the creation of reality-based television may be encouraged by police in order to increase their public support, given that this is one of the key policing aims described in the New Zealand Police Annual Report (2011). Reality TV could function here as one way of encouraging a vision of policing as a collaborative effort through which police and the public become "partners in crime control" (McGovern \& Lee, 2010:457). It is also suggested that police involvement in reality-based crime and policing programmes functions as a recruitment tool through which self-selected audience members may be encouraged to join the police 
(Doyle, 1998). Downing, Mohammadi and Mohammadi (1995) agree that corporations and entities can shape the parameters of discourse through their media productions by calling to attention what audiences should be concerned about through repetitive and conventional frameworks which "provide the guiding myths which shape our conceptions of the world" (Davis \& Bourhill, 1997:39). The ability for the police to promote a controlled image means that the police are provided with the backdrop against which they are able to paint certain acceptable and pro-police stories which are then viewed by audiences as objective, unfiltered glimpses of police and policing.

Because of this mutually beneficial relationship between the police and the media it is necessary to question the representations of crime, police and policing which are subsequently created and presented to the public. By examining 15 episodes of Police Ten 7 this research aims to uncover and explore the representations of crime, offending and policing created by the police and the media and to compare these constructed representations with the known realities. Furthermore, this thesis will critically consider the potential implications of these depictions on public understandings and attitudes towards crime, policing and offending. It is clear that the media and the police have agendas meaning that the resulting programming may not resemble "the real story" of a New Zealand police officer but a representation of police and media collaboration shaped by the needs, agendas and pressures of each industry.

\section{Research so far: The constructed cop}

Since the 1990s and the rise of reality-based TV, academic inquiry into the depiction of crime and policing on such programmes has grown. The majority of studies have focused on American and British reality television. Across these various studies there have been several common findings. One of the key findings was that reality-based television, like newspaper and television news coverage, consistently over-represents violent offending (Oliver, 1994; Monk-Turner, Martinez, Holbrook \& Harvey, 2007; Kooistra et al 1998). One of the earliest and most influential studies was a large scale content analysis of reality based crime and policing shows by Oliver (1994). In her 
research she found that violent crime was significantly over-represented when compared to FBI statistics. In her sample $87 \%$ of offenders were associated with violent crimes and only 13\% with property offences. FBI statistics for 1991 however painted a very different picture with violent offences consisting of only $13 \%$ of total offences while property offences made up 87\% (Oliver, 1994). An analysis of Cops by Monk-Turner et al. (2007) revealed a similar over-representation of violence with violent offences making up 54\% of all offences depicted. Kooistra et al's (1998) analysis of Cops also reported unrealistically high levels of violent offending. These analyses reveal that across various reality-based crime and policing programmes a stable and repeated feature is the presentation of distorted levels of violent crime which are not reflective of official crime statistics.

Another important aspect of media depictions of crime and offending that has been the focus of academic inquiry is the distorted depiction of ethnic minorities. Oliver's (1994) analysis of five reality-based crime and policing programmes revealed that $90.7 \%$ of all police officers depicted were white and only $9.3 \%$ black. When this was compared to the actual ethnic make-up of police it was revealed that white police officers were very much over-represented and black officers under-represented (Oliver, 1994). Similarly, white offenders were slightly under-represented and black offenders over-represented when compared to official FBI statistics (Oliver, 1994). A content analysis of Cops by Monk-Turner et al (2007) found that $67 \%$ of white characters were portrayed as police officers while $90 \%$ of the non-white (black, Hispanic) characters were offenders. Furthermore of all the characters portrayed on Cops as police $92 \%$ were white, $4 \%$ black and $4 \%$ Hispanic (Monk-Turner et al, 2007). Monk-Turner et al (2007) also found that black offenders were more likely to be depicted committing violent offences while white offenders were most likely to be shown committing public order or traffic offences. Similarly, Kooistra et al (1998) describe disproportionately high levels of violent offending by non-white offenders in their analysis of Cops, while white offenders were not depicted as typically committing violent crime.

In common with media depictions of crime and policing in general resolution/clearance rates were found to be much higher in reality-based television 
than demonstrated in official statistics Crime clearance or resolution rates across five reality-based crime and policing programmes totalled $77.8 \%$ compared to FBI resolution rates of 18\% (Oliver, 1994). This depiction of unrealistically high levels of police efficiency and success was echoed by Kooistra et al (1998) with their study reporting $75 \%$ of offenders being arrested on Cops, a success rate not reflective of the official clearance statistics of $21 \%$.

Systematic analyses of the depiction of crime and policing on reality-based programming has also revealed that crime and offending is consistently depicted as caused by individual pathology stripped of the influence of social or economical context (Prosise \& Johnson, 2004; Kooistra et al, 1998; Finley, 2004). Fetveit (1999:794) states that reality-based television does not concern itself with deeper issues of causality but focuses instead on depicting the "surface of the world". In these shows criminals commit crime as a result of personal choice or individual flaws and are commonly portrayed as evil or deficient (Prosise \& Johnson, 2004; Kooistra et al, 1998; Cavender \& Fishman, 1999).

This representation of crime as an individual problem largely mirrors the treatment of crime in the news media more generally where social causes are ignored and individualist understandings of crime are repeatedly emphasised (Entman, 2006). Kooistra et al (1998) argue that reality-based crime and policing programmes reinforce a conception of offenders as the "other", a "strange and dangerous breed, driven to crime not because of poverty or injustice but because they suffer from biological or psychological flaws" (Kooistra et al, 1998:155). Kooistra et al (1998) and Derosia (2002) suggest that one outcome of the depiction of offenders as dangerous "others" who threaten the rest of society is that audiences may be more willing to accept a criminal justice system which is increasingly punitive, supporting harsher penalties for offenders and increased power for police. Prosise and Johnson (2004:74) in their rhetorical analysis of Cops and World's Wildest Police Chases, concluded that the representation of crime and offenders on these shows functioned as "implicit justification for controversial police practices" including racial profiling. 
Just as offenders are repeatedly depicted as dangerous the police are commonly depicted as heroic individuals who stand between the public and the criminals: the "thin blue line" protecting against impending chaos and anarchy (Prosise \& Johnson, 2004; Reiner, 2000; Mason, 2002; Waddington, 1999). Cavender and Fishman (1998) argue that this reinforces an "us versus them" mentality which encourages identification with police by the audience while "distancing them from other characters shown" (Doyle 1998:100). This is supplemented by filming techniques which are used to encourage viewer identification with the police (Doyle, 1998). These include "situating" the viewer in the police car, often "riding" in the passenger seat. The viewer is essentially "deputised" (Greer, 2001) in the sense that they have access to the police paraphernalia as well as the police interpretation of events which Doyle (1998) argues acts to justify police actions which may otherwise be concerning to the public. Fetveit (1999:794) argues that the images function as "visual evidence" of reality but they are supplemented by language in that "the description of what we see helps us to ... focus, not simply our gaze but also our understanding".

Another important feature of reality-based policing programmes is that policing is presented as decidedly exciting, dangerous and action-packed (Prosise \& Johnson, 2004, Soulliere, 2004). The promotion of police as traditional crime fighters (Mason, 2002), as opposed to being involved in the "softer" side of policing, conforms to crime fiction where car chases and danger are more frequently portrayed than the service oriented aspects of policing or paperwork. Prosise and Johnson (2004:76) contend that police are presented as "wholly beneficent defenders of the just social order" and are positioned firmly in the role of "good" versus the "evil" of offenders.

The black and white world of "good versus evil" which is routinely constructed by reality shows does not reflect the nuanced reality of life (Mason, 2002; Palmer, 1998). The absence of ambiguity is a feature of these reality shows which serves to present a simple narrative which Palmer (1998:13) describes as "modern day morality tales". Despite the moral and legal ambiguities which are part of real life crime and policing the creators of reality-based television reduce offenders to "part of the criminal element that stalks backyards and threatens children" while police 
"become gentle, persuasive cop[s] keeping our streets safe at night" (Seagal, 1993:55).

It is clear then that while reality television features actual police and offenders the final product is not an objective representation of the reality of policing and offending. John Langley, producer of USA reality forerunner Cops, states that the ratio of footage filmed to footage screened was roughly 150:1 (Langley, 2001). Seagal (1993:52), a story editor who worked on American Detective, describes the process of editing and creating a narrative out of the raw footage: "by the time our 9 million viewers flip on their tube we have reduced 50 or 60 hours of mundane and compromising video into short action-packed segments of tantalising, crack filled, dope-dealing, junkie-busting cop culture".

Multiple studies have suggested that reality-based crime and policing television presents a picture of crime, and of policing, which is unreflective of the known realities. Unrealistically high levels of violent offending, combined with the overrepresentation of ethnic minority individuals as offenders and the over-representation of white individuals as police abound (Oliver, 1994; Oliver, 2003; Monk-Turner et al). Police are systematically depicted in such shows as extremely efficient and successful with resolution/clearance rates which are often three times that of official resolution rates (Oliver, 1994; Kooistra et al, 1998).

Police are also depicted in the traditional crime-fighting role, emphasising physicality and risk and ignoring the reality of policing which includes significant amounts of "soft" police work such as community policing not to mention the ever present and significant amounts of "paperwork". This representation is set against a backdrop of a black and white, good versus evil morality tale (Doyle, 2003) where offenders are commonly represented as individually deficient people offending because of individual pathology (Kooistra et al, 1998; Prosise \& Johnson, 2004; Cavender \& Fishman, 1998). Previous research emphasises the fact that these programmes represent a constructed view of crime and policing where "the narrative structure of events is determined by the producer, not the police officer" (Mason 2002:4). The final product then cannot offer the lived experience of being a police 
officer but as Doyle (2003:34) asserts "offers a very particular and selective vision of policing".

Previous research about reality-based television has consistently suggested that reality-based programming, while marketed as real, does not represent events as they occurred. The pressures of both main parties involved, the producers and the police, require the end-product to be interesting and popular as well as presenting the police in a positive light. Instead of presenting an objective, value-free representation of reality these shows filter, select and create crime stories which will fulfill these potentially divergent aims. Greer (2001:1) argues "reality TV is not very real. The situations are contrived and the protagonists handpicked", and it is this selection of protagonists and situations that is the focus of this research. The mediated, mutually beneficial and carefully negotiated realities which are created by the media and the police are marketed as realistic, and are typically understood as such by audiences (BSA, 2011). This disjuncture between reality-based programmes and official known realities commonly found in previous international research is the focus of this research which investigates the reality of the most prominent reality-based crime and policing programme in the New Zealand context, Police Ten 7. 


\section{Chapter Three: Research design and methodology}

\section{Research design}

The key objective of this study was to understand the ways crime and policing are portrayed on Police Ten 7 through an analysis of recurring visual images, narratives and language. This was achieved through a qualitative thematic content analysis focussing on the visual and linguistic content of the 2010 season of Police Ten 7. Before explaining the methods further it is useful to go over the basic structure of Police Ten 7 because this structure informed the research design.

Each episode of Police Ten 7 is made up of two distinct parts. The first part consists of a number, commonly three, separate "crime stories". These are discrete stand-alone narratives about crime and policing presented by a "host cop" who typically opens the scene by addressing the audience/camera crew from the driver's seat of the police car on the way to an incident. This is referred to as the "ride-along" section. The crime story is typically resolved when an offender is either identified and dealt with by police, for example by arresting the offender and taking them to the police station, or when the incident is resolved in some other way, for example offenders are asked to produce documentation the next day or are given a warning. It is interesting to note that in the all of these crime stories successful resolution is always forthcoming.

The second part of the show consists of the presenter, Graham Bell, describing a serious offence, narrating the reconstruction of the crime with the aid of the lead detective investigating the case and sometimes supplemented by interviews with the victim or the victims' family. Following the crime reconstruction, a "roll call" of "wanted" faces is presented to the audience, their descriptions and details of their offending are briefly described and the public are asked to help the police identify the "wanted" offenders. This section is referred to throughout this research as the "wanted" section.

Because this research is the first of its kind in the New Zealand context, overseas models of successful research design were emulated. The methods chosen to undertake this exploratory research belong to the broad category of content analysis. The research did not set out to test a particular hypothesis. It did, however, begin with the general expectation that, based on the reading of the international literature, policing would be portrayed as 
exciting and action-packed, that police would be represented positively and offenders negatively, and that the effectiveness and success of police would be emphasised.

The research design included quantitative and qualitative elements. The qualitative component consisted of identifying repeated themes which emerged from the research (Berg, 2004). This was achieved through first identifying common themes from similar international research and literature concerning police culture and media representations. Among the more important of these themes were police as action-oriented crime-fighters, policing as universally successful, offenders as violent, dangerous and individually deficient, non white individuals as violent offenders, white individuals as police and the presentation of a "cop-centric" (Leishman \& Mason, 2003) viewpoint which emphasises viewer identification with police.

This research is underpinned by a constructionist epistemology. Constructionism is the view that "there is no objective truth waiting for us to discover it. Truth, or meaning, comes into existence in and out of our engagement with the realities in our world. Meaning is ... constructed" (Crotty, 1998: 8-9). In keeping with this viewpoint the findings in this study are "one reading of the text" (Neuendorf, 2002:6) and it is accepted that personal experience, beliefs and prior knowledge may alter perceptions of messages and interpretations of findings (Neuendorf, 2002). One common criticism of such research is that categorisations are reflective of socially accepted definitions and that the findings of a particular content analysis are "directly related to the definitions of the various content categories developed by the researcher" (Dominick, 1978:106-107). This cannot be avoided, as Neuendorf (2002:11) notes "all human inquiry is inherently subjective". It is accepted that the categories and definitions used in this research are socially constructed and as such there is a subjective element to the research. While accepting that a degree of subjectivity is always going to be a limitation, attempts have been made to control and mitigate the effects via the employment of through a robust research design. In deploying a reliability index a number of the more extreme subjective elements found in other research have been "designed out", by analysing all 15 episodes and every crime story depicted within and by achieving intersubjectivity.

Babbie (2007:75) states that because of the inherently subjective nature of human inquiry the social sciences "achieve the equivalent of objectivity through intersubjectivity". Intersubjectivity means that different researchers "having different subjective views, can 
and should arrive at the same results when they employ accepted research techniques" (Ibid, 2007:75). In this research intersubjectivity was achieved by using similar definitions and categorisations as international research exploring reality policing shows (Oliver, 2003; Oliver, 1994; Entman, 1992; Oliver \& Armstrong, 1998; Mastro \& Robinson, 2000; Prosise \& Johnson, 2004). These studies' common findings, in particular the over representation of successfully resolved cases, white characters as police officers, nonwhite characters as offenders of violent offences were also found in this research, suggesting that this research achieves intersubjectivity (Babbie, 2007).

\section{Content Analysis}

Content analysis is "any technique for making inferences by systematically and objectively identifying special characteristics of messages" (Holsti, 1968:608). Though content analysis is often considered a positivist and objectivist methodology, its use in qualitative constructionist research is established (Morgan, 1983; Shoemaker \& Reese 1996; Newbold, Boyd-Barrett \& Van Den Bluck, 2002; Macnamara, 2006). Content analysis has often been used to study media content in similarly focused international research (Oliver, 1994; 2003; Mastro \& Robinson, 2000; Soulliere, 2001; Cavender et al, 1999). Berg (2004) agrees that content analysis can be both quantitative, in the degree that it counts the number of times specific events occur but that it can at the same time be qualitative when the quantitative data has been analysed and common themes emerge. In this way the content analysis can be about examining themes and "identifying, organizing, indexing and retrieving data" (Berg, 2004:269).

One common criticism of content analysis is the tendency for large texts to be reduced into numerical data which "does not provide the complete picture of meaning ... since texts may contain many other forms of emphasis besides sheer repetition" (Shoemaker \& Reese, 1996:32). Newbold et al (2002:84) argue that quantitative content analysis alone "has not been able to capture the context within which a media text becomes meaningful". In response to these limitations this research explored both the manifest content, that is "those elements that are physically present and countable" (Berg, 2004:269) as well as latent content which is when "analysis is extended to an interpretive reading of the symbolism underlying the physical data" (Berg, 2004:269). The aim of this was to present a broad picture of Police Ten 7 through quantitative analysis and to explore the potential meanings of the programme through qualitative interpretations of the data. Macnamara (2006:6) 
argues that qualitative content analysis, while conforming less to the scientific ideal of objectivity, "is necessary to understand the deeper meanings and likely interpretations of audiences ... surely the ultimate goal of analysing media content". He further points out that "a combination of the two seems to be the ideal approach".

\section{Preliminary research}

The process of undertaking the content analysis began with viewing six episodes of the 2009 season of Police Ten 7 to gain an understanding of the structure and common and recurring formats and features of the show. This preliminary research utilised open coding; whereby "the central purpose is to open enquiry widely" (Berg, 2004:278). For this initial coding procedure all data about characters portrayed, activities depicted, language used and "shots" filmed in the six episode pilot study was recorded. The goal was to be as comprehensive as possible by including everything that was featured in the six episodes. Once the data became repetitive the open coding preliminary procedure was complete and the systematic coding of the study began with the creation of the coding instrument.

\section{The coding instrument}

The broad range of content recorded in the six episode preliminary study was then reviewed to find similarities such as recurring themes, common police duties represented and a general structure of the show to form the basis of categories. After the preliminary open coding the next step was to create a coding scheme to differentiate between the various possible content so that episodes could be accurately and consistently recorded for analysis. Berg (2004:268) suggests that specific "criteria of selection" must be formally established before coding can begin. In short, the categories and criteria should be complex enough to capture a variety of different depictions as well as clearly defined so that others using the same criteria, watching the same episodes would get the same or similar results (Ibid, 2004).

Following Soulliere (2003) previous content analyses of crime-based reality programs were used to inform and help create initial content categories. These categories were then modified to fit the more specific Police Ten 7 context to allow more of a focus on policing than exclusively on crime. The research design borrowed from research by Oliver (1994) for definitions of coding variables, an example of which is Oliver's definitions of primary 
officers while Neuendorf (2002) provided an example codebook. The methods used by Oliver $(1994,2003)$ provided guidance on how to code scenes with multiple individuals and research by Soulliere (2003) provided a template for this research design.

All content from the preliminary six-episode pilot study was categorised into four sections resulting in a content analysis of three main sub-groups. These were demographics (gender, ethnicity and age) of both police and offenders, basic contextual information such as location, timing, response type (proactive or reactive) and the key variable of offence type. Analysis was also conducted on what was termed "police action-oriented activities" which consisted of variables relating to the actions police were shown to be involved with. Within the policing activities section coding schemes were created for variables such as the use of weapons by police, the presence of physical and verbal aggression and various other policing duties including involvement in car and foot pursuits. Definitions of verbal and physical aggression were modelled on Oliver's (1994) study Crime, Race and Aggression in Reality Based Police Shows?

The fifth section coded for interaction between offenders and police including any physical or verbal aggression/confrontation and language used. A more simplified procedure was achieved for the "wanted" section with the analysis focusing on the key demographics of gender, ethnicity and age of offenders as well as offence type. Note was made of common themes or types of representation particularly in the reconstructions featured in the "wanted" section and included the idea of dangerous criminals, the viewer as virtual victim and an "us versus them" orientation.

A codebook was created to aid both the coder and the coding process. It consisted of definitions of various content and "clues and indicators" which helped maintain consistency across coding (Soulliere, 2003:4-5). The design of the codebook was influenced by research by Neuendorf (2002) and fully described all the variable measures and included definitions and inclusion/exclusion criteria so that each episode was coded consistently. A coding form was created which was a summarised version of the codebook on which all the coding content was recorded. The creation of the codebook was aided by

\footnotetext{
${ }^{9}$ Oliver (1994) modelled her definitions of aggression on Greenberg (1980 cited in Oliver 1994) with verbal aggression consisting of "criticism, insults, cursing" (Greenberg, 1980:108 cited in Oliver, 1994) and physical aggression consisted of "an attack of one human being towards another that involves contact with any body part" (Oliver, 1994:182).
} 
borrowing methodology from Kooistra, et al. (1998) who provided examples on how to code content analyses for ethnicity, age, gender. Similarly, definitions used in Oliver's (1994) research were borrowed, modified, and used to code police officers and offenders. The focus of this research was on the basic quantifiable variables however note was also made of repeated camera and editing techniques and language. This more qualitative data and its interpretation will be discussed at length in Chapter Five.

\section{Coders and reliability testing}

Following Soulliere (2003) a number of steps were taken to ensure that the results of this research would be valid and reliable. As Soulliere (2003) recommends when research of this nature is undertaken by a single coder it is important to ensure that the results measure the media content reliably and consistently. This was achieved through the development of a coding instrument which was then repeatedly tested for its reliability. For the preliminary pilot research, two postgraduate student coders conducted three reliability tests viewing the same episode of Police Ten 7 independently of each other recording the data on the coding sheet. To test for inter-reliability the results achieved by the two coders were then compared. Each crime story was coded on its own coding sheet, each episode consisting of three "ride-along" crime stories ${ }^{10}$ and one "wanted" section. Each coding sheet consisted of five sections and 72 different variables ${ }^{11}$, for example offender and police demographics, offence type, case resolution and types of policing depicted (driving a police car, holding a weapon, arresting an offender). Following reliability testing measures by Gunasekera, Chapman and Campbell (2005) and Mastro and Robinson (2000) a percentage agreement was calculated across each crime story. This was achieved by comparing each individual variable coding choice by each coder. The degree of concordance was determined by adding together all agreeing variables and then dividing them by the number of total variables. This resulted in an overall inter-rater reliability percentage. The first reliability test resulted in the two coders in agreement on how to code the content for $89 \%$ of all variables. The $11 \%$ difference in agreement consisted of differences in coding of age and ethnicity. It was difficult for coders to confidently

\footnotetext{
${ }^{10}$ There were six episodes consisting of two crime stories, seven consisting of three crime stories and two episodes consisting of four crime stories all featuring a "wanted" section, in total this analysis covered 41 separate crime stories.

${ }^{11}$ Each crime story had at least 72 variables to make a judgment call on, in some cases more, e.g when there were subsets to questions, for example when a police officer was processing a offender in the station and was processing intake forms as well as taking offender statements.
} 
differentiate these demographics because of the subjective nature of estimating age and because coders reported uncertainty when coding offenders and to a lesser degree, police, who appeared Maori or Pacific Island in appearance. On the basis of these results the age categories were changed so they were more simple and easier to code. This was done by expanding the age categories from the census categories to capture a wider age bracket which represented broader definitions of youths, young adults, middle aged and elderly which allowed coders more confidence in their judgments ${ }^{12}$. To increase confidence in coding ethnicity, coders were instructed to use a new category "Maori and/or Pacific Islander" when coding individuals who could not be confidently identified as Maori or Pacific Islander alone.

A second reliability test resulted in $87 \%$ agreement and further amendments were made to the category relating to the "tone" of police interactions which were pared down from more complex and subjective judgments relating to nuanced intention and tone and tailored to cover the key common interactions so that less inference about intent was made by coders. A third reliability test resulted in a 98\% agreement across all variables, which was primarily the result of a clearer demographic definitions and the removal of several subjective and difficult to objectively code categories involving the perceived tone of interaction between police and offenders. The average across the three reliability tests was 91\% which met the accepted percentage agreement for reliability (Lombard, 2010). Having gone through that process, and having established the reliability of the framework and the coding scheme a high level of confidence was reached that any observers of the same content would achieve similar scores. The content analysis of all 15 episodes of Police Ten 7 then began.

\section{Variables under investigation}

Analyses were conducted for demographics of police, offenders, witnesses and victims. Other variables analysed included temporal and geographical settings of policing encounters, offence investigated, policing activities such as car chases, foot chases, physical confrontation, verbal confrontation, the presence of weapons and the initiation of

12 The original goal was to use the census age categories throughout the analysis to increase the ease of comparison between the depiction of age on Police Ten 7 and ages of police and offenders in the known statistics. This had to be altered due to continued difficulties in achieving reliability in the age categories resulting in broader categories. 
paperwork. In order to accurately and consistently code these variables several key definitions were developed.

\section{Defining police}

Definitions of offenders and police officers were modelled on Oliver's (1994) coding scheme. Police officers were defined as "any law enforcement official commissioned to solve crimes or catch criminal suspects" (Oliver, 1994:4). As in Oliver's (1994:4) research, only police officers "directly involved in the arrest or questioning of a criminal suspect" were coded and included in the analysis. Officers were therefore coded if they engaged in more than two lines of dialogue with an offender, fellow officer, witness, victim or camera, if they had physical contact with the offender and/or if they were part of the original two officer team featured as the "host" police officers at the beginning of the three crime stories. As in Oliver's (1994) research "back up officers"; those who were featured in the background of scenes but did not speak, were not coded and therefore excluded from the analysis.

\section{Defining Offenders}

Following Oliver (1994: 181-182) criminal offenders were defined as "characters portrayed as committing, having committed, suspected of committing or "wanted" by the police for having committed a violation of the law". In keeping with Oliver's (1994) definition only offenders who were questioned by police or "wanted" by police were coded. If more than one offender was apprehended while responding to a single incident each offender was coded for analysis.

\section{Coding demographics in the "ride-along"}

Gender, ethnicity and age were coded for each police officer and offender. 


\section{Coding Gender}

Gender was simply coded as male, female or undetermined.

\section{Coding ethnicity}

Ethnicity was a more difficult variable to code because ethnicity is not always clearly apparent. As such ethnicity for both police and offenders were coded in three main ways. The first was by self-identification by the character. For example, one offender referred to himself as "three quarters Tuvaluan and one quarter Tokelau". In the second ethnicity was also identified through narrator-identification, when Bell or a police officer would identify an offender's ethnicity. The third involved observer identification. This is when verbal and non-verbal "markers" such as accent and appearance were used by the coder to help identify ethnicity.

The categories for identifying ethnicity underwent some revision during the research design process. Originally the aim was to use the same ethnic groups as the New Zealand Census of Population and Dwellings (2006) (hereafter referred to as "the Census") to facilitate ease of comparison between the depiction of ethnicity on Police Ten 7 and that of offenders in New Zealand and the police organisation as a whole. However following the first and second reliability tests it became clear that ethnicity was commonly proving difficult for coders. This was specifically a problem when coders could not confidently differentiate between Maori or Pacific Island characters. This was also particularly the case when offenders were featured with their identities hidden via pixilation. As a result of this an alternative category for coding ethnicity was developed which was to be used when coders could not confidently decide between Maori and Pacific Island characters. The categories for ethnicity in the final coding scheme became NZ European, Maori, Pacific Island, Asian, Indian, Other (specify), Maori and/or Pacific Island and impossible to determine (typically because of pixilation).

\section{Coding Age}

As with ethnicity the original aim was to employ the same age bands used in the Census. However after the first reliability test age also proved a difficult variable to code. As a result age groups were expanded to encompass a wider range of ages and to provide a 
general insight into the age of police and offenders featured. The age categories were broadened for police to convey four general age groups: young (18-25 years), older (26-40) middle aged (41-55) and those who were older than 56 years. For offenders the ages were similar with 0-16, 17-25, 26-40, 41-55, over 56 years and impossible to determine. This category was used when pixilation, poor quality CCTV footage or disguises such as masks or hooded clothing prevented the coder from being able to see offenders. This category was not needed for police because they were filmed in high quality footage and their identities were not hidden by disguises or pixilation.

\section{Coding offences}

Another key variable was offence type. Following Oliver (1994), offences were defined as "unlawful or potentially unlawful acts for which the criminal suspect was wanted, shown committing or was suspected of committing" (Oliver, 1994:5). Offence types conformed to the seven categories of offences used by New Zealand police when this research began ${ }^{13}$. The categories were violence, sexual, drugs and antisocial, dishonesty, property damage, property abuse and administration. An eighth category "traffic" was added due to the large number of traffic offences featured in Police Ten 7, despite traffic not being a part of the main offences included in the biannual National Crime Statistics. It should be noted that during the time this research was being conducted the police adopted the ANZOC offence classification system in order that New Zealand and Australian crime statistics could be compared (Statistics New Zealand, 2011). Offence type was identified in two ways. The first was when the police or narrator stated the offence being responded to. This was the most common way offences were coded. If the narrator or police did not explicitly state the offence, the observer selected the offence based on the information provided. If an offender was stated or depicted to be involved in two different offence categories, for example a drunk and disorderly offender who assaults an intimate partner, the most serious offence was coded ${ }^{14}$

13 When this research began the New Zealand Police were still using the now obsolete categories violence, property damage, property abuse, sexual, administration, dishonesty, drug and antisocial and traffic. In July 2010 the Australian and New Zealand Standard Offence Classification method became standard in New Zealand. This research uses the old categories and where possible more recent ANZSOC data has been transferred to the old categories in an attempt to compare data from the same year.

${ }^{14}$ This follows the ANZOC practice of recording the most serious, or representative offence (Australian Bureau of Statistics, 2011) 
The resolution or outcome for each crime story was coded. These outcomes included offender not found; detected or escaped; offender cautioned but not arrested; offender informed of future involvement but action postponed; offender arrested, charged and released and offender arrested charged and detained. A further outcome "offender given fine" was exclusively used for traffic offences.

\section{Coding policing}

A main objective of the research was to explore the various ways policing is depicted in Police Ten 7. To do this repeated features of representation, as identified in the preliminary analysis of six episodes, were grouped into eight sections. These sections were demographics of police and offenders, temporal and geographical setting of the crime story, offence type, police-action-oriented activities, offender-to-police actions, police-tooffender interaction and language, crime story resolution and narrator language and content. These sections were created because they logically and organically developed with demographics being one of the first variables to code in a crime story and the following sections flowing out from this through the natural development of the crime story. Demographics, temporal and geographical setting and offence type are self-explanatory however some sections require more detailed explanation. Police-action-oriented activities refers to duties police are depicted as performing in their role of police officer. Some of the key variables in this section included doing paperwork on the street (including writing citations), doing paperwork in the police station, apprehending offenders, using handcuffs and weapons, guarding scenes, driving a police car with siren and/or lights on and engaging in a car or foot pursuit. These potential police actions were taken from the six episode pre-analysis as well as from the Home Office report Diary of a Police Officer (2001).

Offender-to-police interactions and police-to-offender interactions included the use of verbal aggression, physical confrontations and language used. Narrator language and content concerns the language used by the narrator, Graham Bell, during the crime story. For example, positive or negative descriptions of offenders and police as well as general verbal discussion of crime and policing information, for example mentioning community policing or emergency response. The creation of categories and the definitions involved was inductive in that the preliminary research provided a good idea of common settings for crime stories (for example on the street, in a house etc). Information from apprehension 
statistics also provided information about common or recorded offence locations. Categories for the completion of paperwork and other key policing activities were created and defined. This was based in part on Diary of a Police Officer (2001) research and utilised some of the roles or tasks which were discussed in that research as being common policing activities. The definitions for differentiating between reactive and proactive policing were modelled on Soulliere (2004) and research by Mastro and Robinson (2000) was utilised as a modelling tool for the general creation of some variables, for example the presence of foot or car pursuits. Other variables investigated were interactions between police and offenders including the presence of verbal and physical aggression. The goal in this section was to explore the way police work was represented. Drawing on the known realities of policing as reported in Diary of a Police officer (2001), the research wanted to discover whether policing was depicted on Police 107 as either action packed and constantly chaotic or whether more mundane duties such as paperwork, court appearances and preventative policing were given screen time.

\section{Coding the "wanted" section}

When coding the "wanted" section the general process was similar to that used for the "ride-along" section. There were, however, some differences which made the coding of the "wanted" section somewhat easier. The narrator would typically describe the gender, ethnicity and age of the offenders sought whenever this information was available. This resulted in less need for observer identification. Coding was also undertaken for the reconstructions which included demographics and qualitative information such as the way the narrator described the offender.

The focus of this study was primarily on the first section of Police Ten 7, the "ride-along" section because this section makes up approximately three-quarters of the total air time and depicts general rank-and-file police officers and the duties they perform, as opposed to the specialised work of detectives. Therefore the analysis of the "wanted" section only includes simple demographics of the "wanted" faces and the linguistic content of their descriptions.

Where reconstructions were present these were noted and qualitative data relating to repetitive camera techniques, narrative devices and common imagery was gathered. 


\section{Analyses}

After coding all 15 episodes of Police Ten 7, tally sheets were created containing the specific categories for analysis. The data on each coding form was then entered into a master data sheet. Demographic data was recorded and calculated into percentages, for example the ethnic breakdown of all offenders depicted in the "ride-along". For more complex analyses, for example the analysis of character portrayal, each individual portrayed was tallied and their ethnicity and role as either offender or police was recorded and analysed. This process of tallying continued until all the variables under analysis were accounted for. To draw out the key themes in Police Ten 7 thematically similar actions and language were grouped together. In order for something to be considered a "theme" Berg's (2004) recommendation was adopted in that a minimum of three occurrences was considered to be a pattern, in other words a theme. Major themes identified by research on the police were noted. Research specifically focused on police reality-based television was used to draw out key themes of representation. These themes were then compared to key ideas and themes identified in Police Ten 7 to see if there were any similarities or differences in representation.

The analysis first focused on the demographics (gender, ethnicity, age) of police and offenders in the "ride-along" section. This analysis also included "intergroup", "interrole" and "interreality" comparisons (Dixon \& Linz, 2000:547; Entman, 1992). Dixon and Linz (2000) analysed race and victimisation on television news and utilised these three measures to compare the depiction of blacks, Hispanics and whites. This research borrows these three comparison measures to compare the representation of different ethnicities on Police Ten 7. Interrole measures "compare the number of portrayals of a positive role within a racial or cultural group to the number of portrayals of a negative role within the same group" (Dixon \& Linz, 2000:550). The aim of this analysis in Dixon and Linz's (2000) research was to explore whether a "racial groups' appearance on television is marked by a preponderance of positive or negative imagery" (Dixon \& Linz, 2000:550). In this research interrole comparisons refer to the depiction of various ethnic characters as either police or offenders, their "character role/portrayal". This analysis is useful because it provides an insight into the ways different ethnicities are represented and to identify any major differences in that representation. For example, the analysis showed that $80 \%$ of all Pacific Islanders featured on Police Ten 7 were in the role of offenders while only $20 \%$ were depicted as police. This is different from simple percentages of all offenders/police because 
it highlights the pattern of depictions: for example, of all Maori characters portrayed, what percent are shown in the role of offender?

"Intergroup" comparisons explore the depiction of individuals of a common type, for example, comparing portrayals of white and non white offenders and contrasting the frequency of portrayal against each other (Dixon \& Linz, 2000). The intergroup comparison was also used to explore which ethnicity was most often depicted on Police Ten 7. Interreality comparisons are those which compare the "reality" constructed on Police Ten 7 and the known reality as evidenced in demographic information from unpublished HR Police reports (2010) and Annual Police Reports (2010), National Annual Apprehensions (2010), National Recorded Offences (2010) and other official sources. Whenever possible the most recent reports were used for comparison however in some cases, comparisons were made to 2008 and 2009 data because of the transference of recent data to the new ANZOC categories.

The first part of this interreality comparison concerned offence types. This compared offences featured in Police Ten 7 to National Recorded Offences (2010). When the programme was filmed in 2010 the system in place was the National Recorded Offences, as opposed to the ANZOC system. To ensure consistency between the Police Ten 7 depictions and the official recorded statistics the 2010 National Recorded offences were transferred from ANZOC to the old obsolete categories. The second part of the interreality analysis compared the findings related to case resolution. This consisted of comparing the depiction of successful resolutions of crime stories in Police Ten 7 to the actual rates of successful police resolutions in New Zealand as documented in the National Recorded Offences (2010).

Successful resolutions on Police Ten 7 consisted of crime stories depicted in the " "ridealong" section as either offender being cautioned, told of police intentions for future involvement ${ }^{15}$, offender arrested and released, arrested and charged or given a fine. An unsuccessful resolution consisted of police not finding an offender/failing to catch an offender. The third part of the interreality analysis compared the way policing is depicted on Police Ten 7 to the known realities. This section presented a difficulty given the absence of New Zealand based research into the everyday activities of police. As a result several

15 For example, a traffic offender was told by police that he could finish the bus tour he was driving and return to the police station the next day to be processed. 
international sources were used. The first and most important source was the UK based report Diary of a Police Officer (2001). This was research commissioned by the Home Office in order to "gain a fuller understanding of what is involved in a "typical" shift of a police officer" (Home Office, 2001: x). The research consisted of police officers across the UK completing a total of 378 "diaries" detailing "the activities they were engaged in during their shift" (Home Office, 2001: xi). This source provides detailed information from a police service which, while not identical to New Zealand, does share many historical and contemporary features. The degree of similarity between the two countries is such that it justified a large scale recruitment drive for UK police officers to move to New Zealand, complete an 11 week conversion course and begin careers with the New Zealand Police. Other sources utilised for this comparison of policing on Police Ten 7 and the known realities included the Police Annual Report (2006, 2010), and National Annual Apprehension statistics (2010). A further analysis concerned the "wanted" section and consisted primarily of comparing Police Ten 7 representations with the aforementioned Apprehension Statistics and National Recorded Offences (2009, 2010) and demographics of the "wanted" section compared with known offenders.

\section{Limitations}

Beyond the limitations of qualitative research (see page 30) another commonly cited problem when comparing media portrayals of crime to the "reality" of crime is the reliance on official statistics. There are many well documented limitations with official statistics primarily concerning the dark and grey figures of crime (Bradley \& Walters, 2011; Bottomley \& Pease, 1986; Mayhew \& Reilly, 2007). While these limitations are acknowledged it is also accepted that official statistics are commonly used in other similar studies and provide the best comparative source. Furthermore, when comparing the results of the content analysis to official statistics there are some incidents which cannot be compared directly. In particular it was impossible to compare those incidences which were related to traffic offences because these are not included in crime statistics. A further issue which should be addressed is that media content cannot on its own predict how an audience will react to content or assume some kind of universal influence (Reiner, 2007). However, by exploring themes an attempt was made "to shed light on the potential implications of these television presentations on viewer knowledge and understanding" (Soulliere, 2003:15). 


\section{Summary}

This research explored the representation of policing on Police Ten 7. This was achieved through content analyses of 15 episodes of the 2010 Police Ten 7 season which recorded demographics of offenders and police, offence types and case resolutions as well as depictions of typical everyday policing. This content analysis was undertaken after a preliminary open coding process and a reliability test using two volunteer coders. The results of the research were tallied and then compared on various levels to official statistics such as apprehension statistics, recorded crime, annual reports and other sources of information about the activities of police. While it is accepted that there are limitations with content analysis as a methodology, particularly in the potential for subjective results based on interpretations of the material and category selection and creation, it is also accepted that this is unavoidable in this kind of research (Berg, 2004; Neuendorf, 2002; Babbie, 2007). The findings of this research are therefore presented as "one reading" of Police Ten 7 which follows in the footsteps of several previous international studies (Oliver, 1994; 2003; Mastro \& Robinson, 2000; Soulliere, 2001; 2003) and fulfils the overall aim of explorative research on an area of criminology which is under-researched in the New Zealand context but one that is gaining in importance. 


\section{Chapter Four: Findings}

This chapter is divided into two halves. The first half presents the results of the content analysis of what is referred to as the "ride-along" section. This section takes up approximately three-quarters of each episode and features a camera crew accompanying New Zealand police officers on patrol. According to promotional material the aim of this section of the show is to present a "gritty unflinching look at the real day-to-day working lives of police in New Zealand" (TVNZ, 2011b). The "ride-along" section typically presents three separate "crime stories", a term used from here on to describe the discrete stories of crime and policing. The first half of the chapter is made up of three sections. The first presents the results of the demographic analysis of police and offenders/suspects featured on Police Ten 7 broken down by gender, ethnicity and age. The second presents the results of the analysis of the types of offences featured and the third presents the results of the nature or type of police activities featured.

To compare the research findings against the known realities the demographics of police and offenders featured on Police Ten 7 are compared against New Zealand Police human resource data and New Zealand Police National Annual Apprehension and Conviction statistics (2010). Recorded crime statistics on offence types and the distribution of offending in New Zealand are compared with the offences featured on Police Ten 7. Finally, the Diary of a Police officer (2001) is utilised to compare the portrayal of police on Police Ten 7 against the known realities of day-to-day policing.

The second half of the chapter presents the findings of the analysis of the "wanted" section. The "wanted" section of Police Ten 7 occurs at the tail end of each episode and takes up approximately a quarter of the episode's air time. This section consists of a reconstruction of a serious crime featuring an interview between narrator Graham Bell and the lead detective of the specific case, followed by a police "roll call" of mug shots of "wanted" offenders.

The second half of the chapter is made up of three sections. The first presents the results of an analysis of offender demographics, broken down by gender, ethnicity and age. The second presents the results of an analysis of offenders and offence type. In each section the findings of the research will be compared and contrasted against the known realities of crime and offending in New Zealand as measured by the aforementioned Apprehension 
and National Recorded Offence statistics. The third section presents the results of the qualitative analysis of the "wanted" section. Several key themes emerged from this analysis, the "us versus them" ideology, "dangerous criminals" and "policing denotes action" (Waddington, 1999).

Before presenting the findings of the content analysis it is worth briefly recounting the steps taken to ensure that the framework for analysis was applicable, reliable and replicable. The first was to render the content analysis more manageable by breaking it down into a number of pieces. The first step was to conduct a small pilot study of six episodes. This resulted in the creation of three broad categories, namely demographics, offence types and policing activities. Specific variables were then categorised into a coding framework informed by these three categories. A reliability test was then carried out. This involved two independent coders observing the same episode of Police Ten 7 and comparing their observations. In total three reliability tests were conducted with each resulting in revision of the specific variables to be recoded. This was an iterative process which continued until there was sufficient confidence that any other observer employing the same coding framework watching the same episodes would produce similar results.

\section{Section One: The police "ride -along" section}

\section{Representing the police: Demographics}

In this section the gender, ethnicity and approximate age of police officers featured in Police Ten 7 are presented and then compared with the actual composition of New Zealand police as recorded in official New Zealand HR Police reports (NZ Police, 2010b).

\section{Gender}

In total, across all 15 episodes the police officers featured on Police Ten 7 consisted of $83 \%$ male $(n=98)$ and $17 \%$ female $(n=20)$. Compared to the distribution of gender within the New Zealand Police as a whole this representation closely reflects the reality. That is, according to its December 2010 HR scorecard, the New Zealand Police consists of $17.2 \%$ female officers and $82.8 \%$ male officers (NZ Police, 2010b). 


\section{Ethnicity}

To analyse the ethnicity of police officers featured on Police Ten 7 several methods were used simultaneously. Accurately identifying ethnicity can be difficult due to the fact that it is not always visibly apparent. As a result the ethnicity of each officer featured was assigned through self-identification (i.e. by the police officer themselves) and by narratoridentification. The third, and more subjective method, involved the researcher identifying ethnicity on the basis of accent and appearance. It is accepted that identifying ethnicity via observation as opposed to self-identified ethnicity is a limitation due to the subjective nature of observation. However, in the majority of cases there was a degree of confidence that ethnicity had been correctly identified because of the available "ethnic markers" in the form of accent and appearance.

The analysis revealed that $84 \%$ of all featured officers were New Zealand European $(n=99), 5 \%$ were Maori $(n=6), 4 \%$ were Pacific Islander $(n=5), 3 \%$ Maori and/or Pacific Island and a further $4 \%$ British officers $(n=5)^{16}$. To compensate for any inaccuracies created by the subjective nature of observation, a more simple process was created which categorised officers into white and non-white. This analysis found that $88 \%(n=104)$ were identifiable as white and $12 \%$ of officers were identified as non-white $(n=14)$. No Asian or Indian officers whatsoever were featured in any of the 15 episodes. Compared to the relatively diverse ethnic makeup of the New Zealand police these findings represent a rather limited correspondence to the reality, see figure one.

16 Since 2003 the New Zealand Police, with assistance from Immigration New Zealand, have sporadically gone on recruitment campaigns in Britain to attract British police officers to come and work in New Zealand completing 11 week conversion courses and primarily filling Auckland based vacancies. In 2005 a large scale recruitment drive resulted in approximately 200 British officers being recruited and deployed in New Zealand, the majority of whom were deployed to Auckland (NZ Police, 2003, 2006a). 


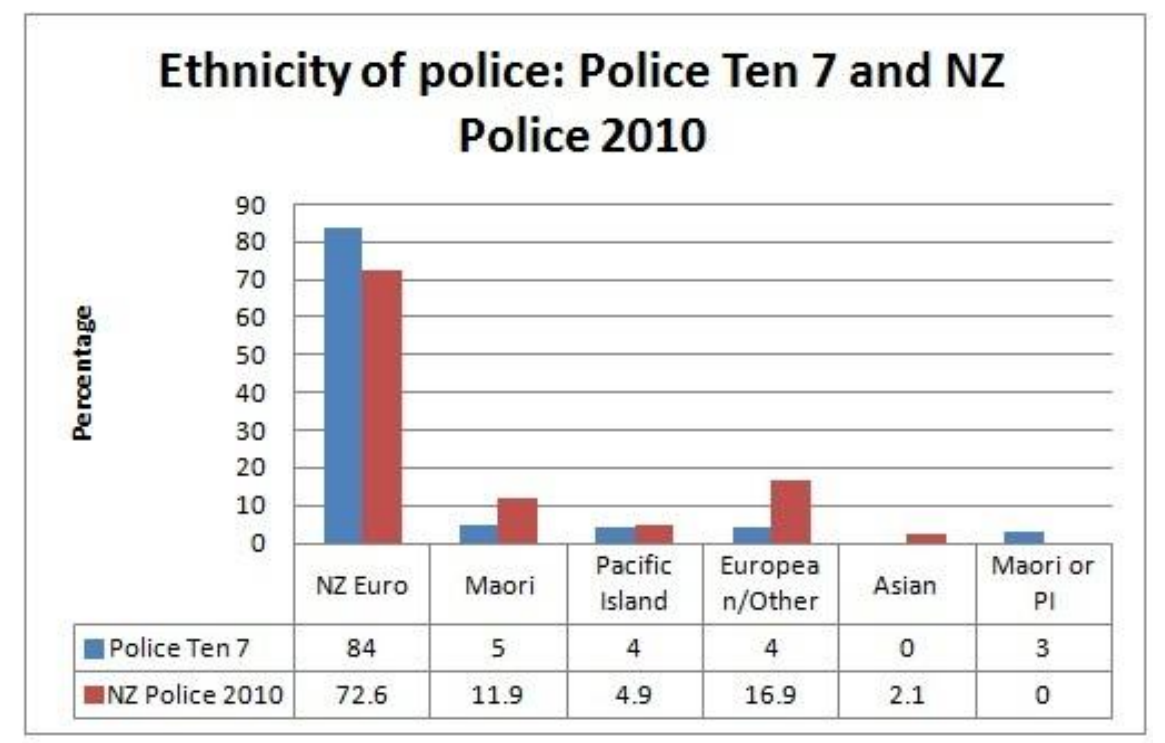

Figure one: Comparison of ethnicity of police officers as represented in Police Ten 72010 season and 2010 official police statistics of the organisation as a whole ${ }^{17}$ (NZ Police, 2010b)

When compared with New Zealand Police HR statistics (NZ Police, 2010b) NZ European officers are clearly over-represented in Police Ten 7. As of December 2010 New Zealand Police were made up of 11.9\% Maori, 4.9\% Pacific Islanders, 2.1\% Asian officers and 72.6\% New Zealand European (NZ Police, 2010b). In Police Ten 7 New Zealand European officers were thus clearly over-represented while Maori and Asian officers were underrepresented relative to their actual numbers within the New Zealand police.

Age

Age was a variable of interest, in part because generally speaking, the age of officers gives us an understanding of levels of experience. In common with ethnicity, accurately identifying the age of police officers featured in Police Ten 7 is subject to a similar limitation. The initial intention was to adopt the same age bands employed by the New Zealand census and to locate featured police officers within these same bands. After the preliminary reliability test however it became apparent it was not always possible to accurately locate them within these narrow bands. In response these categories were expanded until there was a degree of confidence that the general age of the individual could be identified. The age bands were thus expanded to form four main age categories and which identified officers as either young (18-25 years old), older (26-40) middle aged (41-55) and those who were older than 56 years. These broader bands have clear

17 The 2010 Police Annual Report allows police to identify with more than one ethnic group meaning that percentages add to more than $100 \%$. 
limitations. The 26-40 category, for example, covers a broad age range and could therefore be reasonably expected to be the category containing the largest number of officers. However, the main objective here was not to identify the specific age of officers but instead to explore whether Police Ten 7 generally featured young, middle-aged or older officers and the broad proportions of their representation and to thereby gain some insight into the relative experience featured on Police Ten 7.

The overwhelming majority of police officers featured were slightly older officers aged between 26 and 40 years old (75\%). A further $14 \%$ of police officers featured were very young officers (18-25 years), 9\% were identifiably older (41-55 years) and 2\% were aged 56 and over. Those aged 41-55 and those aged 56 and older were clearly under represented. When these officers were featured it was most often in the role of motorway patrols or detectives and specialists involved in drug raids. In comparison to the official police HR data and to the 2006 Census data, Police Ten 7 contains an over representation of younger police officers, as figure two shows.

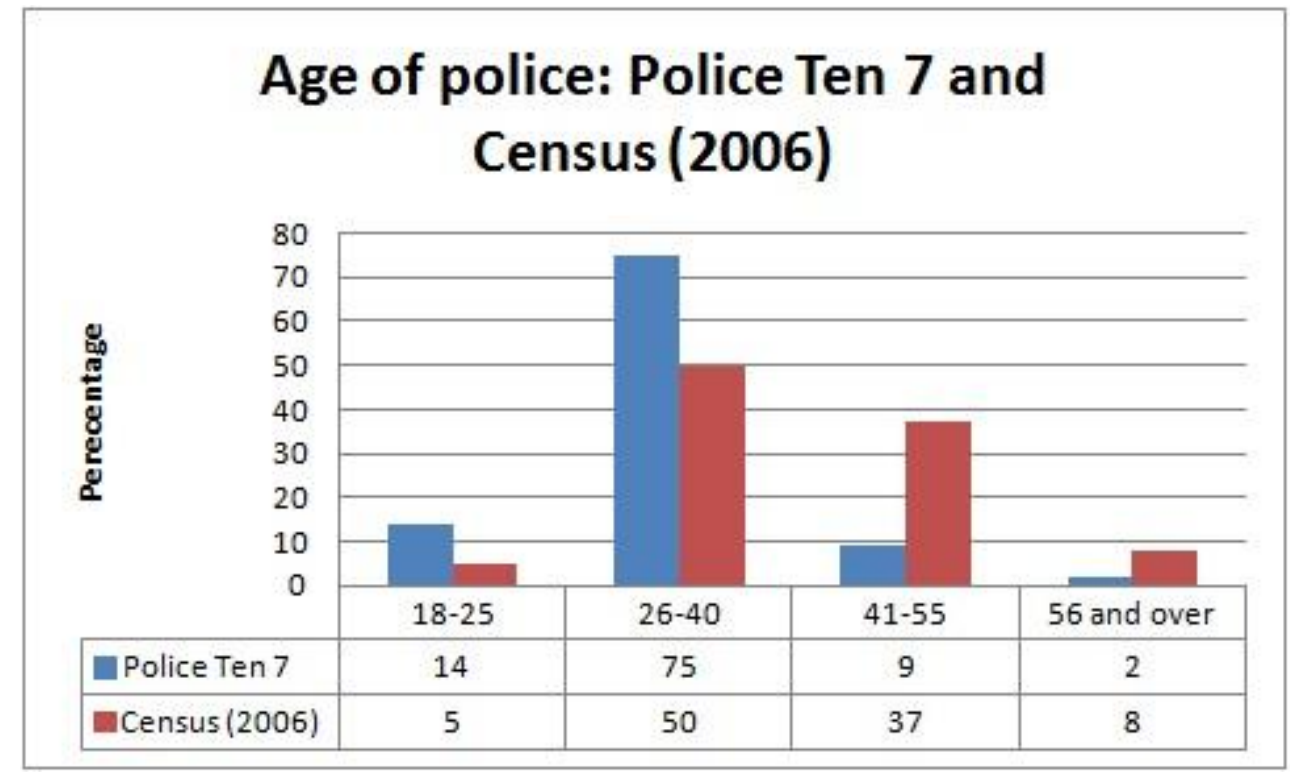

Figure two: Police age as depicted on Police Ten 7 and actual distribution of police age in the Census 2006 (Statistics NZ, 2006)

For example, the actual median age of police officers increased from 34 years in 1999 to 39 in 2010, and police predict the median age of a New Zealand police officer will be 43 by 2019 (New Zealand Herald, 2010a). In other words, by 2019 more than 60\% of New Zealand police officers will be aged over 40 (NZPA, 2010). The New Zealand Police, therefore, is an aging organisation, as figure three demonstrates. 


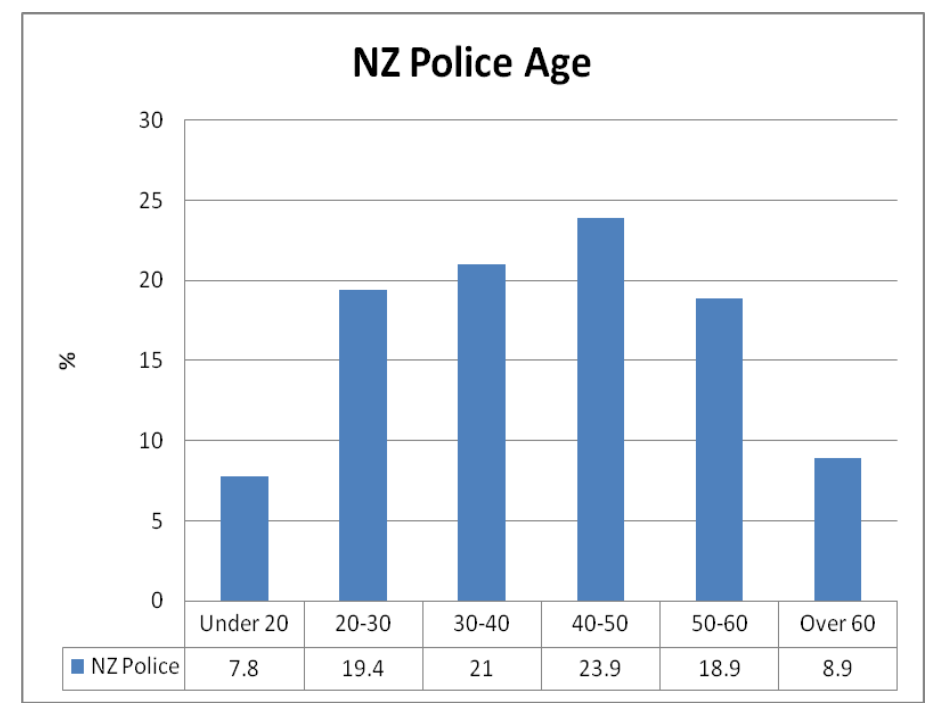

Figure three: NZ Police age curve as of 2008 (NZ Police, 2010b)

The over-representation of younger police on Police Ten 7 compared to the actual makeup of New Zealand Police may, in part, be strategic, as the police are actively recruiting younger police officers and may utilise this avenue of public promotion to connect with and be more attractive to younger audience members. The selective representation of police will be discussed further in relation to the promotional value of Police Ten 7 to the New Zealand Police in Chapter Five.

\section{Representing offenders: Demographics, character portrayal and offence type}

\section{Gender}

Across all episodes of the Police Ten 72010 season, $86 \%$ of offenders depicted in the "ride-along" section were male $(n=50)$ and $14 \%$ of offenders were female $(n=8)$. Compared to police apprehension data (2010) this representation is similar to the actual gender breakdown of apprehension. The National Annual Apprehensions (2010) show that in $201082 \%$ of offenders were male and $18 \%$ female (Statistics NZ, 2010a). The ratio of male to female offenders has been relatively stable across the years with official statistics showing a ratio of around 4:1 going back to the late 1980s (Statistics NZ, 2010a). In this regard, the depiction of gender in Police Ten 7 corresponds to the official statistics and accurately reflects the gender-ratio problem (Bradley \& Walters, 2011). 


\section{Age}

The difficulties encountered in determining the age of police officers were often compounded in relation to estimating the age of offenders due to the practice of face pixilation to protect offenders' identities. As a result, the findings presented must be understood in the context of providing an exploratory insight into the representation of age on Police Ten 7. With that in mind, the following findings can be presented. Throughout the 15 episodes of Police Ten 7 the majority (72\%) of offenders presented were estimated to be aged under $25,20 \%$ estimated to be $26-40,3 \%$ aged $41-55$ and a further $2 \%$ were unknown. Offenders in Police Ten 7 are primarily represented as young adults (less than 25 years) and those aged 41 and over are very under-represented. In order to compare these findings with official statistics is important to note that the there is a degree of difficulty making any clear comparisons due to the different categories employed. As discussed above, it was necessary, to render the content analysis more manageable, to have broader age categories than those used by the census.

National Annual Apprehensions for 2010 demonstrate that $40 \%$ of apprehensions involved those 20 years and under with another $29 \%$ involving those aged 21 to 30 years (Statistics NZ, 2010a). Despite the difficulty in exact matching it can be argued that young offenders in Police Ten 7 are slightly over-represented when compared to official statistics. That said, offenders in Police Ten 7 do more broadly conform to the "age crime curve" (Hirschi \& Gottfredson, 1983). It should be noted, however, that official statistics often inflate the frequency of youth offending due to increased surveillance, public visibility, over policing and over-regulation of youth (Cunneen \& White, 2007; Muncie, 2009). Because young offenders often offend in groups and also are often charged for multiple offences for a single event this can have an inflationary effect on youth crime in general (Bradley \& Walters, 2011). Official statistics can thus inflate the numbers of individuals involved from younger age groups. That Police Ten 7 features a higher proportion of youth offenders than official statistics will be discussed further in the "wanted" section and will be supplemented with more qualitative information about the use of language that often conflated youth with offender in Police Ten 7. 


\section{Ethnicity}

In common with the analysis of the ethnicity of police officers, the ethnicity of offenders was analysed using the same three methods of identification, self-identification, narrator identification and researcher observation. Identifying the ethnicity of offenders is more problematic than that of police due to the fact that offenders' identities are sometimes hidden with the use of pixilation. Moreover, in the absence of self-identification and narrator identification it was at times difficult to distinguish between Maori and/or Pacific Island offenders. In recognition of this, the combined category of Maori and/or Pacific Island was created as one way of compensating for this limitation. While this is not ideal the combination of the three categories of Maori, Pacific Islander and Maori or Pacific Islander allowed a more general comparison with NZ Europeans or whites.

Throughout the 15 episodes of Police Ten 7, as demonstrated in figure four, of the offenders featured in the "ride-along" section 38\% were identified as NZ Europeans $(n=22), 33 \%$ were identified as NZ Maori $(n=19), 12 \%$ as Maori or Pacific Islander $(n=7) 18,10 \%$ Pacific Islanders $(n=6), 2 \%$ Asian $(n=1), 2 \%$ other $(n=1)$ and a further $3 \%$ were unable to be confidently identified due to pixilation and lack of other sources of information such as verbal or non-verbal cues.

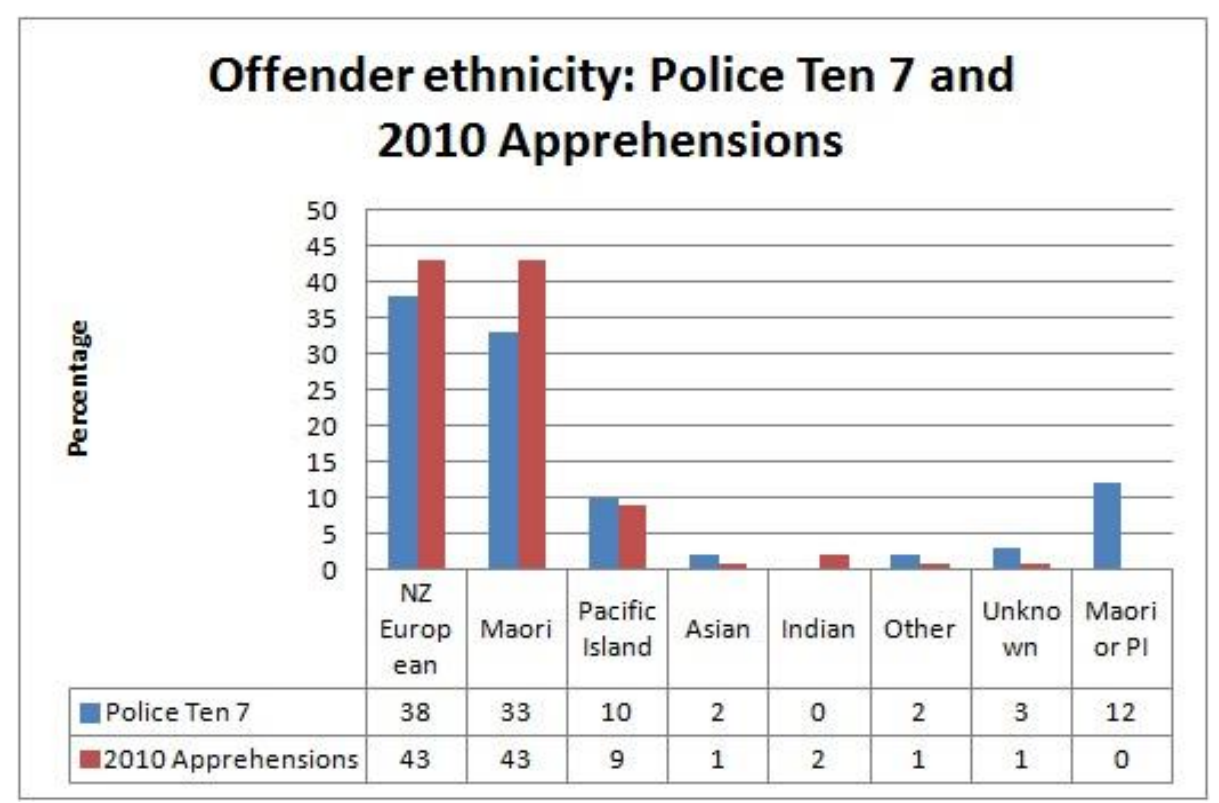

Figure four: Comparison of ethnicity of offenders on Police Ten 7 and National Annual Apprehension statistics (Statistics NZ, 2010a)

18 Figure 2 includes the Maori or Pacific Island category utilised for the analysis coding which is not used in official statistics. 
When compared to official statistics, as demonstrated in figure four, NZ Europeans and Maori were under-represented as offenders on Police Ten 7's "ride-along" section. One has to be careful in interpreting these statistics given the difficulty in separating Maori and Pacific Island ethnicity. However the fact that Pacific Islanders are less frequently featured in both official crime statistics and in Police Ten 7 could suggest that the majority of those categorized as Maori or Pacific Islander were in fact Maori. If it is taken that the majority of offenders classed in this research as Maori and/or Pacific Islanders were in fact Maori then Maori may represent up to $45 \%$ of offenders featured which closely corresponds to the actual police apprehension statistics.

\section{Character portrayal}

In a 1994 content analysis of five reality policing television shows in the United States, Oliver analysed the connection between race and "character portrayal", that is, whether characters were featured as police officers or criminal suspects (Oliver, 1994). In this interrole comparison (Dixon \& Linz, 2000) she found that the majority (61.6\%) of white individuals depicted in the five shows were portrayed as police rather than offenders and the majority of black individuals (77\%) were portrayed as suspects rather than police officers. This research undertook a similar analysis of the different character portrayals of different ethnic groups on Police Ten 7.

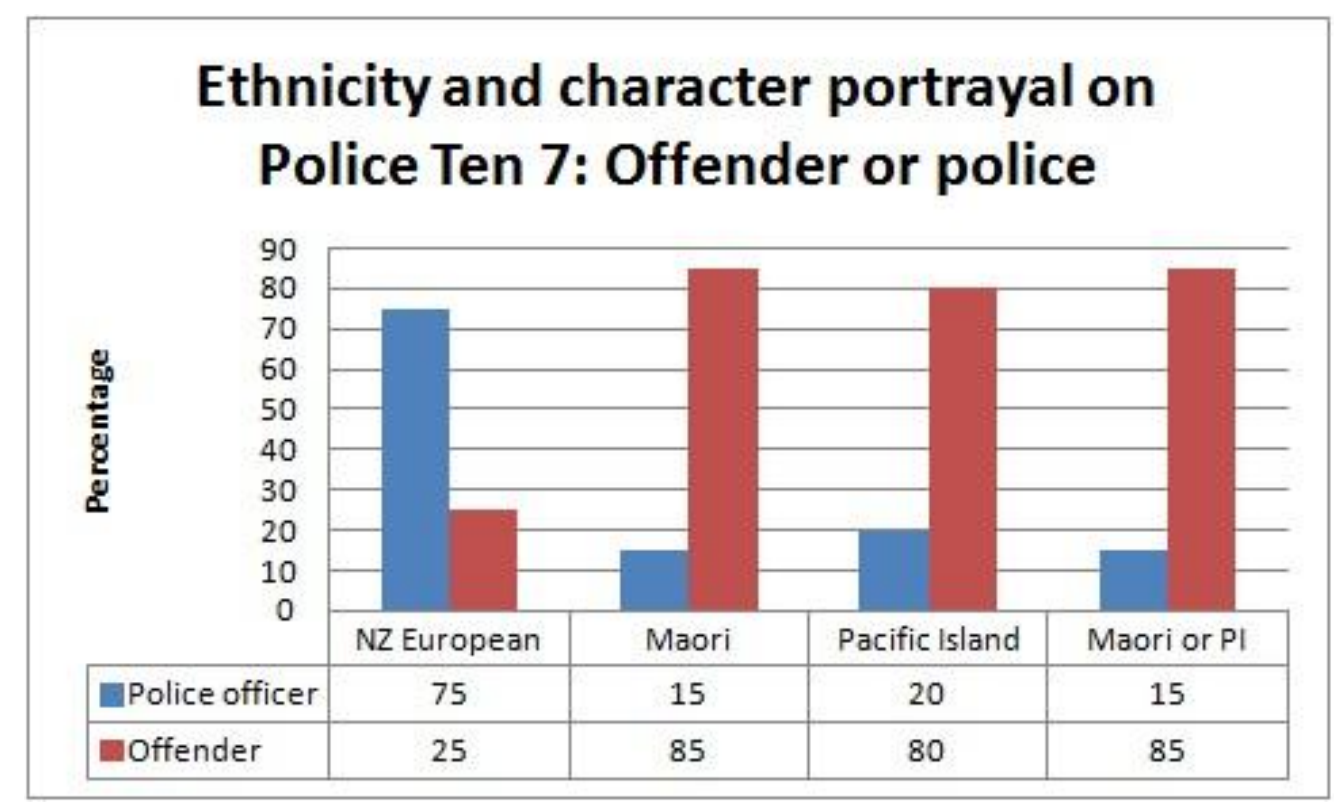

Figure five: Character portrayal and ethnicity on Police Ten 7: Police officer or offender 
Combining the "ride-along" and "wanted" sections, this analysis revealed that the majority (75\%) of New Zealand Europeans were portrayed as police rather than offenders and the majority of Maori (85\%) and Pacific Island individuals (80\%) were portrayed as offenders rather than police officers (see figure five).

The research also analysed the association between ethnicity and offence type. In common with Entman (1992), who found that 84\% of black suspects featured on television news were associated with violent offending, this research found that across the 15 episodes of Police Ten 7 Maori and Pacific Islanders were more often associated with violent offences compared to NZ European offenders. Figure six illustrates the depiction of the ethnicity of violent offenders on Police Ten 7 compared to the actual 2010 Apprehensions.

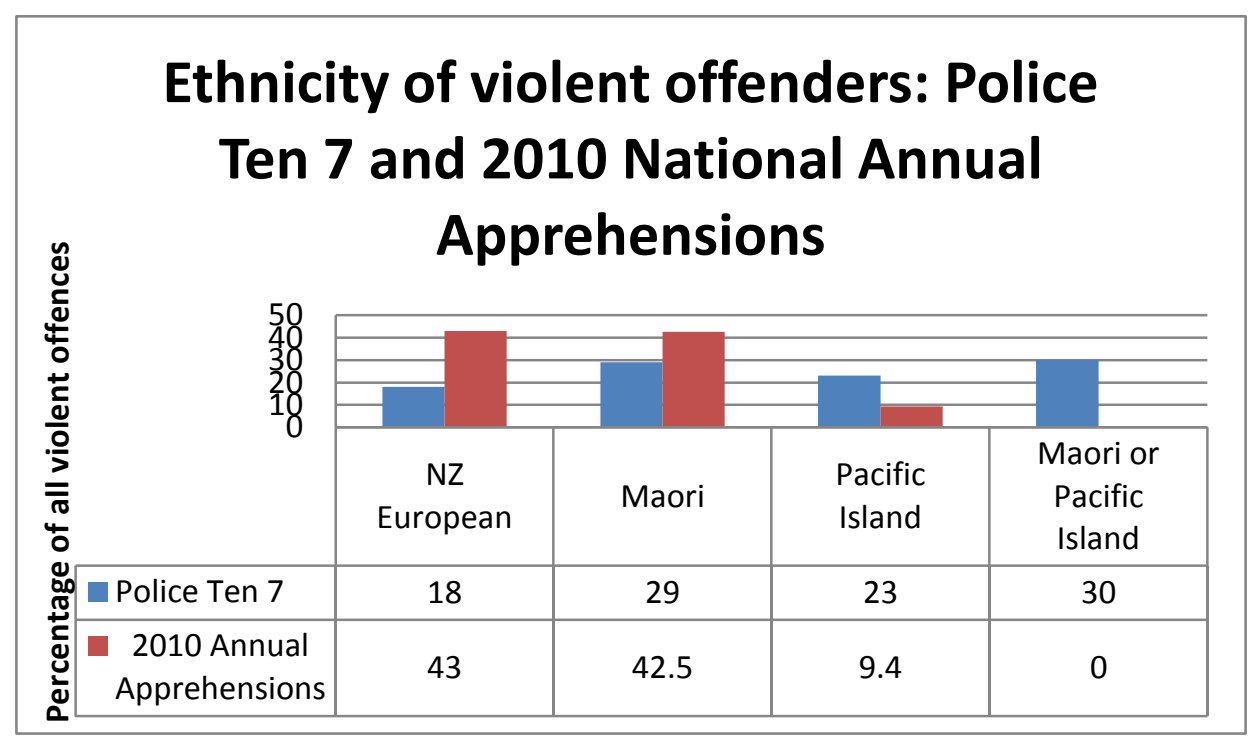

Figure six: Violent offences and ethnicity on Police Ten 7 and 2010 National Annual Apprehensions (Statistics NZ, 2010a)

Of those who were apprehended for violent offences in $201043 \%$ were NZ European, 42.5\% were Maori and 9.4\% were Pacific Islanders. However of those featured committing violent offences on Police Ten 7 only 18\% were NZ European, 29\% Maori, 23\% Pacific Islander and 30\% were identified as Maori or Pacific Islanders. Overall, 82\% of all violent offences featured in Police Ten 7 were committed by non-white offenders. This is an inaccurate depiction of violent offending in New Zealand which over-represents non-white offenders as committing the majority of violent crime and significantly under-represents NZ European offenders as violent offenders. 
Similarly, across all 15 episodes of Police Ten 7 where Maori and Pacific Islanders were featured as offenders they were more often involved in violent offending (36\%) and (50\%) respectively and $76 \%$ for the combined Maori and Pacific Island category (see figure seven below). When NZ European characters were featured as offenders they were most often involved with drug and antisocial offences (40\%).

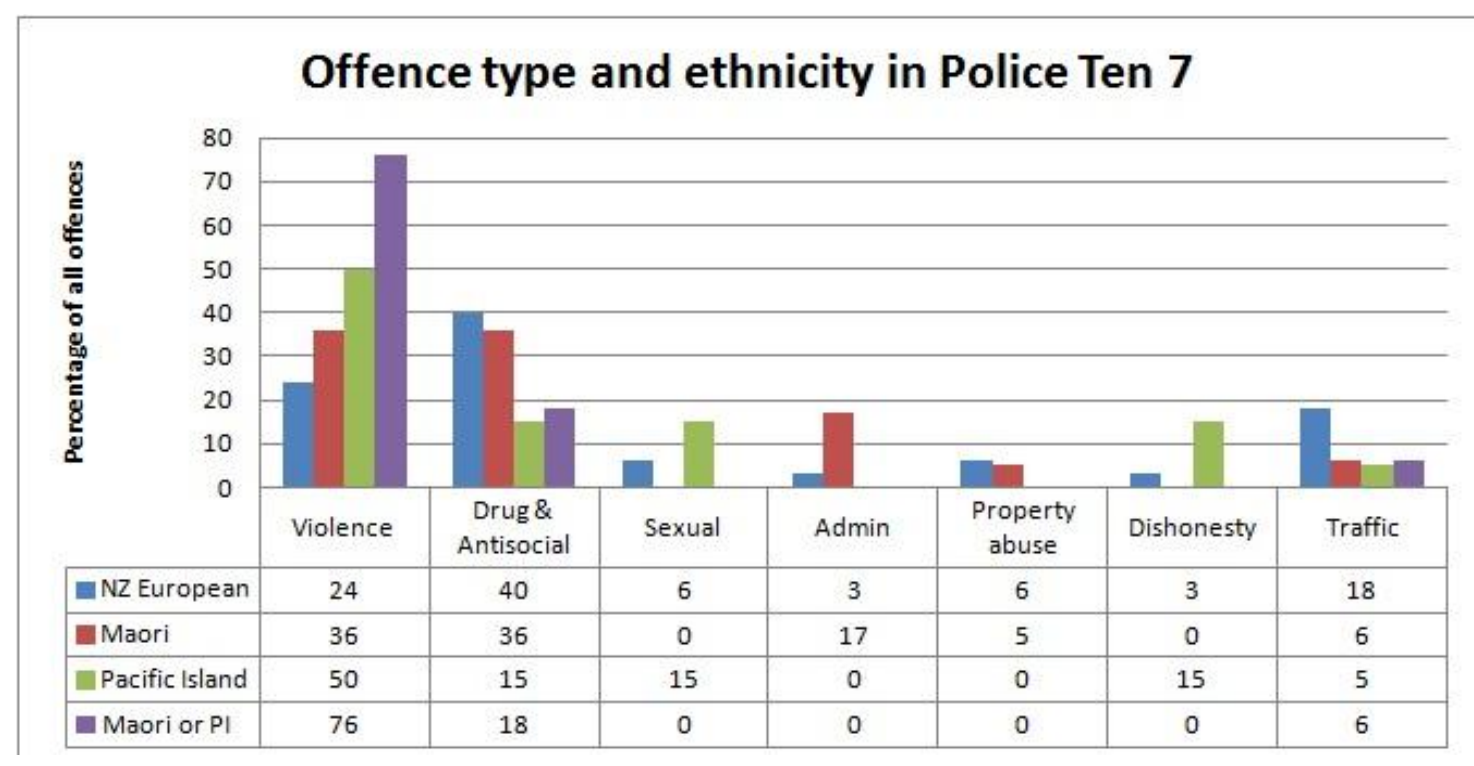

Figure seven: Offenders ethnicity and offence type in Police Ten 7

When compared to actual police apprehensions by ethnicity it is clear that the focus on violent offending for Maori and Pacific Islanders and a concomitant lack of the same for NZ European offenders is not reflective of the reality of offending (see figure eight). In $201039 \%$ of all apprehensions for violent offences involved NZ Europeans, 42\% Maori and only 12\% Pacific Islanders. Similarly, National Annual Apprehensions for 2010 were analysed to see if Maori and Pacific Island offenders commit more violent offences as a percentage of total offending by each ethnicity. This showed that violent offending by Pacific Island offenders made up 30\% of all apprehensions for Pacific Island offenders, significantly less than the 50\% of offences depicted on Police Ten 7 (Statistics NZ, 2010a). Violent offending made up 23\% of all apprehensions by Maori offenders in 2010, which when compared to the percentage of offending by Maori offenders featured on Police Ten 7 (36\%) (and 76\% for Maori or Pacific Islanders) demonstrates an over-representation of Maori offending as violent on Police Ten 7. Violent offending by NZ Europeans was also slightly over-represented, although less so than Maori and Pacific Islanders, in Police Ten 7 (24\%) when compared to the overall percentage of all offending by NZ Europeans in 2010 $(20 \%)$. 


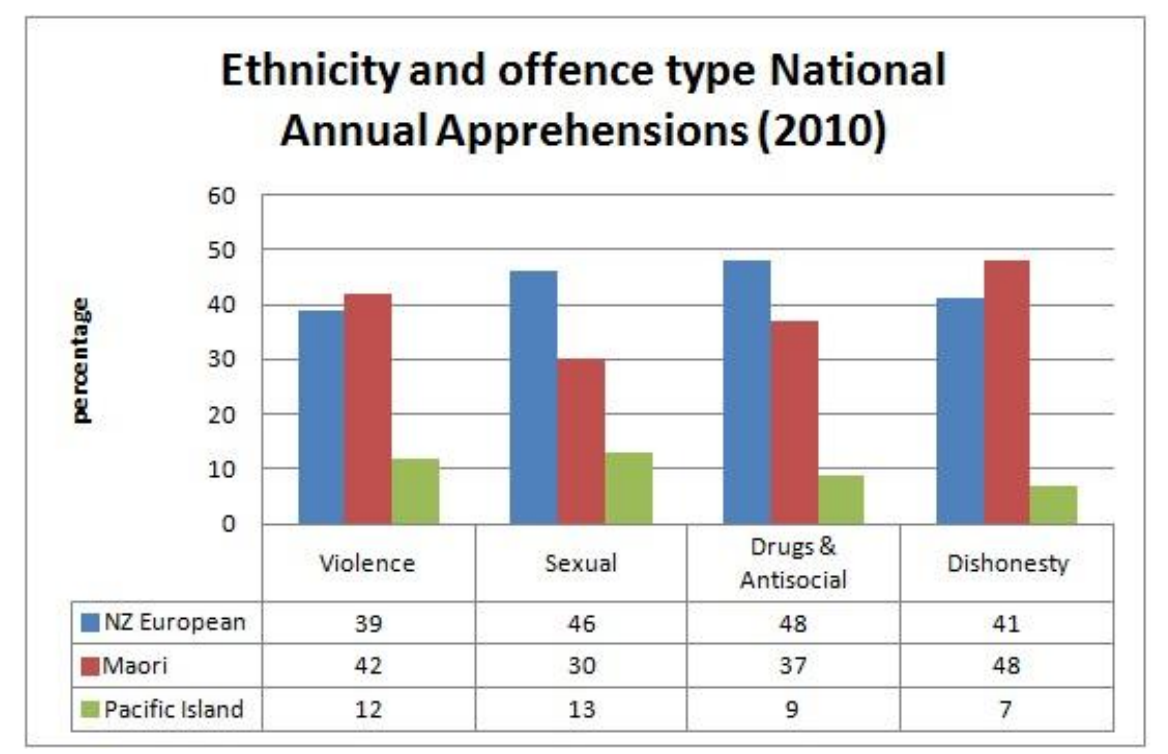

Figure eight Offenders and ethnicity: Percentages of total violent, sexual, drug and antisocial and dishonesty offences committed by all ethnicities (Statistics NZ, 2010a)

\section{Representing Policing}

Earlier in this chapter the results of the demographic breakdown of police were presented and it was shown that while gender quite closely corresponded to the actual make-up of police, ethnicity and age did not. This section now turns to the way in which policing is represented, via the types of duties performed and offences and other incidents responded to.

Although Police Ten 7 is marketed as providing a realistic portrayal of the day-to-day working routines of police, the reality is that the offences police are depicted as responding to are significantly misrepresented. This section compares the portrayal of policing on Police Ten 7 with the actual realities of day-to-day policing in contemporary New Zealand and elsewhere.

\section{Offence types: Over and under representation}

In terms of frequency, the most commonly featured offences in the "ride-along" section were drug and antisocial (52\%), traffic related (19\%), violence (17\%) and property abuse (7\%). Property damage and administration made up $2 \%$ and $3 \%$ respectively. Despite accounting for the majority of actual recorded crime in New Zealand (Statistics NZ, 2010b) no dishonesty offending was featured in the "ride-along" section of any of the 15 
episodes. The significantly higher frequency of drug and antisocial offending and the slightly higher frequency of violent offending ${ }^{19}$ on Police Ten 7 is not reflective of official statistics, as demonstrated in figure nine which shows that in 2010 drug and antisocial offending made up just $16 \%$ of recorded offences and violent offending $14.5 \%$.

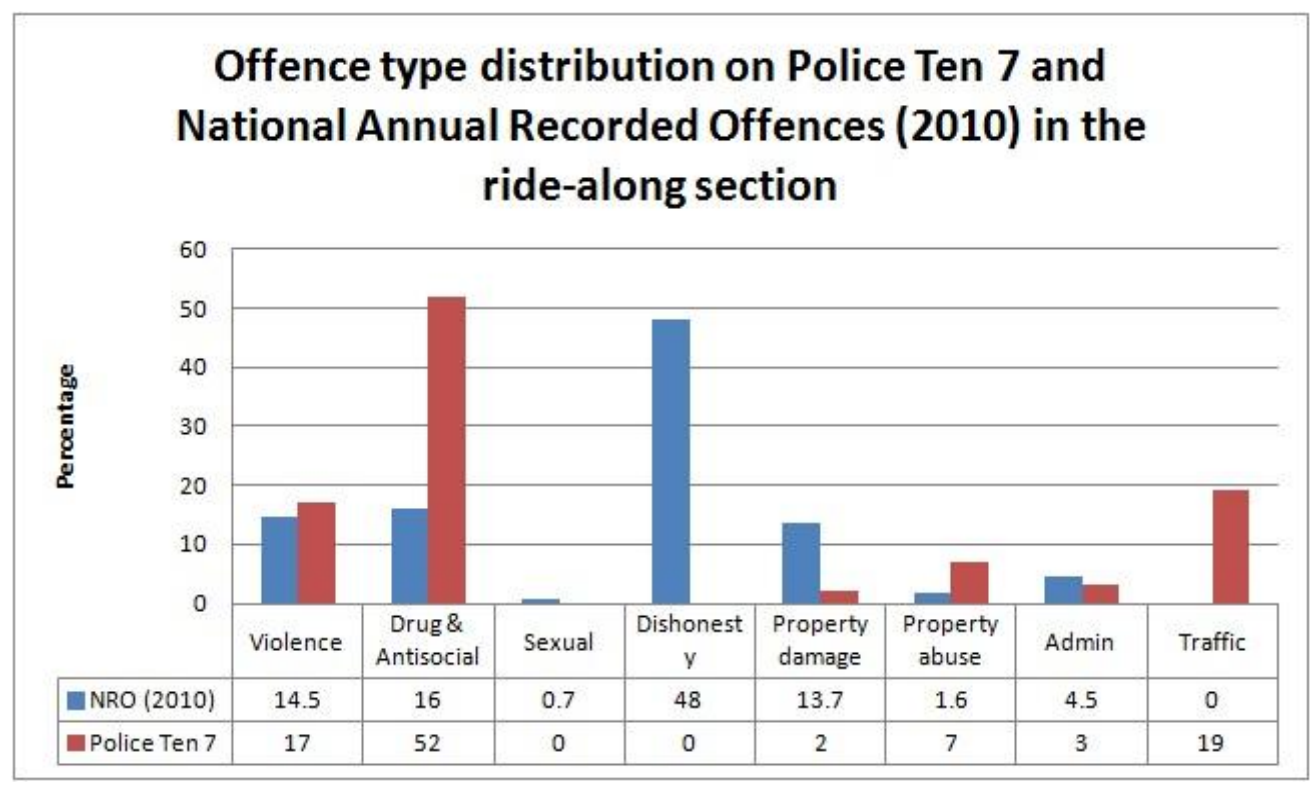

Figure nine: Police Ten 7 offence distribution and Annual Recorded Offences ${ }^{20}$ (Statistics NZ, 2010b)

Moreover, a further point of interest emerged from the analysis in that there were never any very serious offences, e.g. homicide or sexual offences, featured in any of the 15 episodes. It is interesting to think about the reasons for the distorted representation of offending on Police Ten 7. As will be discussed in more detail in the following chapter, three possibilities have been identified: legal requirements, variable resolution rates and the desire to project a positive image of police and production values.

Having covered the basic demographics of both offenders and police, as well as the key variable of offence type distribution, the focus now turns to the other commonly repeated features of policing represented on Police Ten 7 including key contextual features such as the setting of police citizen encounters, resolution type, and whether police used physical means to restrain or control offenders. These contextual variables will then be compared to

\footnotetext{
${ }^{19}$ When coding the episodes it was clear that "drunk and disorderly" behaviour was linked with potential violence. Police arrested offenders for seeming threatening or for posing risks of violence, for example a young woman who was arrested for being "drunk and disorderly" was described as violent.

20 Official police recorded statistics do not include traffic offences however for the purpose of this study it was necessary to include this category as it was a significant and recurring category of depiction.
} 
the known realities of policing by utilising police statistics, annual reports and sources from other countries with similar policing traditions and systems.

\section{Temporal and geographical setting of policing}

The analysis of the setting for police/citizen encounters in Police Ten 7 reveals that the vast majority $(72.5 \%)$ of policing took place in public places and only $22 \%$ in private homes. Sixty percent of encounters (and offences) occurred at night and $40 \%$ during the day. Daytime settings were artificially boosted by multiple police drug warrant searches. This depiction of policing is not reflective of official statistics which show that $32 \%$ of offences in 2010 took place in public places and $43 \%$ in private dwellings (NZ Statistics, 2010b). The difference in geographical setting for offences in Police Ten 7 versus official statistics could be explained by legal requirements for filming, resolution rates and ease of access for the production crew. This will be discussed further in Chapter Five.

\section{Proactive and reactive policing}

In terms of presenting policing as either reactive or proactive when using the broadest categories it is clear that Police Ten 7 portrays a skewed picture of police initiated responses when compared to the known reality. Across the 15 episodes of Police Ten 7 $55 \%$ of police responses were reactive, that is to say that they were either responding to calls for assistance or directives from dispatch. Forty-five percent of all police action depicted was proactive and took the form of police patrols in car parks, multiple large scale drug warrants and targeted police campaigns such as a "police crackdown on traffic offences". This distorts the reality of general duties police by presenting a radically different picture of policing than the reality. The Police are primarily a reactive organisation and are not often involved in self-initiated policing (Home Office, 2001). The depiction of policing in Police Ten 7 presents a more proactive version of policing than Soulliere's (2004) research which found that that $76 \%$ of criminal incidents depicted on Cops were the result of reactive policing. This could reflect the current New Zealand Police organizational mindset which is focusing more on "reducing demand through prevention" by aiming to adopt a more preventative and proactive model of policing (New Zealand Police, 2011a). 


\section{Policing resolution/clearance rates}

Resolution rates on Police Ten 7 are significantly higher than actual police case resolution rates. In $73 \%$ of all cases depicted on Police Ten 7 an offender was arrested and 100\% of all incidents police responded to were successfully resolved. Specifically $56 \%$ of cases ended in offenders being arrested and charged, 17\% were arrested and released, 8\% warned, $12 \%$ were given fines and $7 \%$ were dealt with in alternative ways, for example returned to their homes by police or taken to the police station for "detox". In the "ridealong" section there were no crimes or incidents where police were unable to locate an offender. Similarly, there were no cases where police responded to a crime which did not result in the police making face-to-face contact with the offender. Actual resolution rates for police show that $47.3 \%$ of reported crime is resolved by police (Statistics NZ, 2010b), illustrating the skewed representation of police crime detection and case resolution on Police Ten 7.

\section{Policing as crime fighting}

One of the recurring themes in Police Ten 7 is that police work is primarily about fighting crime as opposed to crime prevention, "paperwork" or other policing duties. This construction of policing is demonstrated by the findings that out of the 15 episodes analysed and the 41 "crime stories" presented therein, there were only two cases which were not related to actively stopping or dealing with criminal offending. Of these, one case involved the story of a young boy who was lost and found wandering around an RSA (Returned Services Association). The second was a police patrol through town late on a weekend with police ushering an inebriated young man home with the narrator stating "it is time for a little preventative policing". All of the other 39 stories of policing consisted of reactively responding to reports of offences or proactively dealing with known offences, for example executing a drug warrant.

This lack of coverage of the other duties routinely performed by police presents a distorted picture of the daily work of New Zealand police officers. The narrow focus on "front end" policing and reactive policing in particular, presents a picture of policing in New Zealand in which police constantly attend incidents and regularly arrest offenders. For example, $73 \%$ of all citizen-police interactions featured on Police Ten 7 resulted in arrest. This particular "reality" of Police Ten 7 is compared to the actual day-to-day realities of 
policing as documented in the Home Office produced 'Diary of a Police Officer'. This (DOAPO) found that overall, police reported spending $43 \%$ of their shifts inside the police station attending to administrative tasks, community support and prisoner processing, and taking breaks. Although this varied depending on whether officers were on early or late shifts, the overall results were clear. Officers on day shifts reported spending only $18 \%$ of their shift attending incidents and officers on night shifts up to $31 \%$ of their time, of which 9\% and 10\% respectively related to criminal incidents (Home Office, 2001). Furthermore, DOAPO concludes that police are regularly involved with a wide range of activities which are not crime related, a particularly common example of which is referred to as "miscellaneous public assistance"21. In common with research by Kappeler, Blumberg \& Potter (1996) this research shows that the almost exclusive focus on "front end" policing misrepresents the actual realities of policing due to Police Ten 7's exclusion of paperwork, court appearances, training and any other duties.

In Police Ten 7 the majority of each crime story consists of a police-citizen encounter outside of the police station and results in police returning to the police station with the offender $52.5 \%$ of the time. The latter is commonly depicted on screen for half a minute or less with the offender locked in a cell and the narrative concluding. This is clearly not reflective of actual processes and procedures followed by police after making an arrest. According to DOAPO, for example, one arrest requires an officer to spend 3.5 hours completing the requisite paperwork and processing the offender (Home Office, 2001). In contrast, in Police Ten 7 cases are resolved, offenders are locked in a cell and in a very short space of time police are free to return to the streets to detect and arrest the next offender. This will be discussed further in relation to the depiction of action and excitement. Furthermore, police on Police Ten 7 do not experience false alarms or become involved in unnecessary interventions where innocent people are targeted. In all policecitizen encounters across all 15 episodes, police interventions were depicted as justified and warranted.

Another way this theme was expressed was in the repeated focus on policing taking place outside the police station, primarily in public streets ( $72.5 \%$ of all cases). In $47.5 \%$ of cases the entire crime story took place away from the police station. In $52.5 \%$ of cases the police

21 Diary of a Police Officer argues that while miscellaneous public assistance could be viewed as reassurance policing it is often those who are "the least vulnerable" who are the most willing to place such demands on police (Home Office, 2001:29). 
officer would return to the police station to process the arrest of an offender. In Police Ten 7 the role of the police on duty is constructed as someone responding to drug and antisocial or violent offences in public places. Furthermore this police officer is depicted as working in the police station only when they have succeeded in arresting an offender. When police were filmed in the station it was in the context of controlling, processing or imprisoning an offender. In none of the 15 episodes were police depicted doing paperwork, preparing for upcoming cases or on meal breaks. There were no cases where police were visiting witnesses or victims in preparation for legal cases. There were no cases where police were involved in education, preventative or community policing. In Police Ten 7 the one thing police are portrayed as doing is responding to and dealing with crime. Police are thus represented in Police Ten 7 as dealing primarily with offenders. While there were 59 offenders depicted in the 15 episodes there were only eleven victims and 15 witnesses with whom police interacted. When these interactions did occur, which was not very often, they were very short in duration.

\section{Policing denotes action}

A key theme that emerged from the analysis was an editorial preference for action and excitement. This is not surprising given that the goal is to appeal to audiences. However it does result in a representation of policing which is focused on the exciting aspects of policing at the expense of the more mundane aspects such as paperwork, education or preventative policing. Across all episodes police were depicted driving police cars with lights or sirens on $47.5 \%$ of the time, engaging in car pursuits $7.5 \%$ of the time, foot pursuits $22.5 \%$ of the time and holding a gun or other weapon $7.5 \%$ of the time. On Police Ten 7 police commonly experienced aggressive threats to their authority in $50 \%$ of the cases dealt with. Police were the victims of verbal aggression from offenders in $49 \%$ of the cases dealt with. Police were also engaged in physical confrontation initiated by offenders in $27.5 \%$ of the cases and engaged in physical confrontations initiated by themselves in $47.5 \%$ of cases depicted. An analysis of differences in representation of police behaviour and gender found that female officers engaged in physical confrontations with offenders $22 \%$ of the time while male offenders engaged in physical confrontation $33 \%$ of the time. This will be discussed further in Chapter Five. 
The focus on action and excitement is reinforced and repeated by the narrator, Graham Bell, who repeatedly utilises emotive language to evoke a sense of danger, drama and excitement. Examples of such language include:

"After coming to the aid of a drunk driver, constables find themselves under fire", "Police are racing to a property to assist in a search for drugs. When they arrive it sounds like they are just in the nick of time" and "Suddenly the call comes through that urgent help is needed where Jacob is surrounded by police".

This use of repeated language which implies speed, action, urgency and drama is further linked to another key theme which has been identified as the "thin blue line" (Doyle, 2003). Doyle argues that within the law and order view of criminal justice police are viewed primarily as fulfilling the "crime fighters" function in society as opposed to order maintenance, crime prevention or emergency responses. Within this conception of police and law and order the answer to "the crime problem" lies in hiring more police and giving police more powers in order to present a tougher and more punitive police force (Doyle, 2003). This will be discussed in more detail in Chapter Five.

The high level of action and excitement featured on Police Ten 7 is not reflective of the known realties of policing. Due to an absence of New Zealand based research that documents the daily working lives of New Zealand Police, other indirect sources were used to compare policing as depicted on Police Ten 7 with that of New Zealand police officers as a whole. One source of information is the 2010 New Zealand Police Annual Report which shows that in the 2009-2010 year 708,079 emergency 111 calls were made of which 128,895 were priority one (p1) events ${ }^{22}$ (NZ Police, 2010a). Furthermore, there were an additional 1,062,675 non-emergency calls presented to police communications in the 20092010 year. The percentage of priority one calls is therefore $7.2 \%$ overall and $18.2 \%$ of all emergency 111 calls. It is clear from these numbers that the majority of calls made to police communications are not emergency or high priority calls.

Another way to contrast the depiction of policing in Police Ten 7 to that of the known realities of policing in contemporary New Zealand is to look at a breakdown of priority one (p1) incidents recorded by police communications. In 2006, the last time such a breakdown was included in the annual report, crime related events made up $44 \%$ of all priority one

22 Priority One events are those which "require an immediate response where there is real threat to life or property" (NZ Police, 2010a:42). 
calls demonstrating that crime is merely one, albeit significant, focus of these emergency calls (NZ Police, 2006b).

\section{The "wanted" section}

The primary focus of this research is on the police "ride-along" section because it represents every day policing and provides the majority of programme time. In addition, however, the research also covered the "wanted" section. This occurs at the end of each episode and consists of Bell, the narrator, attending a crime scene, narrating a reconstruction of a serious crime with the help of a detective and then providing a "roll call of wanted" faces encouraging viewers to help police identify and report the offenders. This section of the show is different in tone and content than the "ride-along" section and provides an intensified version of a number of the themes discussed thus far. The following section presents the key findings.

\section{Representing offenders}

\section{Gender}

In the "wanted" section $94 \%$ of offenders were male, $4 \%$ female and $2 \%$ unknown/impossible to identify. This does not reflect the gender makeup of official statistics which show that $18 \%$ of all apprehensions in the 2010 calendar year consisted of female offenders with $82 \%$ of apprehensions being male offenders (Statistics NZ, 2010a). It may, however, reflect the fact that this section typically features and is focused on more serious crime within which female offenders are under-represented.

\section{Ethnicity}

Because ethnicity is identified by the narrator the analysis is not subjected to the same limitations as the "ride-along" section. This results in a less subjective process of identification by the researcher. Within the "wanted" section $23 \%$ of offenders were identified as Maori, 16\% NZ European, a large percentage were of unknown ethnicity (24\%) 20\% consisted of Pacific Islanders and another 14\% were identified as either Maori or Pacific Islanders. A further $1 \%$ was Indian, $1 \%$ Asian and $1 \%$ other. 


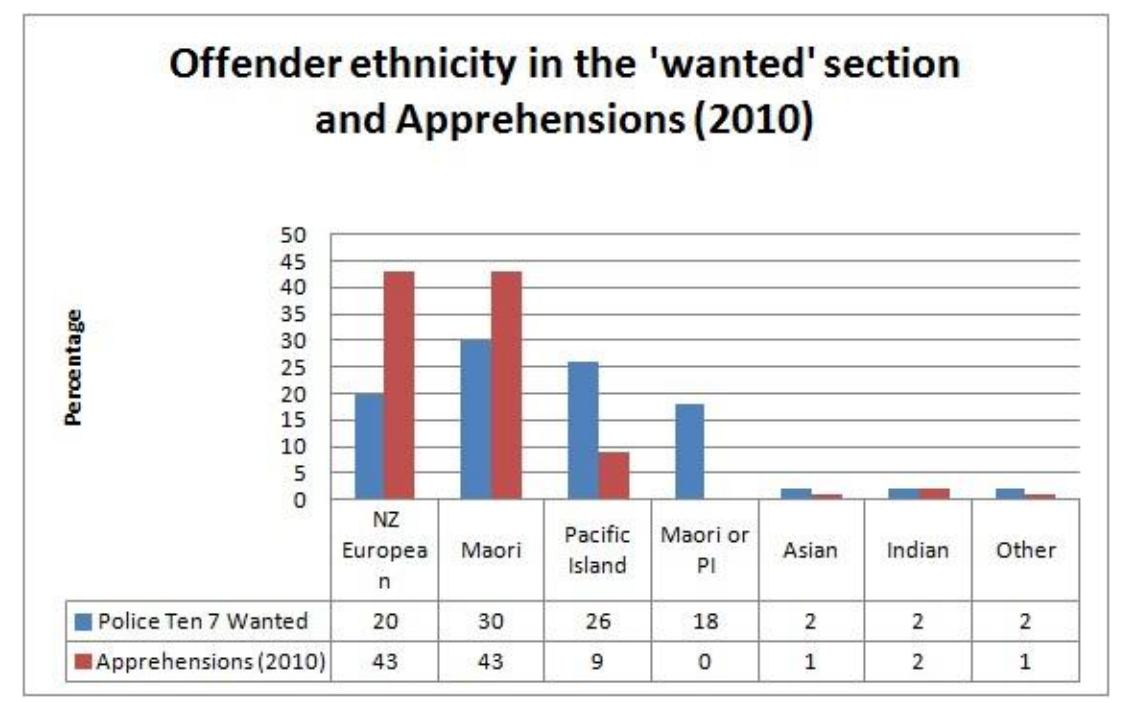

Figure ten: Ethnicity in the "wanted" section and 2010 National Annual Apprehension statistics (Statistics $N Z, 2010 a$ )

This representation of ethnicity is different from the "ride-along" section in that it presents a picture of criminality which is significantly more associated with non-white than white individuals. Figure ten (above) depicts ethnicity in the "wanted" section ${ }^{23}$.

When the various ethnicities are recategorised into white, non-white and impossible to identify the results present a picture of criminality which depicts serious crime as considerably more likely to involve those who are non-white than white. Non-white offenders are over-represented in the "wanted" section with Maori, Pacific Island, Indian and Asian offenders making up 78\% of all offenders identified as a specific ethnicity featured in the "wanted" section but only 55\% of apprehensions in 2010, see figure eleven.

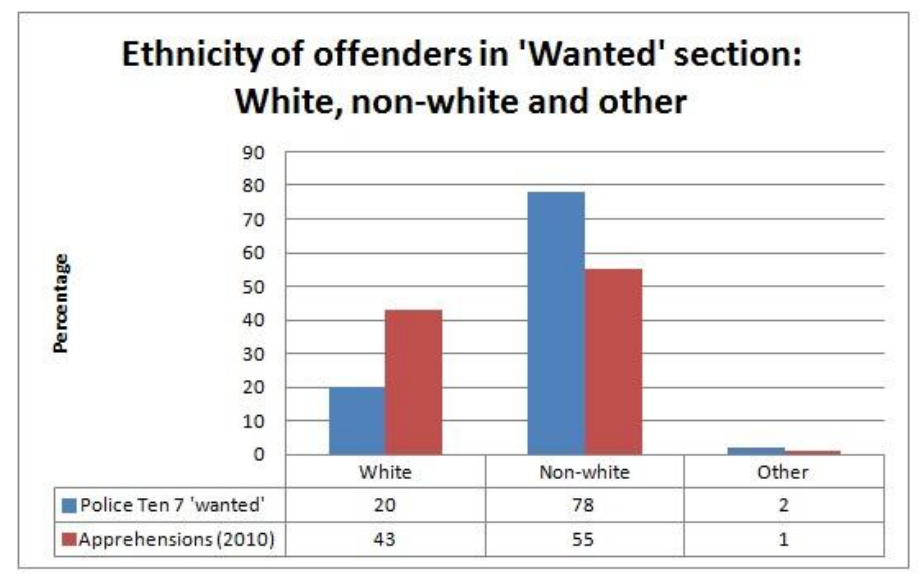

Figure eleven: Ethnicity in the "wanted" section and in the 2010 National Annual Apprehensions (Statistics NZ, 2010a)

${ }^{23}$ This analysis does not include those offenders who were identified in "the wanted section" as 'unknown' or 'impossible to determine' in order to more easily compare ethnicity in "the wanted section" to Apprehension statistics (2010). This inflates all percentages by removing the "unknown"" category and demonstrates ethnicity in "the wanted section" for all offenders who are identified as belonging to a specific ethnicity. 
Conversely, NZ European offenders are significantly under-represented in the "wanted" section making up only $20 \%$ of offenders featured while making up $43 \%$ of apprehensions in 2010 (Statistics NZ, 2010a).

Ethnicity on the "wanted" section was further explored by comparing the above findings to convictions which resulted in custodial sentences in 2010. The rationale behind this comparison was that because the "wanted" section explicitly deals with more serious offences those which resulted in custodial sentences can be reasonably seen to be similarly serious. The majority of the offences featured in the "wanted" section involved violence and sexual offences. Therefore these were the categories used for comparison between offenders featured on Police Ten 7 and those convicted offenders that received a custodial sentence. Custodial sentences were used here as a de facto measure of seriousness ${ }^{24}$.

According to NZ Conviction statistics NZ Europeans made up 28\% of those who received a custodial sentence for violent offences in 2010, in contrast NZ Europeans made up 20\% of offenders featured in the "wanted" section.

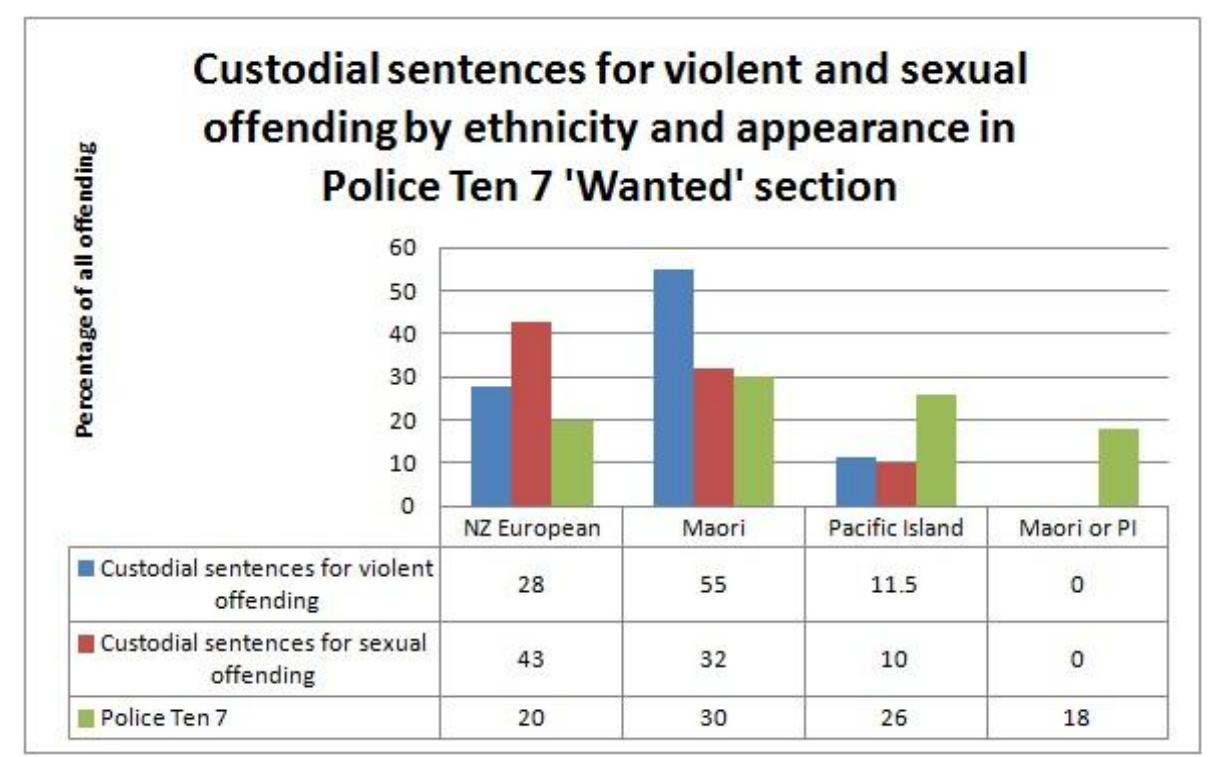

Figure twelve: Custodial sentences by ethnicity 2010 Conviction and Sentencing (Statistics NZ, 2010c)

Of those offenders convicted of a violent offence and sentenced to prison in $201055 \%$ were Maori. In this regard Maori are slightly under-represented in the "wanted" section

\footnotetext{
${ }^{24}$ In the absence of alternative measures, custodial sentences were used as a de facto measure of severity. The aim here was to access whether, or the extent to which, ethnic minorities were disproportionally represented in "the wanted section" by comparison with official statistics on sentencing. As is the case when using official statistics as a comparative source it accepted in this research that their inherent limitations namely the 'dark' and 'grey' figures of crime (Bottomley \& Pease, 1986:34) render official sources subject to institutional bias.
} 
when custodial sentences were used as a means of determining seriousness. Again, if the $18 \%$ of offenders featured on Police Ten 7 who were identified as "Maori or Pacific Island" are in fact Maori then Maori serious offending in the "wanted" section is closer to actual levels of comparable serious offending (48\%). Pacific Islanders continue to be overrepresented on Police Ten 7 when the custodial sentences were utilised in that they made up $26 \%$ of all offenders featured in the "wanted" section but only $11.5 \%$ of offenders receiving a custodial sentence for violence and $10 \%$ for sexual offences.

When custodial offences for violent and sexual offending are compared to the representation of offenders on Police Ten 7 Maori are represented slightly below actual levels of serious offending as measured in the custodial sentences. Pacific Island offenders are significantly over-represented as serious offenders on Police Ten 7 at over twice their actual offending rates while NZ Europeans are significantly under-represented as serious violent and sexual offenders in the "wanted" section of Police Ten 7.

\section{Age}

Because the "wanted" section provides more detailed descriptions of offenders and police some of the limitations discussed earlier regarding age estimation of officers and offenders featured in the "ride-along" section do not apply. Beyond the $30 \%$ of offenders whose age was unknown, exact ages were commonly provided by the narrator. Within the "wanted" section the age distribution was similar to that of the "ride-along" section. There was a large percentage $(30 \%)$ of offenders whose age was unknown and a similar concentration of offenders within both the 17-25 year age group (31\%) and the 26-40 age group (33\%). No offenders belonging to the 0-16 age group were featured and only 5\% of "wanted" offenders were in the 41-55 age group and $1 \%$ in the 56 and over age group. Criminality is thus more frequently associated in this section with offenders 17-40. Furthermore the language used by the narrator commonly conflates youth and offending and repeatedly links youth and crime ${ }^{25}$. This linking together of youth and crime was often unfounded and in one case, totally incorrect. In the case of a young couple who were attacked in a park in Auckland Bell states that the park is:

25 The conflation of youth and offending in the "wanted" section is reinforced by the understanding that the majority of those whose age is unknown are implied, through language used by the narrator, to be younger offenders. For example, offenders whose ages are stated as unknown in the 'roll call' are referred to throughout the reconstruction as "young people" and "youngsters" 
"A bit of a hangout for troublesome young people at night".

Bell implores the parents of these "young thugs" to report their children and states:

"I wouldn't mind betting that these young thugs who carried out this attack are local to the area".

Repeatedly it is presumed that the offenders are young, local to the area and under their parents' care. This assumption however is not correct, as follow up research revealed ${ }^{26}$ that an individual 25 year old male had been arrested for the offence featured in the reconstruction, not a group of intoxicated young local teens. While Bell may have lost his bet about the offender the association between youth and crime had already been communicated to the audience.

\section{Offence type: Over and under-representation}

In common with the "ride-along" section the offences featured in the "wanted" section are not representative of official recorded crime. While the "ride-along" section overrepresents drug and anti social offending the "wanted" section significantly over-represents violent offences and sexual offences while under-representing dishonesty offences and drug and antisocial offences.

Violent offending made up $72 \%$ of all offences featured which, when compared to official statistics, in which violence made up just $14.5 \%$ of the total is a considerable overrepresentation (Statistics NZ, 2010b). Similarly, sexual offences are depicted in the "wanted" section at more than six times the officially recorded rate with $6 \%$ coverage in the "wanted" section compared to less than $1 \%$ of recorded crime.

As in the "ride-along" section dishonesty offences are significantly under-represented in the "wanted" section. Dishonesty offences made up 48\% of all offences in the 2010 National Annual Recorded Offences but only $11 \%$ of offences in the "wanted" section.

26 This research involved identifying the case, tracing it through the court system and investigating the resolution. 
Similarly, while $16 \%$ of all offences in 2010 consisted of drug and antisocial offences only $3 \%$ of offences depicted in the "wanted" section involved drug or antisocial offences.

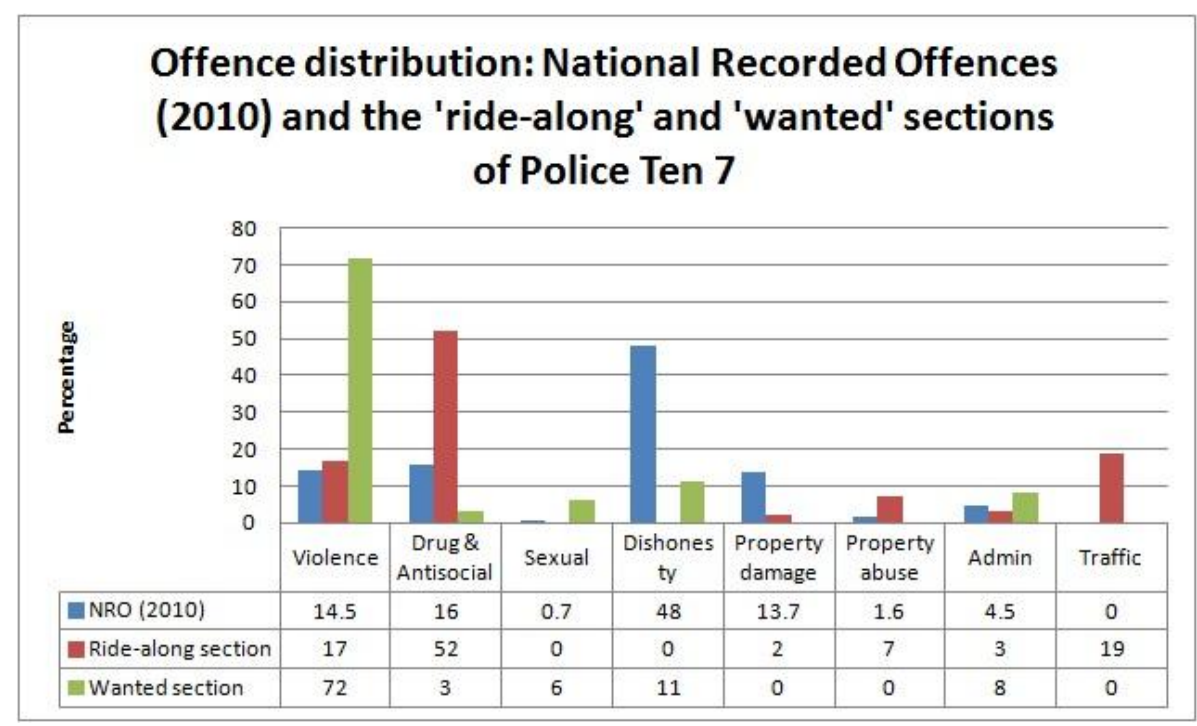

Figure thirteen: Offence distribution in "ride-along", "wanted" section and 2010 National Annual Recorded Offences (Statistics NZ, 2010b)

Having addressed the demographics of the "wanted" section as well as the offences depicted, the focus now turns to the main themes which emerged from the analysis of the "wanted" section of Police Ten 7. The "wanted" section contains some similar elements to the "ride-along" section including camera shots which position the audience as "co-cops". An analysis of the language used revealed two key themes, "dangerous others" and "us versus them" The language and descriptions used in the "wanted" section are noticeably more negative towards offenders and Bell makes negative comments about offenders in $61.5 \%$ of cases compared to $37.5 \%$ in the "ride-along" section. At the same time the language is more colloquial in its description of offenders and more value laden and emotive in tone than the more neutral descriptive language used in the "ride-along" section.

\section{Dangerous criminals}

The first dominant theme relates to the consistent presentation of offenders as dangerous and violent. When referring to offenders Bell commonly does so in ways which communicate the idea of danger and potential violence including terms such as "dangerous thugs" "dangerous and unpredictable", "armed and dangerous", "dangerous predator" and 
"brutal thugs". Danger and threat are the most commonly repeated language theme used in the "wanted" section and is consistently repeated across all 15 episodes.

The highlighting of, and focus on, dangerous offenders is arguably extended to cover all offenders, not just those involved in violent crime. Offenders in Police Ten 7, in common with the findings of Oliver (2003) become a homogenous group of "gutless thugs", "trigger happy half-wits" and "moron criminals". The language used in this section also uses animal metaphors referring to offenders as "mongrels", "a violent predator who disappeared like a rat through a hole" and "dogs who should be put down". This has the effect of dehumanising offenders and further separates "us" from "them" emphasising difference to the extent of implying that offenders are less than human. This blanket labelling of all offenders as violent and dangerous, as well as essentially different from "us", will be discussed further in Chapter Five in reference to shaping audience perceptions of offenders in New Zealand.

\section{"Us versus them"}

"Us versus them" is a very common feature of the literature on police culture which describes the observation that police are encouraged to view themselves as a unique and distinct group who can only rely on each other and who are responsible for protecting society against "them" - the criminal (Waddington, 1999). This element of police culture, in particular the conception of police as "good guys" and criminals as "bad guys" was clearly represented in Police Ten 7 primarily through the use of particular repetitive language by the narrator. One key difference between the traditional "us versus them" division evident in police culture and that observed on Police Ten 7, is that the viewer is in the "us" category usually reserved for police alone. The viewer, in essence, is given the role of honorary cop for the duration of the show, fighting against "them": the criminals (Greer, 2005).

In general the language utilised by Bell in this section can be argued to function as delineating between the "us"; those at home safely watching the crime unfold and "them" those young, minority, violent and dangerous offenders who are not only different from us but are also presented as individually deficient: they are "naive and inadequate", "gutless thugs" and "callous thugs". The "wanted" section provides no contextual information or mention of causation other than generalised assumptions such as 
"It is highly likely that it's been a group of young people drinking in the park here they've come across the young couple and just randomly attacked them".

Criminality in the "wanted" section is therefore repeatedly presented as random, unpredictable and violent.

The "us versus them" division is further reinforced by high levels $(61.5 \%)$ of generally negative language regarding offenders. As mentioned, there is no discussion of causation or of the social context associated with offending. Offenders are presented as a homogenous deviant population with predictable and unpleasant traits (violent, callous, morons, goons, hoods, drunken oaths). Motivation and internal processes are assumed, for example:

"now typical of these arrogant criminals, they've come and helped themselves to someone else's driveway to dump the car" and "while they're driving away in their car with the money laughing they couldn't care less about the emotional wreckage they're leaving in their wake"

The "us versus them" theme is also communicated in the "wanted" section through a clear alignment of the audience with the police and the victims of offences and a distancing from offenders. This is achieved again through language such as

"When you boil it all down these are just two brutal thugs who have gone in there with a screwdriver and terrorised people and we [pointing at the camera] don't want them getting away with it".

This is also communicated through specific filming techniques which encourage audience identification and empathy with victims while at the same time distancing the audience from the offender. This is most clearly demonstrated in reconstructions which commonly feature shots which place the audience in the position of the victim through the use of camera work which films from the often prone position of the victim. Reconstructions of sexual assault in particular utilise these techniques resulting in blurry dark shots of offenders crouched over the victim/viewer assaulting them, shots from the victim's point of view running from attackers and shots of fists flying towards the victim/viewer followed 
by the camera spinning and coming to rest on the dark grass ${ }^{27}$. As Dobash, Dobash, Schlesinger and Weaver (1998) found in their research, these techniques place the audience in the victim's position and force them to experience "vicarious victimisation" from the safety and comfort of their living room. The result is clear: the audience is made to experience victimisation which both reinforces their position as "us" against "them" and symbolically represents the theme that the audience is "the yet to be victimised" (Dobash et al, 1998:52).

This leads to another feature of the "us and them" theme presented in the "wanted" section, that of risk and vulnerability and a concomitant support for law and order ideology. The reconstructions which feature in the "wanted" section reinforce audience fear, risk and vulnerability through the selective nature of offences depicted and through repetitive images, filming techniques and language. By featuring a narrow selection of offences in the reconstructions, namely sexual assaults by strangers, armed robberies and homicide, audiences are presented with a view of criminality which is interpersonal, confrontational and random.

Since the "wanted" section exists to detail offenders who are either known to police and on the run or offenders who are not known to police it is natural that the large majority of the offences depicted, in particular those in the reconstruction section, are those committed against strangers. This results in the common reconstruction being one of three "classic" cases, an armed robbery of a bank or store, a violent street attack on a stranger or a sexual assault of a young woman at night in a public place (Jordan, 2004). These are the sole reconstructions featured on the show and there is a clear commonality between their depictions. This repetition of similar cases reinforces the idea of random victimisation, although statistics reveal that a person is far more likely to be victimised by someone they know (Mayhew \& Reilly, 2007). This repeated depiction of victimisation can be argued to support a very traditional construct of street crime and in particular of the concept of "real rape" (Jordan, 2004). Language used to describe these cases emphasises this idea of threat, for example:

"It strikes at the very heart of vulnerability when our youngest are being virtually picked off the street"

\footnotetext{
${ }^{27}$ It is interesting to note that "filler" shots which flash between the title card "Police Ten 7" and beginning of the show and before and after advertising features multiple blurry shots of bare-chested, dark-skinned men raising threatening fists at the camera.
} 
followed by:

"It could have been any child anywhere; it makes everyone feel very vulnerable".

Furthermore, through the use of language which supports the idea that crime represents an assault on common norms and ways of living "shattering the peace" and that order needs to be established Police Ten 7 arguably reinforces police fetishism (Reiner, 2000) and law and order ideology ${ }^{28}$ (Doyle, 1998). By repeatedly featuring such reconstructions and utilising such language this could function to support traditional law and order conceptions of punishment and harsher penalties for offenders as well as increased control and powers for those who are presented as the only ones who can restore this peace: the police (Reiner, 2000).

\section{Summary}

Police Ten 7, in common with other international police-based reality shows (Oliver, 1994; 2003; Oliver \& Armstrong,1998; Doyle, 2003; Kooistra et al, 1998; Mastro \& Robinson, 2000) functions to present one construction of reality which closely resembles the known realities of policing in some limited aspects but which is not reflective of reality in many others. Key findings presented in this chapter were the disproportionate depictions of offence types which echoed the findings of similar international research (Entman, 1992; Oliver, 2003; Mastro \& Robinson; 2000). There were significant differences in the character portrayals of various ethnicities, specifically an over-representation of non-white characters as offenders and an under-representation of non white characters as police. Furthermore, non-white offenders were commonly featured in crime stories which related to violent offending while white offenders were commonly featured in crime stories about drug and antisocial and traffic offending.

Police Ten 7 presents a picture of policing that privileges action and excitement over the more mundane policing activities and duties such as crime prevention and education. This is further demonstrated by the consistent focus on drug and antisocial and violent offending as well as the low levels of screen time given to common police activities such as

\footnotetext{
${ }^{28}$ Police fetishism is described as "the ideological assumption that police are a functional prerequisite of social order" (Newburn \& Reiner, 2007:912). Doyle (2003) refers to law and order ideology as public discourse which emphasises the decline and decay of modern society and promotes increased punitiveness and "harsher" legislation to deal with the perceived lawlessness and chaos of society.
} 
community policing and paperwork. Police Ten 7 reinforces the conception of crime as violent and random in the "wanted" section focusing almost entirely on violent and sexual offending and simultaneously utilising language which supports an us versus them dichotomy.

It is clear from these findings that Police Ten 7, while claiming to present a "the real dayto-day working lives of police in New Zealand" (TVNZ, 2011b) does so in a way which privileges a specific definition of policing which is almost entirely crime focused and which distorts the reality of policing in order to entertain audiences. The selective focus on crimes of violence and drug and antisocial offending adds to this constructed reality in which police are in constant action battling against the tide of crime, or as narrator Bell states "working tirelessly to fight crime" (TVNZ, 2011b).

The following chapter subjects these findings to a process of more detailed discussion and interpretations where some of the implications of this distorted construction of policing are explored. 


\section{Chapter Five: Discussion}

\section{Introduction}

The findings of this research clearly suggest that the depiction of policing and criminality in Police Ten 7 is substantially different from the reality. The analysis of the entire 2010 season of Police Ten $7^{29}$ found that the typical offender is male (91\%), non white $(69 \%)$, aged 25 years and under (63\%) and was involved in a violent (44\%) or drugs and antisocial related offence (28\%). In contrast the average or typical police officer in Police Ten 7 is male $(83 \%)$, White $(89 \%)$, under 40 years of age $(89 \%)$ and has a $100 \%$ clearance rate. Policing, as depicted on Police Ten 7 is fast paced and over $80 \%$ of all police-citizen interactions ends in the arrest of an offender.

In Police Ten 7 crime occurs primarily in public places (71\%) and violent and sexual crime is exclusively perpetrated by male offenders, and typically against strangers (82\%). Violent and sexual offending is given particular prominence in the "wanted" section of Police Ten 7 where all 15 reconstructions involve violent or sexual offending. Violent offenders in Police Ten 7 are overwhelmingly non-white (80\%), as are sexual offenders $(60 \%),{ }^{30}$ and depictions of sexual offending typically conform to the "real rape" stereotype (Jordan, 2004).

This chapter discusses the key findings of this research and will argue that the ways that crime and policing are depicted is best understood as both a result of the process of production and the use of Police Ten 7 as a promotional tool by the New Zealand police. Given the influential role played by media depictions in informing the public about crime and policing (Marsh \& Melville, 2009; Mawby, 2003; Surrette, 1992; 1998; Leishman \& Mason, 2003; Mason, 2003; Oliver \& Armstrong, 1998; Gerbner et al, 2002), and their perceptions of reality (Kooistra et al, 1998; Oliver \& Armstrong, 1998), the implications of the skewed depictions in Police Ten 7 will be discussed.

\footnotetext{
29

In both the "ride-along" and the "wanted" sections combined

There were five sexual offences depicted in the "wanted" section so the sample is limitingly small. Three of the five offenders were described as Pacific Island males and two were described as NZ Europeans.
} 
Holdaway (1985) argues that traditional police culture is reinforced and promoted through the retelling of "war stories" which emphasise the key aspects of that culture. It is argued here that Police Ten 7 functions as a contemporary medium for the retelling of such "war stories", not only to fellow police but also to the general public. Carmody (1998), MonkTurner et al (2007) and Oliver (2003) argue that the skewed depiction of offenders in reality television can "perpetuate crime myths" (Monk-Turner et al, 2007:1) by privileging certain, inaccurate and unrepresentative, conceptions of policing and crime. Informed by these theoretical insights and arguments this chapter will discuss a range of policing and crime myths perpetuated in Police Ten 7 and their implications for public perceptions of crime, policing and offenders.

The discussion will begin with the key discrepancies between the reality of police and policing and their depiction on Police Ten 7. These discrepancies are policing denotes action, policing is a young, white, male profession and policing is uniformly successful. The discussion then turns to the findings on the key discrepancies relating to crime and criminals and include most crime is violent, most offenders are young, minority males, most offending is public and between strangers and crime is committed by pathological and deviant individuals. Finally the promotional use of Police Ten 7 by the New Zealand police will be discussed followed by the problematic issues surrounding the collaboration of police and producers.

\section{Police work denotes action}

In common with similar international research policing on Police Ten 7 is portrayed as more exciting, action-packed and crime-focused than the known realities suggest (Home Office, 2001; Mossman, Mayhew, Rowe \& Jordan, 2008; Perlmutter, 2000). New Zealand Police commissioned research by Mossman et al (2008:5) states that 80 to $90 \%$ of police work "involves non-criminal or social work type tasks" and Perlmutter (2000:42) estimates that "as much as $97 \%$ of the patrol officer's time is spent on non-criminal matters". Police work in Police Ten 7 however is primarily depicted as revolving around the pursuit and arrest of offenders.

Action, physical confrontations with offenders and crime-fighting were the focus of the majority of the crime stories depicted on Police Ten 7. Physical confrontations, such as police placing offenders in "holds" and tackling offenders to the ground and handcuffing 
them featured in $50 \%$ of all crime stories. Even those scenes which did not involve police scuffling with offenders commonly featured other depictions of danger, action and excitement. For example, one crime story featured "a drug bust following a tip off," that involved no physical confrontation between police and offenders. In this story in which the offender is not physically or verbally aggressive and is actually cooperative with police, police are described as "in hot pursuit of armed offenders" and it is said that "a quick entry is paramount to make sure the target doesn't escape" before police smash the door down and enter the property.

A second crime story began with the narration "a peaceful afternoon in Albany has been interrupted by reports of shots being fired in a residential area, sparking an armed response by North Shore police". The police are then described as "battling through traffic to meet the rest of the armed response team" and the scene featured armed officers hiding in bushes and sneaking around the other side of the property while the narrator informs us that "Nick has spotted a number of offenders so they race back to assist the team inside the property". The conclusion of the crime story is rather anti-climactic with police arresting a group of university students who were shooting a BB gun at cans. Where action is not forthcoming police often explain that there could have been danger if the situation had been different. One example involves a police drug raid that ends when the offender is not home and no drugs are found. However, police search and find "an alarming number" of weapons. Police group together and discuss the offender's "fascination with guns" and the audience is told "if the offender was home we could have had a confrontation because he could arm himself". The fact that no drugs were found and that all of the weapons were actually licensed and thus legal did not stop the editors and producers from using emotive narration to transform a rather ordinary situation into a much more exciting one by highlighting the potential danger.

While Police Ten 7 clearly focuses on crime-fighting, detection and the pursuit of offenders, (only 3 of the 41 crime stories feature non-criminal incidents: a lost child, lost drunk, and a man on a stag do wearing a "mankini"), the reality of policing; that it involves significant amounts of paperwork (Home Office, 2001), court appearances and "miscellaneous public assistance" (Home Office, 2001) is ignored. This is perhaps best illustrated by a 10 minute long segment in episode 6 (March 18, 2010) which features police in Whangamata patrolling after the annual beach hop and in one short segment physically restraining and arresting five different men for various offences relating to 
breaches of the alcohol ban and disorderly, violent behaviour. At one point up to five male officers force a resisting man into the police van which is rapidly filling up. The post-arrest process is covered in just a few minutes and consisted entirely of offenders in the cell fighting each other, vomiting, yelling profanities and demanding medical assistance. The large volume of "paperwork" associated generated by making so many arrests does not feature at all.

This finding resonates with international research which reports that media depictions of policing primarily focus on "front end" policing (Prosise \& Johnson, 2004: 76), that is, detecting, chasing and arresting offenders and the corresponding lack of focus on the "behind the scenes" aspects of policing including the vast amount of paperwork which is known to take up a large degree of police time. For example, British research into the daily work activities of police found that one arrest would result in police being away from their beat doing paperwork for a minimum of 3.5 hours (Home Office, 2001). The known reality of policing as a job made up of mundane tasks such as paperwork and miscellaneous public assistance is at odds with the image of policing presented in Police Ten 7. Here the editing and the narration implies a high degree of nonstop action ranging from dangerous situations including armed standoffs to humorous encounters with half naked men on stag nights. While many cases (75\%) featured various forms of paperwork being completed on the street the majority (67\%) consisted of taking notes from offenders accounts of the incident. $52.5 \%$ of cases featured shots within the police station with the majority of these being at the tail end of the crime story. These were typically comprised of a very short resolution to the case with the officer taking the offender to a cell or to processing, the offender being placed inside their cell, the door closing and the narrator stating the conclusion to the story. The focus of Police Ten 7, as in media depictions of crime in general (Prosise \& Johnson, 2004) is almost exclusively on the role the police play in the "fight against crime" and tend to ignore the legal process that follows. Police, in this reality, are the sole force protecting society from crime and criminals.

The focus on male police performing highly physical work on the front line, as opposed to paperwork and preventative policing has the potential to reinforce the concept of police as a masculine profession and to communicate to the audience the importance of maintaining, or increasing, police powers through the implementation of more punitive police policies (Waddington, 1999, Chan, 1999). In terms of potentially influencing viewer understandings of policing this repeated focus on front line issues emphasizes the 
importance, and over-represents the frequency of, police front line resourcing. Given the limited resources with which government departments are currently operating it is possible that this could function to influence popular opinion regarding the deployment of funding and resources (Perlmutter, 2000).

\section{Policing as universally successful}

Police on Police Ten 7 are overwhelmingly more successful than their real life counterparts; police on Police Ten 7 resolved every one of the crime-stories depicted in the "ride-along" section. There were no cases in the "ride-along" section where police were unable to locate an offender and in $73 \%$ of all cases an offender was arrested. That no crime story in the "ride-along" depicted police as unable to successfully resolve the incident, either by arresting an offender, warning them or fining them, gave the police a $100 \%$ clearance rate. This clearly over-represents successful resolution rates which in 2010/2011 officially sat at $47.3 \%$ (NZ Police, 2010a). When the low reporting and detection rate of criminal offending in New Zealand is included it becomes clear that most offending is not resolved by police. The 2009 NZ Crime and Safety Survey, for example, found that just over $30 \%$ of all victimisations captured by it were reported to the police (Ministry of Justice, 2010). Furthermore $47.3 \%$ of reported offences were resolved which suggests an overall resolution rate of just $15.5 \%$.

There are several possible explanations for the Police Ten 7 portrayal of an overachieving police service. First, the depiction of an extremely successful and efficient police service could be the result of production pressures. Soulliere (2001:225), for example, suggests that the over-representation of successful outcomes could be a "consequence of decisions made by the producers to air episodes in which police were able to interact with suspects/offenders". This could be due to the pure ease of production, simply providing "good" television and a by-product of the symbiotic relationship between police and the producers which results in the portrayal of the police in a flattering light. The desires of the police to appear successful, and of the producers to get exciting footage, could combine to produce this thoroughly unrealistic police infallibility. 


\section{Policing as a young, white male profession}

Previous content analyses of reality-based cop shows have found that white individuals were more likely to be portrayed as police officers than as offenders while non-white individuals were more likely to be portrayed as offenders (Oliver, 1994; Oliver \& Armstrong, 1998; Entman, 1992; Monk-Turner et al, 2007; Dixon \& Linz, 2000). In Police Ten 7 when the "ride-along" and "wanted" sections are combined policing is overwhelmingly presented as a young (89\% under forty years) white $(89 \%)$ male $(83 \%)$ profession. The depiction of gender closely corresponds to the reality in which males make up $82.8 \%$ of all sworn officers (NZ Police, 2010a). However, the number of police who are white (89\%) was quite significantly over-represented in Police Ten 7. The reality, according to the NZ police, is that $72.6 \%$ of all New Zealand Police officers identify as European (NZ Police, 2010a). Not only were significantly more white officers depicted on Police Ten 7 than are actually employed by New Zealand Police but the analysis also revealed that when a white character was featured on Police Ten 7, 75\% were in the role of police officer as opposed to an offender. This was the opposite to portrayals of Maori and Pacific Island characters. That white individuals were much more likely to feature in the role of police officer than offender, while Maori and Pacific individuals were much more commonly depicted as offenders than police, suggests that if audiences do indeed base their knowledge about crime on supposedly realistic sources such as Police Ten 7 then audiences may accept the view that white individuals are more law abiding than non-white individuals (Oliver, 2003). Kooistra et al. (1998:135 cited in Prosise \& Johnson, 2004:76) argue that the representation of ethnicity on reality TV constructs a reality in which "crime is a battle between white officers and non-white violent offenders" and in Police Ten 7 the crime battle is indeed depicted as being fought by white police officers against largely nonwhite offenders.

This repeated depiction of police as white and offenders as non-white is a troubling finding given the findings of a 2000 Ministry of Justice report which describes a culture of distrust and racism within the police. Similarly, the 2010 UK report by the Equality and Human Rights Commission "How Fair is Britain" found that Black and Asian people are disproportionally targeted by police in 'stop and searches'. By reproducing the idea of policing as a white occupation and offending as primarily a minority affair Police Ten 7 could be suggested to support rather than challenge institutional racism. This will be discussed further in reference to recruitment on pages 81-82. 


\section{Recruitment: Young recruits seeking action?}

Police Ten 7 functions as a promotional and recruitment tool for the New Zealand Police as evidenced by the links from the Police Ten 7 show and website to the New Zealand Police "New Cops" recruitment page. Host Graham Bell states that he "has met a lot of people who express an interest in joining the police as a result of what they have seen" (NZ Police, 2004a). Vincent (1990:62-63 cited in Soulliere, 2004) argues that "today's rookie is a product of the television era" and as a result may accept the distorted reality depicted within as "real police work". Vincent (1990:62-63 cited in Soulliere, 2004) goes on to suggest that "to the degree that he was, and continues to be affected by these unreal glamorised television versions of role models, the same degree he may mistakenly try to imitate them". Doyle (1998:96) agrees noting that in the USA COPS has been identified as "informal promotional and teaching footage for would-be police officers" with "police academy instructors indicating that [reality policing shows] have inspired many of their students to enter law enforcement with the students whole idea of what it means to be a police officer being based on these very shows" (Ibid, 1998:111).

The depiction of policing on Police Ten 7 as exciting, primarily concerned with crimefighting and often physically confrontational belies the empirical reality of policing which consists of up to $97 \%$ of time being spent on "non-criminal matters" (Perlmutter, 2000:42). This projected image of policing, while appealing to some potential recruits, could have negative implications for the police.

The promotion of one very narrow definition of policing, where police are constantly pursuing offenders could also work against the police by attracting the wrong kind of recruit. The police service is attempting to attract a more diverse group of recruits and is actively focusing on increasing community policing and communication skills (Broun, 2010). A recruit attracted to policing based on the exciting vision depicted on Police Ten 7 might be ill suited to a police service focusing on change (Broun, 2010). The depiction of policing as exciting, action-packed, physically confrontational and primarily defined by the pursuit and arrest of offenders could inform potential recruits' expectations about policing and, as a result of seeing police so often resort to physical force to gain control over an offender, may be more willing to resort to physical means themselves. Mossman et al (2008:30) state that the canteen culture prized in police subculture is based on masculine brute force and is one in which "fights avoided seldom become part of folklore". This is 
replicated in Police Ten 7 where fights and action become part of the shared folklore which feeds back into traditional police culture potentially adding weight to the importance placed on "real" physical, male policing (Chan, 1999). Police culture is notoriously resistant to change (Waddington, 1999) and any official product which might further impede the work of the New Zealand Police to affect change could be more of a hindrance than a help.

The disproportionate involvement of young officers in Police Ten 7 misrepresents the reality of the New Zealand Police as an aging organisation. New Zealand police are currently on track for 60\% of officers to be aged over 40 years by 2019 (New Zealand Herald, 2010). The over-representation of younger police officers could be the by-product of the focus on front-line policing which, due to career progression, is more likely to involve younger, more recent recruits to the police. The focus on youth reinforces the concept of policing being primarily about action and physicality with younger officers more able and perhaps more likely to be involved in foot pursuits. This is particularly likely given their relative lack of experience through which older police may have developed better communication skills which reduce the need to physically restrain or control an offender. The focus on youth in Police Ten 7 could also be a strategic move by the New Zealand police, who, aware of the need for younger recruits are engaged in a recruitment drive for school leavers (New Zealand Herald, 2010a).

It is suggested here that Police Ten 7, much like police culture itself, does not necessarily promote or celebrate "good" policing, that is policing which utilises a wide range of police skills such as communication and negotiation skills and which leaves the individuals involved feeling that they have been treated fairly and respectfully. Instead Police Ten 7 glorifies policing scenarios where police have essentially lost control of the situation and have to resort to force, all the while presenting the encounter through a pro-police lens which justifies all police actions, including those which without the narration might depict an ambiguity or even failure or misjudgments by police.

In addition to the potential impact on recruits, the continued promotion of police work as exciting, physical and concerned with criminal pursuit could also have implications for police who are already in the job. Soulliere (2004) argues that portrayals of policing which are divergent from the realities of policing could result in both serving officers, as well as recruits experiencing a disappointing gulf between what media portrayals present as 
policing and their real life experiences which will "inevitably fail to meet the expectations and promises of television police portraits" (Soulliere, 2004:227). Arguably, this could be a cause of officer dissatisfaction and potentially an early exit from the job. It is also possible that the focus on crime-fighting and action could influence the public's opinion of what constitutes "real" or worthwhile policing. Perlmutter (2000:43) suggests that by focusing on the most dramatic aspects of crime fighting "the normal, undramatic aspects of police work, which are nevertheless essential to maintaining law and order and keeping the peace, are undervalued and almost unknown". The over-representation of the crime-fighter role could also negatively impact on police-citizen interactions at the personal level with the common refrain, heard in one encounter between police and a drunk woman on Police Ten 7 of "don't you have real criminals to catch?"

\section{Recruitment: Attracting a diverse police service}

The depiction of policing as a white profession could be a barrier to the successful recruitment of ethnic minorities, of which a particular focus is on the recruitment of Maori, Pacific Island and Asian officers (Mossman et al. 2008). The 2008 Police Strategic Plan described increased recruit diversity as a priority and ultimately aimed for Pacific Island recruits to make up 10-15\% of those graduating police college and Maori recruits to make up 20-23\% (Lockwood, 2009). However New Zealand Police strategic recruitment inspector Gary Allcock states that policing is not generally seen as a viable career option for many Maori, a fact he ascribes to past injustices (Lockwood, 2009). If Maori are wary of the police as a result of past over-policing or as a result of colonial hangover as Allcock suggests, then the lack of Maori on Police Ten 7 is unlikely to change this perception where Maori viewers are overwhelmingly more likely to see Maori individuals being arrested and put behind bars than they are to see Maori officers patrolling the city streets. Mossman et al (2008:13) state that ethnic minorities have "little knowledge of policing" meaning that these populations might be more reliant on media depictions of policing to fill their knowledge gaps. If this is the case then Police Ten 7 is not depicting aspirations for ethnic diversity, instead it is reflecting the lack of ethnic diversity in the police and even featuring fewer Maori and Asian officers than the reality. If policing is communicated to these audiences as primarily the domain of white men then the role may not be seen as a very enticing one for those belonging to ethnic minorities. 
The over-representation of white individuals as police officers could also have implications for the retention of non white police, and their rise through the ranks as a result of reinforcing traditional police culture. While Mossman et al (2008:13) report that "the evidence is mixed in terms of racism and police culture, both in terms of its extent and impact" research suggests that ethnic minority officers often have to choose assimilation to the dominant police subculture or risk isolation from their peers (Waddington, 1999). Mossman et al. (2008:13) also report that minority recruits often perceive themselves as "agents of change" willing and eager to help their local communities. The reality of police culture, however, in which Maori and police experience distrust towards each other, and in which racist remarks and attitudes have been reported by two thirds of serving police officers (Ministry of Justice, 2000), means that these hopeful "agents of change" might find themselves in the position of having to choose between their communities and the police. The over-representation of white individuals as police on Police Ten 7 and the concomitant under-representation of Asian, Pacific Island and Maori officers, despite broadly reflecting the actual distribution of ethnicity in the New Zealand Police does not project the image of diversity and cultural responsiveness that the New Zealand Police repeatedly identify as a key goal to improving the New Zealand Police as a whole ${ }^{31}$.

\section{Recruitment: "The Boys in Blue"}

The value placed on physical strength and crime-fighting on Police Ten 7 and in police culture cannot be understated. Smith and Gray (1983 cited in Waddington, 1999) argue that a "cult of masculinity" pervades police culture, the by-products of which are a cultural obsession with action, excitement and the police "sense of mission" (Waddington, 1999). The assimilation of these values is an important part of being seen by fellow police as a "real" cop doing "real" police work (Chan, 1999). The primacy given to the action-oriented and physically demanding conception of policing on Police Ten 7, despite being wholly unrepresentative of the experiences of most police most of the time, has the potential to

\footnotetext{
${ }^{30}$ The New Zealand Police have many positive recruitment strategies in place for the recruitment of a more representative police service (see Mossman et al. 2008) and the aim here is not to devalue these efforts. However because Police Ten 7 is such a wide-reaching and visible representation of policing it is suggested that the inclusive and progressive positive and forward-looking strategies which the police are developing to become more culturally responsive and attractive to minority groups might be particularly useful in Police Ten 7 given its audience reach and cultural salience.

${ }^{32}$ One advertisement promoting the double billing of Police Ten 7 and Motorway Patrol stated "Do you think you are a safe driver? Check out these tips from the boys in blue" (TVNZ, 2009).
} 
reinforce the stereotype that policing is a masculine profession more suited to male officers.

The number of female police featured on Police Ten 7 broadly conforms to the actual distribution of gender in the New Zealand Police as a whole. In both the "ride-along" and "wanted" sections, however, there are high levels of police physical confrontations with offenders and unrealistically high levels of public order and violent offending. This suggests a reality in which officers are likely to be forced to resort to physically confronting and restraining offenders as opposed to other means. As a result, physical strength and readiness to deal with violent and dangerous situations becomes the most important requirement for potential police (Prokos \& Padavic, 2002 cited in Mossman et al, 2008). In Police Ten 7, male officers are more commonly involved in physical confrontations with offenders (33\% versus $22 \%$ of female officers) and male officers are more likely to be involved in vigorous physical confrontations, such as those resulting in the offender being taken to the ground. This apparent distribution of labour along gender lines, along with the general focus on pursuit and arrest, echoes Cavender et al's (1999) assertion that reality policing TV perpetuates the myth that women fulfill social work roles and men are best suited to physical confrontation and arrest.

The over-representation of citizen-police interactions which culminated in an arrest (73\%) as well as the over-representation of public-order offences, typically "drunk and disorderly", and the conspicuous lack of police interaction with witnesses and victims, also has the potential to support the idea that the most important aspect of being a police officer is the ability to pursue and take down an offender. Mossman et al (2008) suggest that despite the fact that the majority of police work is not related to crime, and despite advances which have been made for women entering the profession, the traditionally masculine aspects of police work, including involvement in "highly physical tasks" remain as the "bedrock of policing work" (Mossman et al, 2008:5) and the standard by which all police are measured.

The New Zealand Police, like international police services, has been described as suffering from a male-dominated police culture where "real" policing is akin to traditionally "masculine" policing (Mossman et al, 2008; Waddington, 1999; Bazley, 2007). While the New Zealand Police currently aim to have $30 \%$ of all new recruits officers being female (Broun, 2010) current figures reveal female officers make up only $17.2 \%$ of all sworn 
officers (NZ Police, 2010a) and that only 6\% of female police rank as senior sergeants or higher (Mossman et al, 2008). While no one factor can be singled out as the cause of the lack of gender diversity in the New Zealand Police the perceived danger and masculinity of the role has been identified as one significant barrier to the recruitment and retention of more female officers (Mossman et al, 2008; Lockwood, 2009). Mossman et al (2008:8) report that the "macho crime-fighting image" of policing can deter potential female recruits and Inspector Gary Allcock, strategic recruitment manager for the New Zealand Police, concurs stating that one challenge to the recruitment of female officers is the "general perception that it [policing] is dangerous" (Lockwood, 2009). The importance placed on physical strength naturally privileges males in the police despite findings which suggest that an increased focus on communication skills, starting from recruitment requirements and training, would "better reflect competencies required for the job" (Mossman et al, 2008:8; Broun, 2010). Mossman et al (2008:8) further argue that there is a "clear lack of evidence ... that strength or fitness predicts job performance or affects the safety of officers", thus challenging the belief that female officers put their fellow officers at risk due to their reduced size and strength. Carol Train, police diversity and equity manger for the New Zealand Police argues that female officers often bring better communication skills to potentially violent situations helping to resolve situations without violence and can help increase cooperation and reporting of offences from female victims of violent and sexual offending (cited in Broun, 2010) ${ }^{33}$.

Despite the increased focus in recruit training on the development of communication skills which reduce the need for physical confrontations, Police Ten 7, like the New Zealand Police itself ${ }^{34}$, continues to emphasise the likelihood of police becoming involved in physical confrontations with offenders and downplaying the much more common service and non-crime related functions and tasks of policing (Mossman et al, 2008).

\footnotetext{
${ }^{33}$ Recruitment copy which featured as advertisement alongside episodes of Police Ten 7 on the TVNZ on demand website included "You can be XS and Extra Strong", "Not all heroes look like the hulk" and "We're looking for new female recruits. And contrary to popular belief, you don't need to be big and burly. It's your courage, compassion and communication skills that count".

${ }^{33}$ The mixed messages are also evident in the New Cops recruitment website which lists the first benefit of working for the New Zealand Police is that it is an "exciting career"(New Cops, 2011). Out of the 17 featured "real stories" website 10 feature explicitly crime-fighting stories (catching burglars, violent offenders and responding to homicides). The other stories focus on dramatic events such as bus crashes, diving for bodies and being a dog handler. None of the featured stories discusses community policing or education and commonly feature language such as "catching a crook", "excitement" and "I wanted to drive fast cars".
} 
Police Ten 7 could increase its promotional appeal to potential female recruits by featuring more service stories and less crime pursuit and arrest. Mossman et al (2008) found that female recruits placed more emphasis on the importance of helping people when considering a career in the police as opposed to crime-fighting. Recent police recruitment campaigns, such as the "Extraordinary stories" campaign seems to place more emphasis on this helping function of policing. Police Ten 7, however, while at times showing police helping people, much more commonly depicts police arresting people. The police's awareness of this conception of policing, and of the less than favourable distribution of gender in the New Zealand Police, should pose some questions about the way the police choose to promote themselves. Recruitment campaigns in the past have focused heavily on action-packed "Better Work Stories ${ }^{35 ", ~ I f ~ t h e ~ s o l e ~ c o n c e r n ~ w a s ~ t o ~ p r o v i d e ~ a n ~ a c c u r a t e ~}$ portrayal of day-to-day police work, Police Ten 7 could provide a platform for that. However, the focus on crime and pursuit suggests that the desire to depict real police work is hindered by commercial interests (Mason, 2003).

\section{Police Ten 7 as a vehicle for the promotion of police culture}

Police Ten 7's depiction of police as crime-fighters, and of policing as action-packed and exciting, despite the empirical realities repeatedly suggesting the opposite, aligns with the high importance value given to the crime-pursuit and exciting incidents in police culture (Waddington, 1999). Researchers have consistently reported that police culture in Western societies commonly emphasises certain traits or beliefs about the profession (Waddington, 1999, Reiner, 1992). These commonly held beliefs about policing and crime contribute to a strong police culture which binds police together, resulting in positive and negative consequences. Positive consequences of police culture include a sense of belonging and trust in fellow officers while negative consequences can include corruption, rejection of more community based policing philosophies, the "blue code of silence" and resistance to efforts to increase police diversity (Waddington, 1999; Bazley, 2007).

\footnotetext{
35

Recent recruitment material has moved on from the "Better Work Stories" campaign to "Extraordinary Stories" campaign which depicts 4 stories about police officers, one featuring traditional "thief catching" by two female officers, one about a female detective investigating a child sexual abuse case, one about an Asian male officer comforting relatives of the victims from the Christchurch earthquake and a further male officer helping pull a victim from rubble (New Zealand Police, 2011b). While recruitment campaigns such as the "Extraordinary Stories" campaign seems to focus less on "crime fighting" other media, such as the General Duties NZ Police unmonitored twitter account appear to fall back on the narrow conception of policing as being primarily about fighting crime.
} 


\section{Could too much success lead to unrealistic expectations?}

While high trust in police is necessary for effective policing evidence also suggests that the promotion of unrealistically successful police services has the potential to work against the police. One early study by Arcuri (1977) involved gathering serving police officers' opinions about fictional policing shows. Arcuri reported that police were concerned that the "supercop" image depicted in the media could "lead the public to expect too much from the police" by presenting a police service who solved crimes quickly and successfully (Arcuri, 1977:242). This concern has also manifested itself in the now much debated "CSI effect" which suggests that viewers, and as a result, juries, have unrealistic expectations about forensic science evidence presented in court cases. While the CSI effect itself remains controversial anecdotal evidence suggests that television may indeed have an influence on real life criminal justice. New Zealand Forensics Officer Jason Smith has pointed out that "They [juries] expect you to get fingerprints off everything, even in a dusty, dirty place. Even a judge has said: 'I saw it on CSI. Why can't you do it?"” (North Shore Times, 2007).

In this way the portrayal of police in Police Ten 7 as almost universally successful and effective could function to boost the police image by increasing public trust but could simultaneously lead to unrealistic public expectations which could, when not met, result in dissatisfaction with service. One of the main reasons why respondents in the Citizen's Satisfaction Survey 2011 described experiencing service "worse or much worse than expected" was that the response time was too slow (New Zealand Police, 2011d). It is impossible to know on what basis respondents judged the appropriate or normal length of time a person should be expected to wait after calling for police assistance. However, given the significant influence that television portrayals, and particularly those located within the reality genre, have on public perceptions of crime and policing (Oliver \& Armstrong, 1998) it is likely that expectations about response times could be gleaned from media portrayals. In the case of Police Ten 7 the fact that police are depicted as pursuing and catching offenders, often "in the act" of committing offences, could result in audiences feeling dissatisfied with what they perceive to be lacklustre efforts from their local police. 


\section{The portrayal of crime and criminals: Ethnicity}

In Police Ten 7 the ethnicity of offenders depicted broadly reflected official apprehension statistics. Nonetheless there were some issues of concern relating to differences in the depictions of typical or common offending by white offenders and non-white offenders. When we compare the official statistics for convictions for violence by ethnicity with the depiction of violent offenders in the "wanted" section we find major discrepancies. In particular Maori and Pacific Islanders were more often depicted as violent offenders than New Zealand Europeans. While NZ European offenders were most commonly involved in traffic or drug and antisocial offending Maori and Pacific Island offenders dominated crimes involving violence. $50 \%$ of all offences featuring Pacific Island offenders involved violence. According to the 2010 apprehension statistics, however, only $30 \%$ of apprehensions by Pacific Islanders involved violent offending (Statistics New Zealand, 2010a). Similarly in the "ride-along" section $36 \%$ of offending by Maori was violent while apprehension statistics show that 23\% of offending by Maori in 2010 involved violent offences. In the "wanted" section, which involves more serious offences, when depictions of serious offending are compared to custodial sentences actually handed down it is revealed that NZ Europeans are under-represented as violent offenders while Maori are slightly under-represented and Pacific Islanders significantly over-represented. The overall picture across the "ride-along" section and the "wanted" section over-represents violent offending significantly by Maori and Pacific Island offenders while under-representing offending by NZ Europeans. In common with similar research overseas (Entman, 1992; Monk-Turner et al. 2007; Dixon \& Linz, 2000), one final analysis between character role portrayal, that is between officer or offender revealed that white individuals were much more likely to feature on Police Ten 7 as police than offender while the opposite is true for Maori and Pacific Island individuals who are much more likely to be depicted as offenders.

In depicting this difference in offending for white and non white offenders Police Ten 7 could be communicating the message that non-white offenders are more dangerous while white offenders are more commonly involved in traffic and drug and antisocial offences as opposed to serious inter-personal crimes. There is no doubt that the "wanted" section actively constructs a threatening and frightening picture of criminality. This is achieved by using music commonly heard in horror movies and repeatedly reconstructing sexual assaults, murders or armed robberies. These reconstructions also feature cinematic techniques which communicate danger including dark and choppy footage, blurry images 
of aggressive offenders punching towards the camera and narration which highlights vulnerability, violence and the inevitability of future reoffending.

Oliver (2003) suggests that reality TV which routinely depicts non-whites as offenders can function to imply guilt merely by being a minority, a concern echoed by Robinson (2000:134) who argues that repeated media depictions of black individuals as offenders can mean that "blackness is treated as a sign for increased criminality". Oliver (2003:11) argues that this could "prime" viewers to "implicate essentially any black man as potentially threatening or violent" which she argues is associated with an increased risk of false identification of non-white offenders.

Following this line of thinking Police Ten 7, by under-representing white offenders as violent, and over-representing Maori and Pacific Islanders as offenders as opposed to police could imply to the public and to officers, both future and current, that their suspicions about the greater criminal potential of Maori are warranted (Doyle, 1998; Oliver, 2003; Prosise \& Johnson, 2004). Prosise and Johnson (2004) suggest that the systematic portrayal of non-white offenders combined with the common portrayal of police as uniformly successful can function to legitimise racial profiling by justifying potentially illegal pretextual stops when police hunches are inevitably proven right. Keeping in mind that all police-citizen interactions in Police Ten 7 are depicted as warranted, then there is potential for the reinforcement of the "discriminatory behaviour" that is "part of the police occupational culture” (Ministry of Justice, 2000:28, Waddington, 1999).

This is a particular challenge for the New Zealand Police within which Maxwell and Smith (1998) discovered almost one in four frontline officers in their sample had negative attitudes about Maori, where two thirds of those officers reported having heard fellow officers using racist language and in which one third reported having a greater tendency to be more suspicious of Maori than non-Maori (Maxwell \& Smith, 1998; Ministry of Justice, 2000). As Chan (1999:21) suggests, policing is "largely dictated by officers' perception of what constitutes suspicious activities" and that "stereotyping and prejudice on the part of police officers can easily lead to harassment and community resentment". Because police are encouraged to see themselves as crime-fighters, and because many officers see Maori as being part of the "crime problem" (Maxwell \& Smith, 1998; Ministry of Justice, 2000) they are more likely to suspect Maori of offences and, in turn, more likely to stop and 
search them (Ministry of Justice, 2000; Sharples, 2011). Such potentially discriminatory behaviour is likely to have a further impact on official crime statistics.

The representation of the majority of non-white individuals as offenders and white individuals as police also has potential implications for police recruitment. The New Zealand Police are actively recruiting more Maori, Pacific Island and Asian officers in an attempt to construct a more diverse and representative police service (Mossman et al, 2008). If minority viewers are presented with a view of policing that paints non-whites as more likely to be offenders than officers then potential recruits from ethnic minorities may be less willing to consider policing as a career. This depiction of Maori as offenders and white individuals as police is also unlikely to help build trust between Maori audiences and police who report strong levels of distrust of police and a belief that police are fundamentally “anti-Maori” (Te Whaiti \& Roguski, 1998; Mayhew \& Reilly, 2007).

\section{Crime as public, inter-personal and violent}

The over-representation of public order and violent offending in Police Ten 7 conforms to similar international research as well as perpetuating some common features of crime and policing on fictional television (Cavender \& Bond-Maupin, 1993). The picture of crime projected by television crime news, newspaper coverage and fictional crime television is one dominated by interpersonal violence (Cavender \& Bond-Maupin, 1993; McGregor, 1993). This is echoed in the "ride-along" section with drug and antisocial and violent offending combined making up $69 \%$ of all crime featured. When offending in the "wanted" section is included almost half of all offences depicted on Police Ten 7 are violent and sexual offending. This is not reflective of official recorded statistics in which dishonesty offences make up half of all recorded offending and violence and drugs and antisocial offending make up only 30\% combined (Statistics New Zealand, 2010b). Offending in Police Ten 7 occurs primarily in public places (72.5\%) and when violence is depicted in the "wanted" and the "ride-along" sections it is always inter-personal and almost always between strangers ${ }^{36}$. Crime featured in Police Ten 7 is not dishonesty offending, white collar or corporate crime, but public order offending in public places by male offenders, and violent offending. There are several potential factors behind this skewed and

In the "ride-along" there were only three crime stories which involved violence between family members or romantic spouses 
unrealistic depiction relating to broadcast pressures for the producers and image control by the police.

The over-representation of public-order and violent offending in Police Ten 7 could be related to broadcast pressures to obtain interesting, high-rating footage which appeals to audiences. Former Cops producer and executive producer of World's Wildest Police Videos, Dick Herland states that violence does well in ratings while corporate or white collar offending “doesn't make very interesting reality TV” (Glynn, Czarnecki, Bishop \& Donovan, 2002). The need to entertain is arguably greater than the need to educate which explains why crime distributions are so inaccurate on Police Ten 7. Another possible explanation for the over-exposure of public order and violent offending, and the concomitant lack of coverage of dishonesty offences, could be a by-product of legal broadcasting requirements, in particular the need for producers to acquire the permission of victims and property owners to broadcast their image. The increased involvement of victims and property owners which comes with dishonesty offences could result in the increased likelihood of uncooperative victims more often than other offences which require only the involvement of offenders and police. The over-representation of public order offending could also be the result of a reliance on disorderly offences by producers given that they provide drama, conflict and police interaction with offenders in ways which purely reactive post-offence criminal investigations do not.

More strategically, dishonesty as a category suffers from one of the worst levels of crime resolution across the seven categories of analysis (23\% resolved in $2009^{37}$, Statistics New Zealand, 2009). Sexual offending also suffers from low resolution rates relative to other offence categories (62\% in 2009) (Statistics New Zealand, 2009). The absence of sexual and dishonesty offences in the "ride-along" section could relate to issues of appropriateness in terms of the former and because these offence categories do not reflect positively on police.

Conversely, those offence categories with the highest resolution rates feature more regularly on Police Ten 7 . The most common category, drugs and antisocial (52\%) boasts a 93\% resolution rate in the 2009 statistics. Violence, the next most common offence

${ }_{36}$ This low resolution rate is the result of multiple contextual variables, primarily the large number of offences reported due to legal requirements from insurance agencies (Bradley \& Walters, 2011) and the reactive nature of response to this offence type. 
category ${ }^{38}(17 \%)$ in Police Ten 7 , enjoys an $82 \%$ resolution rate. Image work by police could be one potential reason behind the disproportionate representation of violence and drug offending in Police Ten 7 given the desire of the police to reassure the public that the police are efficient and successful at resolving offences. This suggestion cannot be verified without the cooperation of the police or the producers of Police Ten 7, however executive producer Philly De Lacey, in an article published in the Ten One Police Online Magazine, stated that "police involved in a broadcast case are able to have significant control of the information included in the item" and that the "police really know how to utilise the programme" (NZ Police, 2004b). The importance placed on the promotion of good public relations, both internationally and locally, and the increased professionalisation of police/media relations (Mawby, 2001) suggests that the over-representation of offence types with high resolution rates could be part of an effort by police to project the "right" image. Doyle (2003) argues that this occurs in media-police collaborations which rely on mutual cooperation and when production teams internalise pro-police values in order to present the police in the most positive light.

It could be also be that the factors which result in a high resolution rate for police, namely the availability of evidence, are easier to procure in relation to public order offences which only require police evidence to arrest. It may also be that such offending provides "good" raw product for broadcast for Police Ten 7 and is preferred on that basis. A police investigation which involves visiting a "cold" burglary does not provide the conflict or drama which makes "good" television. The highly resolved categories of offences may therefore be selected by police to appear on Police Ten 7 either consciously in an attempt to increase public confidence in the police or as the result of less deliberate decision making guided by the desire to provide the producers with footage which they can easily gather, easily obtain permission to use and which will be high-rating. Offences with high resolution rates may also provide "better" narratives of crime and justice than categories with low resolution rates because they conform to traditional story narratives featuring a beginning and an end as well as a hero and a villain (Doyle, 1998). Often police provide the producers with a clear filming opportunity, for example a drug warrant execution or a patrol through town on a weekend night, which is guaranteed to provide useable footage and which, simultaneously, whether by design or not, belongs to a offence type with high resolution rates.

38 After traffic offending (19\%) which cannot be compared through these figures 


\begin{tabular}{|c|c|c|}
\hline Offence & $\begin{array}{l}\text { Official Police } \\
\text { Resolution/ } \\
\text { Clearance rate } \\
\text { percentage (2009) }\end{array}$ & $\begin{array}{l}\text { Police Ten } 7 \\
\text { coverage } \\
\text { percentage }\end{array}$ \\
\hline $\begin{array}{l}\text { Drugs \& } \\
\text { Antisocial }\end{array}$ & 93 & 52 \\
\hline Violence & 82 & 17 \\
\hline Traffic & $\mathrm{n} / \mathrm{a}$ & 19 \\
\hline $\begin{array}{l}\text { Property } \\
\text { Damage }\end{array}$ & 30 & 2 \\
\hline Property Abuse & 74 & 6 \\
\hline Admin & 95 & 3 \\
\hline Dishonesty & 23 & 0 \\
\hline Sexual & 62 & 0 \\
\hline
\end{tabular}

Table 1: 2009 police resolution rates and percentages of Police Ten 7 coverage per offence type (Statistics NZ, 2009)

Furthermore, by presenting a "reality" that highlights violent, interpersonal and public crimes instead of white collar crime, fraud or domestic abuse the show can be argued to "set the agenda of public discourse" (Cavender, 1998:86) surrounding crime so that when the audience thinks of prison or criminals they are more likely to think of murderers and rapists and consequently more likely to support punitive sentences and prison conditions (Oliver, 2003). The creation of "the criminal other" through presenting the most sensational and violent crimes in Police Ten 7 allows for social distancing and dehumanising legislation being more likely to receive public support (Greer, 2005).

\section{"Dangerous predators" and "moron criminals"}

Another feature of the depiction of crime in Police Ten 7 is the way offenders, particularly in the "wanted" section, are repeatedly referred to in negative terms which function to demonise, dehumanise and "other". In common with Cavender \& Bond-Maupin (1993), offenders in Police Ten 7 are depicted as dangerous and a menace to society. Sometimes Bell, the narrator, offers his opinion which as a retired detective sergeant is given privilege to make broad generalisations and assumptions about offenders' motivations or potential 
actions. He says about an offender who carried out an armed robbery which did not result in physical violence: "I have no doubt that if he needed to he would have pulled the trigger" and makes assumptions about their motivations and internal processes, stating: "While they're driving away in their car with the money laughing they couldn't care less about the emotional wreckage they're leaving in their wake". This portrayal of offenders in Police Ten 7 is similar to that of offenders in America's Most Wanted and Unsolved Mysteries, where criminality is depicted as a "master status" Cavender \& Bond-Maupin (1993:312). This functions to group all offenders as "typical criminals" who commit armed robberies, despite the fact that the "typical criminal" is more likely to be engaged in lowlevel dishonesty offending (Statistics NZ, 2010b). This also separates the viewers and police from the offenders, reproducing the "us versus them" mentality common in police culture (Waddington, 1999).

The depiction of offenders also has the potential to induce fear in the audience through filming techniques which replicate traditional horror movies by using threatening music, shaky camera work, a stalking view of the victim through the eyes of the offender and seeing the attack through the offender's eyes, all of which function to allow viewers to feel the fear of the situation. That offending is so commonly depicting as random emphasises the idea that anyone could be a victim (Dobash et al., 1998). The repeated dehumanisation of offenders as "dogs" "rats" and "animals" who "need to be put down" and who "escape like rats down holes" further dehumanizes offenders and encourages a personal positioning of the audience on the side of the police.

As well as describing offenders in negative terms Bell actively refutes any potentially positive or at least neutral aspects of reconstructed crimes. An offender involved in an armed robbery is depicted by the detective involved in the case as calm and not aggressive and Bell states to the camera

"Now it really frustrates me when I hear about moron criminals, like this guy, saying that they don't want to hurt people when they've gone into someone else's property carrying a firearm. That is a recipe for disaster and if anything had gone wrong there would have been only one person who got hurt and that would have been the victim". 
The narrative control by the police and the producers means that an anti-offender and propolice position can be maintained which reinforces the "us versus them" (Waddington, 1999) mentality so commonly found in police culture.

\section{Offenders as individually deficient and out of control}

Leishman \& Mason (2003), Prosise \& Johnson (2004:75), Soulliere (2001) and Cavender \& Fishman (1998) argue that reality television routinely "portrays crime as a threat to citizens that results from the pathology of individual criminals - not from the social and environmental conditions within citizen-suspects are situated". In common with this international experience Police Ten 7 rarely provides any contextual information about why offences take place. In the "ride-along" section this is less obvious with some crime stories implying that alcohol or drugs are the cause of offending. In general, however, the why of offending is not prioritised. Instead the focus is clearly on the ways offending takes place.

Soulliere (2001) argues that offending is typically presented as the result of individual deviancy, cruelty or greed as opposed to social causes like poverty, education or family background. This can be found in Police Ten 7 through the "events orientation" (McGregor, 1993) of the crime stories which begin when the police are dispatched to a crime scene and end when the offender is subdued either by arrest or by alternative means. There is a clear implication that once the offender is inside the police cell the story is over. Although the narrator often informs the audience of the outcome of sentencing the repeated shots of the cell door slamming shut followed by a cut to the next crime strongly implies the end of the story. There is little to no explanation for offences or discussion of motivation behind crimes beyond the fact that offenders are just "typical criminals" and "ticking time-bombs". This is most clearly demonstrated in the "wanted" section of the show where the vast majority of offending is decontextualised and presented as random or inexplicable.

By focusing solely on individualised explanations for crime, personal blame and responsibility are assumed as opposed to systems of social or economic inequality (Soulliere, 2004). Soulliere (2004:108) suggests that policies which might be created based on such individualised conceptions of crime could prove to be "inadequate if they reflect media-inspired explanations which advance the solution to crime as a matter of adjusting 
individual personalities rather than altering the social structure". Monk-Turner et al, (2007) and Cavender and Bond-Maupin (1993) argue that the repetition of this myth about crime, so common in fictional television and an important feature of Police Ten 7, reduces the understandings of the causes of crime to a much more simplistic case of "evil offenders" (Britto, Hughes, Saltzman \& Stroh, 2007:51-52). Moreover, offenders are placed beyond the control of society and solutions to these unpredictable and unexplainable crimes are reduced to "policing and tough sentences" (Britto et al., 2007:51-52) than less punitive causation-focused alternative such as rehabilitation (Chong Ho Shon \& Arrigo, 2006).

\section{Fear of crime and the assessment of risk}

One of the main concerns with a construction of reality which over-represents violent and public order offending is the possibility for increased levels of fear of crime among viewers (Soulliere, 2004). The high informative and educational value placed on the media (Oliver \& Armstrong, 1998) means that when reality TV "prioritises crimes of violence" it has the potential to "amplify public fears that crime is spontaneous, random and indiscriminate" (Jewkes, 2004:155). The New Zealand 2011 Citizen's Satisfaction Survey found that the main reasons given by those who rated themselves as feeling "unsafe or very unsafe" included "youths, particularly those hanging around in groups" "alcohol and drugs problems in the local area" and "fights/arguments/attacks on the street" (NZ Police, 2011b:3). It is interesting to note that these circumstances for feeling unsafe often relate to public order offending and street crime, which are significantly over-represented on Police Ten 7. While it is difficult to quantify causes of fear of crime studies have found that "regular viewers of Cops were significantly more fearful than infrequent viewers of being sexually assaulted, beaten up, knifed, shot or killed" (Haghighi \& Sorensen, 1996:23). Research by Cavender et al. (1999) suggests that viewing reconstructions of violent sexual assaults on women increases fear of victimisation for female viewers.

In line with cultivation theory these depictions, particularly when understood by audiences to be real (Kooistra et al 1998; Oliver \& Armstrong, 1998), could shape audiences' conceptions about "the crime problem". There are numerous implications for the depiction of a crime problem which systematically over-represents public order offending and violent crime against the individual. 
If viewers do use Police Ten 7 as a source of information they may experience fear of crime as well as inaccurate conceptions of risk. That so much of the offending presented on Police Ten 7 occurs in public, involves disorderly behaviour and depicts violent offending involving strangers viewers could, understandably, experience increased fear of crime and be presented with an inaccurate understanding of victimisation risk (Soulliere, 2001). The crime featured in the "wanted" section is unrepresentative of actual offending as a result of self-selected criteria. The offences most likely to be unsolved are those which occur between strangers which mean that conceptions of risk are skewed through Police Ten 7.

This is best illustrated by the depiction of sexual offences in the reconstructions featured in the "wanted" section. All of the sexual offences which were reconstructed conform to the "real rape" scenario (Cavender et al, 1999; Mossman, Jordan, Macgibbon, Kingi \& Moore, 2009) featured young women being attacked by strangers at night in public places and suffering injuries. That no other sexual offending features on Police Ten 7 perpetuates the myths surrounding rape and ignores the myriad of other ways victims experience sexual offences and thus reinforces a narrow conception of sexual assault. The risks of victimisation are similarly erroneously depicted, suggesting that women are most at risk from stranger assaults whereas the reality is that acquaintances, family and romantic partners are much more likely to be the offenders in the majority of sexual offences (Cavender et al, 1999; Mossman et al, 2009).

One risk from this perpetuation of the "real rape" myth is that the public might ignore more commonly risky situations and might not see other kinds of sexual offences as legitimate crimes (Carmody, 1998). If the depiction of sexual assault on Police Ten 7 presents a legitimate victim and offence and "real rape" is consistently committed by violent strangers who are "frequently poor minority men who might be psychotic" (Cavender et al, 1999:645) then sexual assault by family, friends or acquaintances which do not occur in public or involve physical violence may be seen as less criminal, real and legitimate. This is particularly concerning given that Police Ten 7's producers advertise that the show is helpful because it "shows who is committing the offences, why, how the victims got involved in the situation and what people can do to protect themselves" (NZ Police, 2004b). If that was the aim of producers then more varied and common forms of victimisation should be featured which would more accurately show the victimisation risks of most offences. 
The clichéd depictions of sexual offending however could be argued to at least remind audiences of the damaging nature of sexual victimisation and could, while potentially reinforcing harmful and inaccurate stereotypes of what constitutes "real" victimisation, have positive implications. Bell, while discussing a sexual assault addresses the audience states:

"Now some of you might be saying what was that young woman doing walking home at that hour of the morning? I subscribe to the view that everybody has the right to walk unmolested through our city streets".

This unsolicited pre-emptive rebuke against victim blaming is an important message to communicate to viewers, potentially increasing public trust in the police to report such offences, which are considerably under-reported (Jordan, 2004; Mossman et al. 2009). Similarly, despite the under-representation of domestic violence on reality TV, Soulliere (2001) argues that when domestic violence is featured the depiction of mandatory domestic violence policies could be useful to audiences who become more aware of policies regarding domestic violence which could increase visibility of domestic abuse and in turn increase reporting of domestic violence. While there may be some positive benefits to at least depicting some instances of domestic violence it is also possible that such media depictions of violence against women in reality crime and policing shows could "impede effective public policies" by more generally perpetuating inaccurate myths surrounding violence against women (Cavender et al 1999:172).

It is also possible that repetitive depictions of "crime" as street crime could function to reinforce the misconception that most crime is violent, facilitating the continued disregard for other, often more damaging offences. Reiman (1990:52) argues that "because we believe ... that the model for crime is one person intending to harm another, we accept a legal system that leaves us unprotected against much greater dangers to our lives and well being than those threatened by the typical criminals". This narrow conception of crime and harm arguably reinforces the idea that corporate and white collar crime is less extensive, dangerous and harmful than traditional street crime and provides no educational value in terms of educating viewers about the real distribution of and impact of crime. Soulliere (2001:72) suggests that by ignoring white collar and corporate crime on TV viewers are not made aware of the risks and may "likely ignore them and ultimately fall prey to corporate wrongdoing" which as Bradley \& Walters (2011) point out is responsible for 
much more violence, death and physical damage than all conventional street crime combined.

\section{Giving voice to police, silencing offenders}

While the narration does not contextualise or explain offending the opposite is true for police actions. All narrative and explanatory control is given to the police officers and the narrator meaning that offenders' motivations and realities are obscured by the official "copcentric" (Leishman \& Mason, 2003) reality created in Police Ten 7. The action is entirely presented through police explanations, and while police are commonly given the ability to present their version of events, offenders are never given the same opportunity. This is achieved in several ways in Police Ten 7 through both the narrative structure and the filming techniques. Filming occurs from inside the police car with the camera situated in the front passenger seat placing the viewer in the role of fellow police officer and all information, images and conclusions are drawn from this privileged and highly subjective position (Mason, 2003). Images build up the cop-centric view point through filming consistently through the dashboard of the police car, often filming nothing but motorway and large amounts of windscreen (see image one) but in doing so highlight the fact that the audience is experiencing raw reality, the viewer is physically and mentally on the side of police (Cavender, 1998).

The information is delivered to the audience through police giving their opinion about the situation and through the narrator translating the action and the reasons behind particular actions. This results in a police constructed view of the crime with all police actions justified through the narrator and the police (Prosise \& Johnson, 2004).

One example of this "cop-centric" (Leishman \& Mason, 2003) view is demonstrated in a crime story in which a "wanted" offender is arrested by armed police and suffers injuries from a police dog. The offender appeals to the film crew and displays his bleeding injuries and the narration justifies the police actions by reminding the audience that the offender was in a public place where vulnerable hospital visitors and patients might become at risk of harm. The police are given the opportunity to defend and justify potentially ambiguous actions while offenders are denied this opportunity. This demonstrates the way that all action is mediated through the police vetted lens providing contextualisation and background to police actions but never to the actions of offenders. 
The construction of all events through this police mediated lens means that reality can be "constructed by the officer" (Doyle, 1998:102) and viewers must "rely on a police interpretation of events" (Doyle, 1998:102) in order to understand the context and events being presented. This inevitably gives police the ability to present a view of events which flatters police. Cavender and Fishman (1998:79) argue that this elicits identification with the police and creates viewer identification with police aims so that "their success is our success".

\section{Police Ten 7 as a vehicle for the advancement of pro-police sentiment}

The over-representation of violent and public order offending, depiction of police as crimefighters, promotion of offenders as individually pathological and deviant "others" and the presentation of all action through a "cop-centric" lens have several important implications for understandings of crime and policing in New Zealand.

Doyle (2003) argues that by presenting the police as the crime-fighting heroes battling against the often violent "arrogant criminals", reality TV supports a law and order view of policing which places crime fighting as most important. As a result support and advocacy for increased police and police powers as a solution to 'the crime problem' is encouraged. Cavender and Fishman (1998) argue that this in turn primes viewers to support law and order policies which give police power against criminals who, as in Police Ten 7, are commonly dangerous, inhumane, violent and unpredictable. Palmer (1998:3) adds that through reality TV police are able to further their "vested interest in maintaining the fear of crime" increasing the likelihood of audiences accepting the control and authority of police. In line with the cultivation hypothesis, the type of language used by Bell in the "wanted" section, which consistently labels offenders as dangerous and violent, could result in the reinforcement of public conceptions of offenders as the dangerous, violent other. Soulliere (2004:230) suggests that "through storylines that depict intense violent crime scriptwriters can heighten arousal or fear in viewers and then later reassure them by projecting images of police as effective crime fighters".

Similarly, Palmer (1998:12) suggests that this collaboration between the media and the police helps "construct the new citizenry of fear" which he argues paves the way for the acceptance of punitive crime and justice policies based on the fear of what could happen if 
the "mongrels" portrayed as hunting innocent victims and "striking at the very heart of vulnerability are treated too leniently. This too is linked to the concept of policing by consent (Cavender, 1998:79) where the public is convinced that violence and crime is rapidly "spiralling out of control" (Gillespie \& McLaughlin, 2003:2). Cavender et al (1998:661) argue that reality TV "sends a message to the audience that the only defence against the ever-present dangers ... is to trust the police". The NZCASS (2009) reports that "those who express high worry and concern about crime and disorder are more likely to believe that the criminal justice system is ineffective in controlling crime" (Ministry of Justice, 2010:90). This suggests that for those who fear public order offending and violent interpersonal crime, reality TV might generate support for increased police powers and potentially even controversial or punitive means to protect the public from such fear (Prosise \& Johnson, 2004).

\section{The Promotional Power of Police Ten 7}

While Police Ten 7 promotes itself as providing "an unflinching, behind the scenes look at the real work our police do" (Screentime, 2011) and prides itself on "show[ing] who is committing the offences, why, how the victims got involved in the situation and what people can do to protect themselves" (NZ Police, 2004b), the discrepancies between the realities of policing, offending, crime and victimisation and their depiction in Police Ten 7 demonstrates that the show does not actually educate viewers about the real risks associated with victimisation, about the real distribution of crime in New Zealand or about the real work done by police on a daily basis. If the goal is not to educate audiences about the realities of policing then it becomes clear that from the perspective of the police, one of the aims of Police Ten 7 is the promotion of the NZ police and to elicit the identification of the audience with the police, providing a sort of "symbolic reassurance" and increasing the degree to which the public associate the success of the police with their own personal success (Oliver, 1994).

The involvement of the police in the creation of Police Ten 7 must surely provide some benefits to the organisation, if it did not it is highly unlikely the police would grant the media such unfettered access. It is undeniable that, via the "wanted" section, Police Ten 7 helps police solve crimes, and police have referred to Police Ten 7 as "an invaluable tool for police investigating cases" (NZ Police, 2005a). However, the "wanted" section does not provide the main focus of or content for the show. Rather, the "ride-along" section takes up 
the majority of programme time. The benefits for the police, then, must be more than simply the potential information gleaned from the "wanted" section, and this is arguably the provision of a platform for the projection of positive "image work" (Mawby, 2001; Doyle, 2003, Mason, 2003). ${ }^{39}$

The New Zealand Police is in a constant recruitment drive, attempting to entice more diverse populations of potential recruits ${ }^{40}$ (Mossman et al, 2008). Police Ten 7, on air since 2002, can be seen as an alternative form of campaigning, in terms of fostering good will among the populace by providing symbolic reassurance and by offering a view of policing which appeals to potential recruits. The New Zealand Police Strategic Plan to 2010 specifically acknowledges the importance of projecting a positive public image, stating that this "has a positive impact on trust and confidence in police. By communicating the good news stories, by being visible ... we send clear messages which will strengthen support for police" (NZ Police, 2005b:7).

If Police Ten 7 does function, at least in part, as promotional material for the police then the consequences of such depictions should, logically, benefit police. There are certainly many ways in which the skewed depictions of policing and crime work in favour of the police. Despite research revealing that the majority of police work is mundane, repetitive and concerned with incidents not related to crime (Perlmutter, 2000; Mossman et al., 2008; Home Office, 2001) the appeal of policing as an entertainment subject and as a career still appears to lie with the conception of the role as exciting. By presenting a construction of policing which appeals to this desire for excitement Police Ten 7 functions to reinforce the stereotypical idea of policing being all about crime-fighting. That involves significant amounts of physical confrontation with offenders, which simultaneously reinforces aspects of police culture.

The depiction of crime as commonly public and violent and of offenders as at times inhumane and out of control, combined with the depiction of police as wildly successful at

\footnotetext{
${ }^{39}$ The Police Act Review (2006) investigated the police perceptions and expectations of public focus groups in Auckland and Hawke's Bay. This review found that crime victims' perceptions of police were the result of actual personal experience. Positive "real life" experiences with the police resulted in victims being more likely to discount negative reports about the police in the media (New Zealand Police, 2006b).

The New Zealand police's increased use of new media to appeal to young members of the public demonstrates a multi-pronged approach to recruitment which sees traditional recruitment drives combined with Twitter campaigns, graffiti-inspired advertising and Police Ten 7
} 
resolving crime and justified in potentially ambiguous situations, supports a "thin blue line" (Doyle, 2003) conception of policing where police alone stand between dangerous offenders and the vulnerable public. Reiner (2000) suggests that this functions to create support for traditional law and order conceptions and harsher penalties for offenders as well as increased control and powers (Reiner, 2000). The repeated depictions of dangerous offenders being controlled by efficient and infallible police has, according to cultivation theory, the ability to support and "legitimise a particular social order" (Gerbner et al., 2002:44). In the case of reality crime and policing shows this is a reality where more police and more police power easily equates to a safer public.

Police Ten 7 presents itself as depicting reality while clearly constructing an image which is at the mercy of production and industry pressures which demand action and excitement instead of detailed and nuanced explorations of crime causation and police pressures. That these require police-producer collaboration for the continued existence of the show does not mean that either party consciously sets out to deceive the public or to potentially create harmful implications. Palmer (1998:17) suggests instead that the skewed reality of reality TV is not "because of an old-fashioned conspiracy theory but as a happy meeting of professionals who find their aims merging as they attempt to re-connect with a lost public" (Palmer, 1998:17). The desire to provide the public with an insight into policing in New Zealand is not harmful in itself. However the depiction of a realistic and educational insight into most offending and policing in New Zealand is clearly not the primary objective of Police Ten 7. Despite honourable intentions to help solve crime and allow the public the chance to become involved in their criminal justice system, commercial and promotional requirements have the potential to derail attempts at furthering the public's understanding of crime and policing.

This thesis does not suggest that the police do not act fairly and professionally or that they are undeserving of positive praise. Nor does it suggest that the police consciously or subconsciously treat victims and offenders differently based on stereotypes or prejudices. The suggestion is that the way the media represent the police, victims and offenders and construct "real" police action is in keeping with an entertainment based framework and agenda. Such a framework utilises police in a way which promotes media conceptions of what policing should be and which constructs a picture of policing in New Zealand which is not representative of the experiences of most police officers nor may it be in keeping with police aims and objectives. It is suggested that while a "cop-centric" and thin blue line 
ideology which bolsters the police image is presented, such ideologies have the potential to make police work more difficult through raised public expectations, unrealistic expectations of recruits and a lack of public understanding for what motivates most police work. If, as it suggested here, Police Ten 7 exists, at least in part, to act as or provide a vehicle for the dissemination of pro-police messages, and as a recruitment tool for the New Zealand Police, then one concern is whether it is appropriate for the New Zealand Police to be in a collaboration with a commercial entertainment company which turns actual police interactions and offender encounters into general entertainment for the masses.

\section{Reality TV: Issues for consideration}

There are potentially negative consequences for a portrayal of crime and policing which is unrepresentative of reality and which has the potential to influence public perceptions of crime and policing. While there are broad concerns about how audiences may understand the core business of policing, the realities of offending, and the risks of victimisation, a further concern is more specifically linked to the premise of the show itself. The police who feature on Police Ten 7, who are without exception depicted in a positive light, are aware that they are being filmed and consent to being involved in this commercial production. The same is not always true for those offenders who are featured (BSA, 2011), who experience a different form of policing and punishment than those who are not filmed and broadcast to a national audience. This raises concerns for how police image management and promotion might actually impact those who are policed by forcing upon them police interventions which are more public and thus potentially shaming than normal police-citizen encounters and which have the potential to be influenced by commercial interests.

Doyle (2003) suggests that the act of filming can alter the act of policing and of being policed. For police he suggests there can be pressure to either "act up" for the camera, by way of being lenient in order to lecture the audience and the offender, and by treating offenders more punitively because of the desire to show tough policing or live up to the situation. Similarly, because the offender is featured on Police Ten 7 and according to the Broadcasting Standards Authority (2011) is not required to sign any release forms if they are in a public place, the offender may experience a significantly more punitive intervention as a result of "the shaming effect of TV" (Doyle, 2003:6). 
In a very real way the show impacts the criminal justice system by adding an extra-legal punishment to offenders who already experience punishment through the formal criminal justice system by shaming them on television. Worryingly, viewers do not seem concerned with this element of Police Ten 7 equating broadcast on the show as a deserved form of punishment. Viewers responding to New Zealand research on reality TV stated that those who break the law "should probably lose their right to privacy" (BSA, 2011:15). That offenders may not in fact be guilty was not a concern and the acceptance of additional punishments on top of the official criminal justice systems punishment seemed acceptable. Punishment in contemporary reality TV is not solely the domain of the criminal justice system and police but of media outlets who can engage in public shaming, echoing longsince abandoned public “spectacles of punishment” (Pratt, 2007).

Because police on Police Ten 7 are always depicted as justified in their interventions and successful in their efforts to resolve a case the mere appearance of an individual may strongly imply guilt regardless of whether the offence was proven or not in court (Mason, 2002). Research by the BSA (2011) suggests that viewers do not believe that reality TV programmes attempt to edit participants in a negative fashion and that any footage depicting negative attitude or behaviour is a result of what individuals "actually... are, rather than what the programme is attempting to depict them" (BSA, 2011:9). Based on this information, and the knowledge of the amount of editing which actually does take place in reality TV (Seagal, 1993) offenders featured on Police Ten 7 who are described as "arrogant" are likely to be accepted as such by viewers. The impact of this on featured offenders is unclear. Research by the BSA (2011), however, described the unwanted exposure of participants on similar New Zealand reality shows as potentially traumatising and harmful.

\section{Breaches of privacy?}

In July 2010 the BSA ordered TVNZ to pay $\$ 2500$ to a complainant featured on Police Ten 7 who claimed that his privacy was breached when Police Ten 7 camera crews filmed his family while police carried out a drug raid on his house (New Zealand Herald, 2011). The BSA found that producers failed to gain consent, which TVNZ claimed was not needed given that arrest was a "matter of public record" and the face of the offender was blurred. The BSA disagreed and ruled that the invasion of privacy was "highly offensive". In 2008 a Chinese male jumped from the seventh story of a brothel when Immigration New 
Zealand, the New Zealand Police and a television crew from TVNZ reality show Borderline conducted an unauthorised raid (Fawkes, 2009). In 2007 an elderly couple unsuccessfully took TVNZ to court over an invasion of privacy when they were filmed without their consent (Stuff, 2008). The ethics behind filming people, victims and offenders alike, without their consent and then broadcasting this to a national audience are hazy. TVNZ has used the defence of "public interest" in previous court cases and that some offenders have been apprehended as a result of Police Ten 7 (Stuff, 2008). However the fact that it is a commercial product and that its creation was motivated more by the desire to achieve high viewer ratings than to educate and inform, raises more questions about the propriety of using real-life, often life-altering, personal tragedies as a form of public entertainment.

Collaborations between those doing serious, important work (police) and those creating entertainment (production companies) can have consequences more far-reaching than influencing audience attitudes regarding crime and policing. Like the New Zealand Borderline incident, reality policing TV in other countries has been linked with a number of accidents and deaths. In the USA a film crew filming for reality show The First 48 accompanied police conducting a raid of a house during which police accidentally shot and killed a seven year old girl sleeping in the family living room. Lawyers for the family stated that the concerns of the production company to obtain exciting footage, achieved in one part by police throwing a flash grenade through the window, influenced police on the scene who "were excited they were on TV" (MSN NZ, 2010). Similarly, an ex-police officer turned lawmaker and television personality was charged in 2009 with organising murders so that he could be the first on the scene and film the incident and thereby "increase the audience of his TV show" and thus its popularity (Associated Press, 2009:1). While these are clearly extreme examples of the potential dangers of collaboration between commercially driven production companies and police they help demonstrate Doyle's (2003) claim that filming real life events can change and/or influence how those events will be experienced for all involved.

Whether it is the role of commercial production companies to dole out additional punishment for offenders by shaming them on television and to present allegedly unbiased crime stories with the collaboration and creative control of the New Zealand Police is a timely issue. Given that the commercial pressures of creating a "hit" television show might often collide with the New Zealand Police's aims of image control and the presentation of 
a positive, pro-police vision of policing, it is arguable that the stated desire to "show who is committing the offences, why, how the victims got involved in the situation and what people can do to protect themselves" (NZ Police, 2004b) and to give an insight into every day policing may be compromised. What seems clear is that while Police Ten 7 does indeed depict real people involved in real actions, the edited version of those events, while "drawn from the immediacy of live events, form nothing more than stories" (Andersen, 1994:8).

\section{Conclusion}

Television plays a significant role in contemporary Western society providing entertainment and education (Oliver \& Armstrong, 1998; Surrette, 1992; Reiner, 1992; Leishman \& Mason, 2003). In areas where first-hand experience is rare, as is the case for the publics' knowledge of crime and policing, television can fill a knowledge gap (Oliver $\&$ Armstrong, 1998). The powerful influence of television is further strengthened when viewers believe the television portrayal to be accurate, and it has been established that Police Ten 7 is promoted as providing an insight into "real" policing. The image of policing promoted by the show and, arguably, by police, is one in which police are unrealistically successful and engaged in action packed crime-fighting far more than the known realities suggest. It depicts white individuals as far more likely to be police than offenders and non-white individuals are much more likely to be depicted as offenders than police. Furthermore, offenders are commonly depicted, particularly in the "wanted" section, as individually pathological, violent, dangerous, inhuman and decidedly "other".

The findings of this research are based on a study of one season of Police Ten 7 and while similarly focused international studies support many of the conclusions reached herein, the ways audiences understand the content presented in Police Ten 7 cannot be predicted. The aim of this research was to explore the portrayal of police and crime on Police Ten 7 and this aim has been accomplished.

Reality TV continues to flourish in New Zealand and remains extremely popular with viewers. The collaboration between the producers of Police Ten 7 and the New Zealand Police remain strong ${ }^{41}$. The potential implications of these depictions for police, victims 
and offenders are significant, and given the continued popularity of reality TV in New Zealand it is suggested that further study is needed to create a deeper and more complex understanding of the underlying messages, meanings, intentions and narratives which are presented in this highly visible, public, accessible and popular representation of New Zealand policing. In particular, it would be prudent to explore the ways police perceive Police Ten 7 and participants, both police and offenders, could provide some timely and significant insight into how their involvement with the show corresponds to their experience of policing and being policed.

Without the claim of reality these representations may be merely interesting. However the potential consequences in terms of the affirmation of negative stereotypes, misconceptions regarding the work of police and the construction of certain accepted forms of victimisation combine to suggest that when it comes to the responsible depiction of contemporary policing, crime and punishment, reality TV tells viewers more about production decisions and the vision of policing that the police want to project than about the work most police actually do and the actual distribution of crime and victimisation in New Zealand. 


\section{References}

Adams, G. (2011) September $2^{\text {nd }}$, Steven Seagal killed my puppy, says man seized in reality TV police raid, The Independent, retrieved October $12^{\text {th }} 2011$ from www.independent.co.uk/news/world/americas/steven-seagal-killed-my-puppy-says-manseized-in-reality-tv-police-raid-2347845.html

Andersen, R. (1994) Reality TV and criminal justice, The Humanist 8:8-13.

Arcuri, A. (1977) You Can't Take Fingerprints off Water: Police Officers' views towards “Cop” Television Shows, Human Relations: 1977; 30, 237-247.

Associated Press (2009) August $12^{\text {th }}$ Cops: Reality TV show arranged murders, retrieved August $3^{\text {rd }}$, The Palm Beach Post, from http://www.pbpulse.com/tv/reality$\underline{\text { tv/2009/08/12/reality-tv-show-allegedly-arranged-murders-to-boost-ratings/ }}$

Australian Bureau of Statistics (2011) Australian and New Zealand Standard Offence Classification, retrieved August $31^{\text {st }} 2011$, from http://www.abs.gov.au/ausstats/abs@.nsf/mf/1234.0

Babbie, E. (2007) The Practice of Social Research, $11^{\text {th }}$ edition, CA: Thompson Wadsworth.

Bazley, M. (2007) The Report of the Commission of Inquiry into Police Conduct. Wellington: Commission of Inquiry into Police Conduct.

Berg, B (2004) An Introduction to Content Analysis, Qualitative research methods for the social sciences, $5^{\text {th }}$ edition, New York: Pearson.

Bottomley, K. \& Pease, K. (1986) Crime and Punishment: Interpreting the Data. Milton Keynes: Open University Press

Bradley, T., Rowe, M., \& Sedgwick, C. (2010) Not in my backyard: Crime in the neighbourhood. The Howard Journal, 50 (1), 34-51 
Bradley, T., \& Walters, R. (2011) Introduction to Criminological Thought, $2^{\text {nd }}$ ed.: Auckland: Pearson.

Breslin, J. (1990) America's Most “wanted”: How Television Catches Crooks. New York: HarperCollins Publishers

Britto, S., Hughes, T., Saltzman, K. \& Stroh, C. (2007) Does "Special” mean young, white, and female? Deconstructing the meaning of "special" in Law \& Order: Special Victims Unit, Journal of Criminal Justice and Popular Culture, 14 (1)

Broadcasting Standards Authority (2011) The Real Deal: Experiences of and Attitudes Towards Reality TV. Mobius Research and Strategy, retrieved October $27^{\text {th }} 2011$ from http://www.bsa.govt.nz/assets/Research/The-Real-Deal.pdf

Broun, B. (2010) July $16^{\text {th }}$, More Women Joining Police, Stuff.co.nz, retrieved August $19^{\text {th }}$ 2011 from http://www.stuff.co.nz/national/3924264/More-women-joining-the-police

Carrabine, E. (2008) Crime, Culture and the Media, Polity: University of Michigan.

Carmody, D.C. (1998) Mixed Messages: Images of Domestic Violence on Reality Television. In G.Cavender and M.Fishman (eds). Entertaining Crime: Television Reality Programs. New York: Aldine de Gruyter.

Cavender, G. (1998) In the Shadows Of Shadows: Television Reality Crime Programming. In G. Cavender and M.Fishman (eds). Entertaining Crime: Television Reality Programs. New York: Aldine de Gruyter.

Cavender, G. \& Bond-Maupin, L. (1993) Fear and Loathing on Reality Television: An analysis of America's Most "wanted” and Unsolved Mysteries, Sociological Inquiry, 63 305-317.

Cavender, G., Bond-Maupin, L. \& Jurik, N. (1999) The Construction of Gender in Reality Crime TV, Gender and Society, Vol. 13, No.5 (Oct., 1999), 643-663 
Cavender, G. \& Deutsch, S. (2007) CSI and Moral Authority: The Police and Science, Crime, Media, Culture, 2007; 3; 67-81.

Cavender, G. \& Fishman, M. (1998) Television Reality Crime Programs: Context and History in G. Cavender and M.Fishman (eds) in Entertaining Crime: Television Reality Programs, New York: Aldine De Gruyter.

Chan, J. (1999) Police Culture, in A Culture of Corruption: Changing an Australian Police Service, D.Dixon (ed) NSW: Hawkins Press.

Chermak, S., Weiss, A., (2006) Community Policing in the News Media, Police Quarterly June 2006 vol. 9 no. 2 135-160.

Chibnall, S. (1977) Law-And-order News, London: Tavistock.

Chong Ho Shon, P. \& Arrigo, B. (2006) Reality Based Television and Police-Citizen Encounters: The Intertextual Construction and Situated Meaning of Mental Illness as Punishment, Punishment Society, 2006:859-85.

Corner, J. (2000) Documentary in a Post-Documentary Culture? A Note on Forms and their Functions, retrieved June $12^{\text {th }} 2011$ from http://www.lboro.ac.uk/research/changing.media/John\%20Corner\%20paper.htm

Crotty, M. (1998) The Foundations of Social Research: Meanings and Perspective in the Research Process. London: Sage.

Cunneen, C. \& White, R. (2007) Juvenile Justice: Youth and Crime in Australia, $2^{\text {nd }}$ ed. Melbourne: Oxford University Press

Davis, H. \& Bourhill, M. (1997) Crisis: The Demonization of Children and Young People in P. Scraton (ed) Childhood in Crisis, London: UCL Press. 
Derosia, M. (2002) The Court of Last Resort: Making Race, Crime and Nation on America's Most "wanted” in J. Friedman (ed) Reality Squared: Televisual Discourse of the Real, New Brunswick, NJ: Rutgers University Press.

Dixon, T.L., \& Linz, D. (2000) Overrepresentation and underrepresentation of African Americans and Latinos as lawbreakers on television news. Journal of Communication, 50(2), 131-154.

Dobash, R.E., Schlesinger, P., Dobash, R. \& Weaver, C. (1998) "Crimewatch UK": Women's interpretations of televised violence in G.Cavender and M.Fishman, (eds) Entertaining Crime: Television Reality Programs, New York: Aldine De Gruyter.

Dominick, J. (1978) Crime and Law Enforcement in the Mass Media, in C.Winick (ed)Deviance and Mass Media, 105-128, Beverly Hills, Cal: Sage.

Downing, J. Mohammadi, A. \& Mohammadi, A. (1990) Questioning the Media: A Critical Introduction. London: Sage Publications.

Downing, J., Mohammadi, A., \& Mohammadi, A. (1995) Questioning the Media: A Critical Introduction. $\left(2^{\text {nd }}\right.$ ed). London: Sage Publications

Doyle, A. (1998) "Cops": Television Policing as Policing Reality, in G. Cavender \& M. Fishman (eds.) Entertaining Crime: Television reality programs, New York: Aldine De Gruyter.

Doyle, A. (2003) Arresting Images: Crime and Policing in front of the Television Camera, Toronto: University of Toronto Press Incorporated.

Entman, R. (1992) Blacks in the news: Television, Modern Racism, and Cultural Change. Journalism Quarterly, 69, 341-361.

Equality and Human Rights Commission (2010) How Fair is Britain? The First Triennial Executive Summary, retrieved 6/7/2012 from http://www.equalityhumanrights.com/uploaded_files/triennial_review/tr_execsumm.pdf 
Entman, R. (2006) Young Men of Color in the Media: Images and Impacts, Joint Center for Political and Economic Studies, Health Policy Institute

Eschholz, S.,Blackwell, B.S., Gertz, M. \& Chricos, T. (2002) Race and Attitudes toward the Police: Assessing the Effects of Watching "reality" Police Programs. Journal of Criminal Justice, 20, 327-341.

Fawkes, B. (2009) February $21^{\text {st }}$, Police Banned From Brothel Raids, Stuff.co.nz, retrieved July $18^{\text {th }} 2011$ from http://www.stuff.co.nz/national/1752325/Police-banned-from-brothel$\underline{\text { raids }}$

Fetveit, A. (1999) Reality TV in the Digital Era: A Paradox in Visual Culture?

Media, Culture and Society, Vol. 21:787-804, London, Thousand Oaks and New Delhi: Sage.

Finley, L. (2004) Using Content Analysis Projects in the Introduction to Criminal Justice Classroom, Teaching Sociology, Vol 32, No. 1 (Jan 2004) pp 129-137, American Sociological Association.

Friedman, J. (2002) Reality Squared Televisual Discourse on the Real, New Brunswick, NJ: Rutgers University Press.

Gerbner, G. \& Gross, L. (1976) Living with television: The violence profile, Journal of Communication 26, 173-199.

Gerbner, G., Gross, L., Morgan, M. \& Signoriello, N. (1980) The mainstreaming of America: Violence profile no.11. Journal of Communication, 30 (3), 10-29

Gerbner, G., Gross, L., \& Morgan, M. (2002). Growing up with television: Cultivation processes. In J. Bryant \& D. Zillmann (eds) Media effects: Advances in theory and research (2 ${ }^{\text {nd }}$ ed., 43-67) Mahwah, NJ: Erlbaum.

Gillespie, M. \& McLaughlin, E. (2003) Media and the Shaping of Public Knowledge and Attitudes Towards Crime and Punishment, Rethinking Crime and Punishment, London: Esmee Fairbairn Foundation. 
Gilliam, F.D. \& Iyengar, S. (2000) Prime Suspects: The Influence of Local Television News on the Viewing Public. American Journal of Political Science, 44, 560-573.

Glynn, K., Czarnecki, J., Bishop, C., Donovan, M. (producers), Moore, M. (director), (2002), Bowling For Columbine (film), USA: United Broadcasting.

Greer, C. (2005) News Media, Victims and Crime, in P. Davies, P. Francis and C.Greer (eds) Victims, Crime and Society, (20-45). London: Sage

Greer, G. (2001) Watch with Big Brother, review, The Observer $24^{\text {th }}$ June 1-2 retrieved May $26^{\text {th }} 2011$ from http://www.guardian.co.uk/theobserver/2001/jun/24/features.review7

Gunasekera, H., Chapman, S. \& Campbell, S. (2005) Sex and drugs in popular movies: an analysis of the top 200 films. Journal of the Royal Society of Medicine, 98, 464-470.

Haghighi, B. \& Sorensen, J. (1996) America’s fear of crime. In T. J. Flanagan \& D.R. Longmire (eds), Americans view crime and justice: A national public opinion survey (1630). Thousand Oaks, CA: Sage.

Hall, S. (1973) The Determination of News Photographs, in S.Cohen \& J.Young (eds) The Manufacture of News, 226-243, London: Constable.

Hall, S., Critcher, C., Jefferson, T., Clarke, J.\& Roberts, B (1978) Policing the Crisis London: Macmillan.

Hanke, P.J. (2005) Book Review: Good Cop/Bad Cop: Mass Media and the Cycle of Police Reform, Criminal Justice Review, 2005:20, 123-125.

Hirschi, T. \& Gottredson, M. (1983) Age and Explanation of Crime. American Journal of Sociology, 89, 552-584

Holdaway, S.(1985) Inside the British Police: A Force at Work. Oxford: Basil Blackwell 
Holsti, O.R (1968) Content Analysis. In G.Lindzey \& E.Aaronson (eds), The Handbook of Social Psychology. Reading, MA: Addison-Wesley

Home Office, (2001) Diary of a Police Officer, Police Research Series Paper 149 Lawrence Singer (Ed) Crown Copyright

Hurley, B. (2011) Guts to lead relentless pursuit, The Herald on Sunday, March 202011 page 47 of Sunday Insight.

Jermyn, D. (2007) Crime Watching: Investigating Real Crime TV, New York: Palgrave Macmillan

Jewkes, Y. (2004) Media and Crime, London: Sage

Jordan, J. (2004) The Word of a Woman, Police, Rape and Belief, Palgrave: Macmillan

Kappeler, V.E., Blumberg, M. \& Potter, G.W. (1996) The Mythology of Crime and Criminal Justice, $\left(2^{\text {nd }}\right.$ ed) Prospect Heights, Il: Waveland Press Inc.

Kappeler, V.E., Potter, G.\& Green, E. (2011) Police Ethics, Legal proselytism, and the Social Order: Paving the Path to Misconduct in M. Braswell, B.R. McCarthy, B.J. McCarthy, B.J ( $7^{\text {th }}$ ed) Justice, Crime and Ethics, Andersen Publishing: Burlington.

Keith, L. (2009) November $25^{\text {th }}$, Lawyer appeals drink drive conviction, Taranaki Daily News, Retrieved March $3^{\text {rd }} 2011$ from http://www.stuff.co.nz/national/crime/3094299/Lawyer-appeals-drink-drive-conviction

Knowsley, J. (2011) April $3^{\text {rd }}$, Surf Wars, how real is reality TV? The New Zealand Herald, retrieved May $20^{\text {th }} 2011$ from www.nzherald.co.nz/nz/news/article.cfm?c_id=18objectid=10716848

Kooistra, P.G, Mahoney, J.S \& Westervelt, S.D. (1998) The World of Crime According to 'Cops' In G.Cavender \& M.Fishman (eds) Entertaining Crime: Television Reality Programs (141-158) New York: Aldine De Gruyter. 
Kreft, B. (2011) TV ratings: $1^{\text {st }}$ August 2011, Throng.co.nz, retrieved August $16^{\text {th }} 2011$ from www.throng.co.nz/ratings/tv-ratings-1-august-2011

Langley, J. (2001) "Interview with John Langley, Executive Producer and Creator of Cops" retrieved April $13^{\text {th }} 2011$, available from http://www.tvcops.com/pages/exclusive_langley_crime.html

Leishman, F. \& Mason, P. (2003) Policing and the Media; Facts, Fictions and Factions, Oregon: Willan Publishing Ltd.

Levenson, J. (2001) 'Inside information: Prisons and the Media' Criminal Justice Matters, no. 43 , Spring, 14-15.

Lockwood, S. (2009) A Shift in the Police Force, Sunday Star Times, retrieved November $17^{\text {th }} 2011$ from http://www.stuff.co.nz/sunday-star-times/features/179055/A-shift-in-thepolice-force

Lombard, M. (2010) Practical Resources for assessing and reporting intercoder reliability in content analysis research projects. Retrieved September $5^{\text {th }} 2010$ from http://astro.temple.edu/ lombard/reliability/

Lovell, J.S. (2003). Good cop/bad cop: Mass media and the cycle of police reform. New York: WillowTree Press.

McGovern, A. (2009) The Best Police Force Money Can Buy: The Rise of Police PR, Paper presented at the Australian and New Zealand critical criminology conference, December 2009, Monash University, Melbourne.

McGovern, A. \& Lee, M. (2010) Cop[ying] it Sweet: Police Media Units and the Making of News (2010) 43(3) Australian and New Zealand Journal of Criminology 444-464.

McGregor, J. (1993) Crime News As Prime News in New Zealand's Metropolitan Newspapers. Auckland: Legal Research Foundation. 
McGregor, J. \& Comrie, M. (1995) Balance and Fairness in Broadcasting News (19851994). Auckland: New Zealand Law Society.

McGregor, J. \& Comrie, M. (2002) 'Crime News: The Cutting Edge' in J. McGregor \& M.Comrie (eds) What's News?: Reclaiming Journalism In New Zealand, Palmerston North: Dunpore Press.

MacDonald, J. (2008) Who Talks, What They Talk About and How Much They Say: A study of Bulletin Structure and Source Use in New Zealand Free-to-air Television News Programmes, retrieved October $27^{\text {th }} 2011$ from http://mro.massey.ac.nz/bitstream/handle/10179/922/02whole.pdf?sequence=1

Macnamara, J. (2006) Media Content Analysis, Uses, Benefits and Best Practice Methodology: A Research Paper, AU: Media Monitors.

Marsh, I. \& Melville, G. (2009) Crime, Justice and the Media, New York: Routledge.

Mason, P. (2002). The Thin Blurred Line: Reality Television and Policing. The British Criminology Conference. July, 2002.

Mason, P. (2003) Criminal Visions: Media Representations of Crime and Justice, Portland: Willan Publishing.

Mastro, D. \& Robinson, A. (2000) Cops and Crooks, Images of Minorities on Primetime Television, Journal of Criminal Justice 28385-396.

Mawby, R.C (2001) Promoting the Police? The Rise of Police Image Work, Criminal Justice Matters 43:44-45.

Mawby, R.C. (2003) Completing the 'half-formed picture'? Media Images of Policing. In P. Mason (ed.) Criminal visions: Media representations of Crime and Justice (214-237). Devon, UK:Willan Publishing.

Maxwell, G. \& Smith, C. (1998) Police Perceptions of Maori: A Report to the New Zealand Police and Te Puni Kokiri. Wellington: Victoria Link Ltd. 
Mayhew \& Reilly (2007) The New Zealand Crime and Safety Survey: 2006. Wellington: Ministry of Justice.

Ministry of Justice (2000) Maori Responsiveness in Police and Justice Sector, retrieved September $19^{\text {th }} 2011$ from http://www.courts.govt.nz/publications/publicationsarchived/2000/report-on-combating-preventing-maori-crime-hei-whakarurutanga-mo-teao/maori-responsiveness-in-police-and-justice-sector

Ministry of Justice (2010) New Zealand Crime and Safety Survey: 2009, Main Findings Report Crown Copyright.

Monk-Turner, E., Martinez, H., Holbrook, J. \& Harvey, N. (2007) Are reality TV crime shows continuing to perpetuate crime myths? Internet Journal of Criminology, retrieved July $29^{\text {th }} 2010$ from www.internetjournalofcriminology.com/MonkTurner\%20et\%20al\%20Reality\%20TV\%Crime\%20Shows.pdf.

Morgan, G. (1983) Social Science and Accounting Research, Accounting, Organizations and Society, 8: 385-388.

Mossman, S.E., Mayhew, P.M., Rowe, M.A, \& Jordan, J. (2008) Literature Reviews about the Barriers to Recruiting a Diverse Police Workforce, Wellington: New Zealand Police.

Mossman, E., Jordan,J., MacGibbon, L., Kingi, V., \& Moore, L. (2009) Literature Review Part 1, Responding to Sexual Violence: A review of literature on good practice, Ministry of Women's Affairs.

MSN NZ (2010) May $18^{\text {th }}$, Sleeping girl shot dead during police reality TV raid, MSN New Zealand, retrieved October $14^{\text {th }} 2011$ from http://news.ninemsn.com.au/world/1053763/sleeping-girl-shot-during-police-reality-tv-raid

Muncie, J. (2009) Youth Crime ( $3^{\text {rd }}$ Ed.) London: Sage. 
Neuendorf, K. (2002) The Content Analysis Guidebook online, an accompaniment to the Content Analysis Guidebook, retrieved February $2^{\text {nd }} 2010$ from http://academic.csuohio.edu/kneuendorf/content/hcoding/hcindex.htm

Newbold, C. Boyd-Barrett, O., \& Van Den Bulck, H. (2002). The media book. London: Arnold (Hodder Headline).

Newburn, T. \& Reiner, R. (2007) Policing, in Maguire, M., Morgan, R. and Reiner R. (Eds.) The Oxford Handbook of Criminology, $\left(4^{\text {th }}\right.$ ed), Oxford: Oxford University Press.

New Zealand Herald, (2010a) July 202010 Police officers getting older, New Zealand Herald, retrieved $29^{\text {th }}$ March 2011 from http://www.nzherald.co.nz/employment/news/article.cfm?c id=11\&objectid=10660012

New Zealand Herald (2010b) October $5^{\text {th }}$, Scott Guy Murder on Police Ten 7, New Zealand Herald, Oct 5, 2010 retrieved May 13 2011 from http://www.nzherald.co.nz/nz/news/article.cfm?c_id=1\&objectid=10678276

New Zealand Herald (2011) February $28^{\text {th }} 2011$, Reality TV show breached privacy- BSA, New Zealand Herald, retrieved $14^{\text {th }}$ April 2011 from $\underline{\text { www.nzhearald.co.nz/entertainment/news/article.cfm?c_id=1501119\&objectid=10709357 }}$

New Zealand Police, (2003) 74 cops recruited from UK destined for Auckland, New Zealand Police, June $26^{\text {th }} 2003$ retrieved June $1^{\text {st }} 2011$ from http://www.police.govt.nz/news/release/989.html

New Zealand Police (2004a) Ten One, (The New Zealand Police online magazine) August 2004 "Ten 7 series continues to catch crims" New Zealand Police. Retrieved January $13^{\text {th }}$ 2011 from www.police.govt.nz/tenone/20040820-264/feature_107.htm

New Zealand Police (2004b) Ten One (The New Zealand Police online magazine), May vol 2 2004, Praise for pleasant and positive liaison New Zealand Police, retrieved April $18^{\text {th }} 2011$ from www.police.govt.nz/tenone/20040528-261/feature hikoi.htm 
New Zealand Police (2004c) Ten One (The New Zealand Police online Magazine) May

Volume 2, 2004, New Zealand Police, retrieved August $13^{\text {th }} 2011$ from

http://www.police.govt.nz/tenone/20040528-261/

New Zealand Police (2005a) Ten One (The New Zealand Police online magazine)

November vol 1 2005, Teamwork Gets Results, New Zealand Police, retrieved October $15^{\text {th }} 2011$ available from http://www.police.govt.nz/tenone/20051028-

278/feature tenseven.htm

New Zealand Police (2005b) Strategic Plan to 2010, Wellington: New Zealand Police, retrieved May $4^{\text {th }} 2011$ available from http://www.police.govt.nz/resources/2006/strategicplan-to-2010/index.htmlnewzealand.govt.nz

New Zealand Police (2006a) Ninety-Six UK officers to join the New Zealand police, New Zealand Police, June $22^{\text {nd }} 2006$ retrieved June $1^{\text {st }} 2011$ from http://www.police.govt.nz/news/release/2472.html

New Zealand Police (2006b) New Zealand Police Annual Report for the year ended $30^{\text {th }}$ June 2006, Wellington: New Zealand Police, retrieved June $6^{\text {th }} 2011$ from www.police.govt.nz/resources/2006/annual-report/police-annual-report-2006.html

New Zealand Police (2010a) New Zealand Police Annual Report for the year ended $30^{\text {th }}$ June 2010, Wellington: New Zealand Police retrieved April 12 2011 from www.police.govt.nz/annual-report-2010

New Zealand Police (2010b) Monthly HR scorecard December (unpublished) Human Resources Information Team, Wellington: New Zealand Police.

New Zealand Police, (2011a) Proactive team gets results, retrieved August $13^{\text {th }} 2011$ from www.police.govt.nz/featured/proactive-team-gets-results 
New Zealand Police (2011b) Ten One (The New Zealand Police Online Magazine) July 2011, Real Events Inspire Recruit Drive, New Zealand Police, retrieved September $9^{\text {th }}$ 2011 from www.tenone.police.govt.nz/tenone/July11National6.htm

New Zealand Police (2011c) Police Urge Wellingtonians to watch Police Ten 7 tomorrow night, retrieved July $12^{\text {th }} 2011$ from www.police.govt.nz/news/release/28497.html

New Zealand Police (2011d) Citizens'Satisfaction Survey 2011 retrieved 12/10/2011 from http://www.police.govt.nz/citizens-satisfaction-survey-2011

North Shore Times (2007) September $9^{\text {th }}$, Real CSI lacks TV Glamour, Stuff.co.nz, retrieved $12^{\text {th }}$ December 2010 from www.stuff.co.nz/auckland/local-news/north-shoretimes/48506/Real-CSI-lacks-TV-glamour

NZPA (2010) Cops getting older, young recruits required, TVNZ August 172010 retrieved $29^{\text {th }}$ March from http://tvnz.co.nz/national-news/cops-getting-older-young-recruitsrequired-3708115

NZPA (2011) February 20 , Police pull “cougar" advertisement, retrieved March $29^{\text {th }} 2011$ from http://www.stuff.co.nz/national/4644836/Police-pull-cougar-advertisement

NZTBC (2009) Frequently Asked Questions, New Zealand Television Broadcaster's Council, retrieved October $14^{\text {th }} 2009$, from http://www.nztbc.co.nz/index.php

Oliver, M. B. (1994) Portrayals of Crime, Race and Aggression in 'Reality Based' Police Shows: A Content Analysis Journal of Broadcasting and Electronic Media, 38, 179-192.

Oliver, M.B. (2003) African American Men as "Criminal and Dangerous": Implications of Media Portrayals of Crime on the "Criminalization" of African American Men, Journal of African American Studies, 2003, 7(2):3-18

Oliver, M.B. \& Armstrong, G.B (1995) Predictors of Viewing and Enjoyment of RealityBased and Fictional Crime Shows, Journalism of Mass Communication Quarterly, 72, 559-570. 
Oliver, M. B. \& Armstrong, G.B. (1998) The Color of Crime. Perceptions of Caucasians and African American's Involvement in Crime in G.Cavender \& M. Fishman (eds) Entertaining Crime: Television reality programs (p 95-116) New York: Aldine De Gruyter.

Oliver, M.B. \& Fonash, D. (2002) Race and Crime in the News: Whites' Identification and Misidentification of Violent and Nonviolent Criminal Suspects. Media Psychology, 4, $137-$ 156.

Palmer, G. (1998) Police Shows on British Television, New Police Blues, from Jump Cut: A Review of Contemporary Media, no 42, December 1998, 12-18, retrieved September $10^{\text {th }}$ 2011, from http://www.ejumpcut.org/archive/onlinessays/JC42folder/UKpoliceShows.html

Paulin, J., Searle,W.,\& Knaggs, P. (2003) Attitudes to Crime and Punishment: A New Zealand Study. Wellington: Ministry of Justice.

Perlmutter, D. (2000) Policing the Media, Thousand Oaks, CA: Sage.

Potter, J.W. (1986) Perceived reality and the Cultivation Hypothesis, Journal of Broadcasting and Electronic Media, 30, issue 2, 159-174.

Pratt, J. (2007) Penal Populism. Oxon: Routledge.

Prosise, T. \& Johnson, A. (2004) Law Enforcement and Crime on Cops and World's Wildest Police Videos: Anecdotal Form and the Justification of Racial Profiling, Western Journal of Communication 68(1) Winter 2004 72-91.

Reiman, J. (1990) The Rich Get Richer and the Poor Get Prison: Ideology, Class and Criminal Justice, Boston: Allyn and Bacon.

Reiner, R. (1992) Policing A Postmodern Society, The Modern Law Review, Vol 55, Issue 6, November 1992 p 761-781.

Reiner, R. (1997) Media Made Criminality, The Representation of Crime in the Mass Media, in R.Osborne \& D. Kidd-Hewitt (eds) Crime and The Media: The Post-modern Spectacle, London: Pluto Press. 
Reiner, R. (2000) The Politics of the Police, $\left(3^{\text {rd }}\right.$ ed) New York: Oxford University Press

Reiner, R. (2007) Media Made Criminality, The Representation of Crime in the Mass Media, in M.Maguire, R. Morgan, R. Reiner (eds) The Oxford Handbook of Criminology, $\left(4^{\text {th }}\right.$ ed) New York: Oxford University Press.

Robinson, M. (2000) The Construction and Reinforcement of Myths of Race and Crime, Journal of Contemporary Criminal Justice, 16, 133-156.

Schlesinger, P., \& Tumber, H. (1994) Reporting Crime: The Media Politics of Criminal Justice, New York: Clarendon Press.

Screentime (2011) Our Programmes, retrieved May 12 2011 from www.screentime.co.nz/index.php/page/6/Our+Programmes

Seagal, D. (1993) Tales from the Cutting Room Floor, Harper's Magazine, Nov 1993, retrieved February $28^{\text {th }} 2011$ from www.d.umn.edu/ jmaahs/Crime\%20and\%20Media/pdf\%20files/tales_cutting_foom_floor Harpers.pdf.

Sharples, P. (2011) October $10^{\text {th }}$, Dr. Pita Sharples: Tackle prejudice in justice system, New Zealand Herald, retrieved October 192011 from http://www.nzherald.co.nz/maori/news/article.cfm?c id=252\&objectid=10757807

Shoemaker, P.J, Reese, S. (1996) Mediating the Message: Theories of influences on mass media content $\left(2^{\text {nd }}\right.$ ed.) New York: Longman.

Signorielli, N. (1990) Television's mean and dangerous world: A continuation of the cultural indicators perspective. In N. Signorielli \& M. Morgan (eds), Cultivation Analysis: New Directions in Media Effects Research (85-106). Newbury Park, CA: Sage

Soboleva, N \& Chong, J (2006) Conviction and Sentencing Report for Ministry of Justice retrieved 1/4/2011 from http://www.courts.govt.nz/publications/globalpublications/c/conviction-and-sentencing-of-offenders-in-new-zealand-1996-to2005/documents/report.pdf 
Soulliere, D. (2001) Prime-time Criminal Justice: If all we knew was what we saw on Television, Dissertation submitted to the Graduate School of Wayne State University, Detroit: Michigan.

Soulliere, D. (2003) Prime-Time Murder: Presentations of Murder on Popular Television Justice Programs, Journal of Criminal Justice and Popular Culture, 10 (1) (2003) 12-38.

Soulliere, D. (2004) Policing on Prime Time: A Comparison of Television and Real-World Policing, American Journal of Criminal Justice: AJCJ; Spring 2004; 28. 2; Proquest Criminal Justice, 215.

Sparks, R. (1995) Television and the Drama of crime: Moral Tales and the Place of Crime in Public Life. Philadelphia, PA: Open University Press

Statistics New Zealand (2006) Census of Population and Dwellings, Statistics New Zealand, Wellington, retrieved February $17^{\text {th }} 2011$ from www.stats.govt.nz/Census/2006CensusHomePage.aspx.

Statistics New Zealand (2009) National Annual Recorded Offences for the Latest Calendar Year, retrieved May $17^{\text {th }} 2011$ from wdmzpub01.stats.govt.nz/wds/TableViewer/tableview.aspx

Statistics New Zealand (2010a) National Annual Apprehensions for the Latest Calendar Years $(A S O C)$ retrieved May $18^{\text {th }} 2011$ from www.stats.govt.nz/tools_and_services/TableBuilder/recorded-crime-statistics/ASOCapprehension-calendar-year-statistics.aspx\#national

Statistics New Zealand (2010b) National Annual Recorded Offences for the Latest Calendar Years, retrieved May $20^{\text {th }} 2011$ from www.stats.govt.nz/tools_and_services/TableBuilder/recorded-crime-statistics/ASOCapprehension-calendar-year-statistics.aspx 
Statistics New Zealand (2010c) Criminal Conviction and Sentencing Statistics: 2010, retrieved October $20^{\text {th }} 2011$ from Www.stats.govt.nz/tools_and_services/tools/tablebuilder/conviction-and-sentencingtables.aspx

Statistics New Zealand (2011) Criminal Conviction and Sentencing Statistics: 2010, retrieved August 24 2011 from www.stats.govt.nz/tools_and_services/tools/TableBuilder/conviction-and-sentencingtables/asoc.aspx

Strenger, C. (2011) The Fear of Insignificance: Searching for Meaning in the Twenty-First Century, Basingstroke: Palgrave Macmillan.

Stuff (2008) March 11 ${ }^{\text {th }}$, Delamere sues over brothel raid show Stuff.co.nz, retrieved August $8^{\text {th }} 2011$ from http://www.stuff.co.nz/national/309115/Delamere-sues-over-brothelraid-show

Surrette, R. (1992) Media, Crime and Criminal Justice: Images and Realities. Pacific Grove, CA: Brooks/Cole Publishing Company.

Te Whaiti, P. \& Roguski, C. (1998) Maori Perceptions of Police. Wellington: He Parekereke, Victoria Link Ltd.

TV Guide (2010), Best on the Box, 2010 retrieved January $2^{\text {nd }}, 2011$ from Screentime http://www.screentime.co.nz/index.php/page/show/pi_showid/8

TVNZ (2008) October $14^{\text {th }}$, The issues that influence voters, TVNZ, retrieved September $15^{\text {th }} 2010$ available from http://tvnz.co.nz/content/2200873/484445/article.html

TVNZ (2011a) March $16^{\text {th }}$, Paul Henry tops in best of the box awards, TVNZ, retrieved April 2 from http://tvnz.co.nz/entertainment-news/paul-henry-top-in-best-box-awards$\underline{4067349}$

TVNZ (2011b) About Police Ten 7, TVNZ, retrieved January 22 2011 from tvnz.co.nz/police-ten-7/4075575 
Waddington, P. J. (1999) Police (canteen) sub-culture: an appreciation, British Journal of Criminology vol 39, no 2, 1999, 287-309.

Zoglin, R. (1992) April $6^{\text {th }}$, The Cops and the Cameras, Time 62 retrieved March $7^{\text {th }} 2011$ from

http://www.time.com/time/magazine/article/0,9171,975238-2,00.html 
Appendix 1

\section{Codebook \\ The representation of policing on Police Ten 7}

Unit of Analysis: Each self-contained scene following police in their duties. Usually there are three such scenarios per episode, usually concluded by an ad break. The "wanted" section follows the three main stories. For each "crime story" use a separate coding sheet.

\section{Contextual information: location, timing, response type}

Variable 1: Setting for this policing scenario: Please indicate where this policing scenario takes place

0 In a public place (for example in the street)

1 in a private home

2 Other private space (for example inside a shopping mall, in a pub)

3 in the police station

4 in a workplace

5 other (please explain)

Variable 2: Time of policing scenario: Please indicate the time this policing scenario takes place

0 Day

1 Night

Variable 3: Response type: Reactive or proactive

Reactive: Incidents reported to police through a police report of through a call to 111 Proactive: Incidents discovered through routine patrol, during the course of another investigation or through a police 'sting' operation (Soulliere, 2004:224).

0 - Self-initiated response: Proactive

1- Dispatched to incident via comms: Reactive

\section{Demographic characteristics}

Variables 4-6:4 relate to the observed demographic characteristics of the police, offenders, victims and witnesses involved in the depicted scenario. Ethnicity and age are accepted to be subjective measures and are can only therefore be achieved to the best of your ability.

Definition of police officer(s) for coding: The police officer who is driving the car a) and the police officer who is speaking to the camera at the beginning of the scene are the two primary police officers. If a police officer comes into physical contact with the offender they will be coded. Other officers who are at the scene and do not speak to the camera or offender and do not have physical contact with the offender will not be coded.

Definition of offender(s): The offender is/are the individual(s) who is/are the primary focus of police attention. If this concerns a traffic offence then this refers to the person driving the car. The primary offender(s) is/are the person/people who receive(s) the majority of police attention and who is/are the focus from the beginning of the scenario or who receives police attention as a result of their behaviour or actions during the police encounter.

Definition of witness: The witness is the individual who police identify as a witness, who gives the police a statement. If there are multiple witnesses in a group please code the 
primary witness who does the majority of the talking. If there are many individual witnesses please code each of these witnesses individually.

Definition of victim: The individual who is identified by police as the victim. If there are more than one victim please code only the primary victim. The primary victim is the one who police address questions to or who is highlighted by the narrator as the victim.

Definition of victim/witness combined: Occasionally the victim will also be a witness and should be coded in this category if they provide a statement to the police or are interviewed on camera

Due to the nature of the show, featuring many instances of individuals with pixilated faces in order to hide their identity and the subjective nature of ethnicity based on outside estimates it is accepted that in some cases it will be difficult to select an age or ethnicity for a particular individual. In this case please use contextual features such as dress, accents; speaking style and activity represented in order to aide you in making your choice. If you are unable to choose between two potential overlapping categories, for example in some cases offenders in particular may be described as a "Maori or Pacific Islander" in this case please select 6) unsure i) Maori or Pacific Islander. If any of these individuals for coding are not featured, for example only one offender is represented strike a line through the variables relating to this individual.

\section{4:1 Police officer 1 Gender}

0 - male

1- female

2- unable to determine

V 4:2 Police officer 1 Ethnicity

0- NZ Maori

1- NZ European

2- Pacific Islander

3- Asian

4- Indian

5- Other

i) $\quad$ British/UK

ii) Eastern European

iii) (please state)

6- Unsure

i) Maori or pacific islander

ii) Impossible to determine

V4:3 Police officer 1 Age

1- $17-25$

$2 \quad 26-40$

$3 \quad 41-55$

456 and over

5 Unknown

V 4:4 Police officer 2 Gender 
0 - male

2- female

3- unable to determine

V 4:5 Police Officer 2 Ethnicity

0- NZ Maori

1- NZ European

2- Pacific Islander

3- Asian

4- Indian

5- Other

iv) British/UK

v) Eastern European

vi) (please state)

6- Unsure

iii) Maori or pacific islander

iv) Impossible to determine

\section{4:6 Police officer 2 Age}

$1-17-25$

$2-26-40$

3- 41-55

4- 56 and over

5- Unknown

\section{4:7 Police officer 3 Gender}

0 - male

4- female

5- unable to determine

\section{4.8 Police Officer 3 Ethnicity}

7- NZ Maori

8- NZ European

9- Pacific Islander

10- Asian

11- Indian

12- Other

vii) British/UK

viii) Eastern European

ix) (please state)

13- Unsure

v) Maori or pacific islander

vi) Impossible to determine

V 4:9 Police officer 3 Age
6- 17-25
7- 26-40
8- 41-55
9- 56 and over
10- Unknown 
V 5:0 Offender 1 Gender

0 - male

1- female

2- unable to determine

\section{5:1 Offender 1 Ethnicity}

0- NZ Maori

1- NZ European

2- Pacific Islander

3- Asian

4- Indian

5- Other

x) British/UK

xi) Eastern European

xii) (please state)

6- Unsure

vii) Maori or pacific islander

viii) Impossible to determine

\section{5:2 Offender 1 Age}

$0-0-16$

$1-17-25$

2- 26-40

$3-41-55$

7- 56 and over

8- Unknown

\section{5:3 Offender 2 Gender}

0 - male

1- female

2- unable to determine

\section{5:4 Offender 2 Ethnicity}

0- NZ Maori

1- NZ European

2- Pacific Islander

3- Asian

4- Indian

5- Other

xiii) British/UK

xiv) Eastern European

$\mathrm{xv)}$ (please state)

6- Unsure

1- Maori or pacific islander

2- Impossible to determine

\section{5:5 Offender 2 Age}

0 - Under 16

1- 17-25 
$2 \quad 26-40$

$3 \quad 41-55$

456 and over

5 Unknown

\section{5:6 Victim Gender}

0 - male

1- female

2- unable to determine

\section{5:7 Victim Ethnicity}

0- NZ Maori

1- NZ European

2- Pacific Islander

3- Asian

4- Indian

5- Other

xvi) British/UK

$\mathrm{xvii)}$ Eastern European

$\mathrm{x}$ viii) (please state)

6- Unsure

3- Maori or pacific islander

4- Impossible to determine

\section{5:8 Victim Age}

0 - Under 16

1- 17-25

2- 26-40

3- 41-55

4- 56 and over

5- Unknown

\section{5:9 Witness Gender}

0 - male

1- female

2- unable to determine

\section{6.0 Witness Ethnicity}

0- NZ Maori

1- NZ European

2- Pacific Islander

3- Asian

4- Indian

5- Other

xix) British/UK

xx) Eastern European

xxi) (please state)

6- Unsure

5- Maori or pacific islander

6- Impossible to determine 
V 6.1 Witness Age

0 - Under 16

1 - 17-25

2- $26-40$

3- 41-55

4- 56 and over

5- Unknown

V 6.2 Witness/Victim Gender

0 - male

1- female

2- unable to determine

V 6:3 Witness/Victim Ethnicity

0- NZ Maori

1- NZ European

2- Pacific Islander

3- Asian

4- Indian

5- Other

xxii) British/UK

xxiii) Eastern European

xxiv) (please state)

6- Unsure

7- Maori or pacific islander

8- Impossible to determine

\section{6:4 Witness/Victim Age}

0 - Under 16

1 - 17-25

2- $26-40$

3- 41-55

4- 56 and over

5- Unknown

Variable 7: Relationship between offender and victim Please indicate whether the offender and victim are:

0- Strangers

1- Acquaintances

2- Family members

3- Spouse/wife/husband/romantic partner

4- Former spouse/wife/husband/romantic partner

5- Not stated/impossible to tell: i.e. the victim is not depicted or discussed

6- Not applicable i.e. there is no victim

Variable 8: What behaviour is being investigated? (This question asks why the police are involved? This can be either explicitly stated by police, the narrator or if not then by your observation) 
Definitions: Violence $=$ grievous assaults, group assemblies, homicide, intimidation and threats, kidnapping and abduction, minor assaults, robbery, serious assaults

Drugs and anti social= Alcohol, disorder, drugs, family offences, gaming, vagrancy offences

Sexual offences $=$ abnormal sex, immoral behaviour, sexual affronts, sexual attacks

Dishonesty $=$ Burglary, car conversion, fraud, receiving, theft

Property damage $=$ destruction of property, endangering

Property abuse $=$ animals, arms acts offences, littering, postal $/$ rail/service abuses, trespass

Administration= against justice, against national interest, births, deaths, marriages, by law breaches, immigration, justice, racial

0- Violence

1- Drugs and anti social

2- Sexual offences

3- Dishonesty

4- Property Damage

5- Property abuse

6- Administration

7- Driving/traffic offences

\section{Police action-oriented activities}

The following variables relate to actions which may be undertaken by police. Please indicate whether the following activities are depicted in this scene.

9:1) Guarding scenes or prisoners

0- No

1- Yes

9:2) marshalling or directing traffic

0- no

1- yes

9:3) Paperwork on the street

Paperwork refers to any paperwork completed on the street including both formal ticketing of offences as well as informal note taking and gathering information from witnesses, victims and offenders

0- no

1- yes

i) Taking notes from offenders

ii) Taking notes from victims

iii) Taking notes from witnesses

iv) Issuing formal paperwork such as speeding tickets. Fines, pink stickers 
9:4) Processing offenders within the police station

0- no

1- yes

if yes are they

i) Filling in victim statements

ii) Filling in offender statements

iii) Filling in witness statements

iv) Processing offenders police station intake forms

v) Completing paperwork for upcoming court cases

vi) Utilising legal paperwork, policies etc

vii) Waiting to be processed in the station

viii)Locked in cell without processing due to
a) Intoxication
b) Violence/threat of violence
c) Uncooperative behaviour
d) Other (please explain)

9:5) training new police recruits, learning how to use police equipment
0- no
1- yes

9:6) Using police equipment such as police radios

0- no

1- yes

9:7) Scene examinations

0- no

1- yes

9:8) Explaining the law

0- no

1- yes

i) To offenders

ii) To victims

iii) To witnesses

iv) To the viewer at home

9:9) Driving police cars using flashing lights and sirens

0- No

1- Yes

10:0) police hold gun/taser/weapon

0- no

1- yes

10:1) police engaged in car pursuit

0- no

1- yes

10:2) police engaged in foot pursuit

0- no 
1- yes

10:3) Briefing and debriefing

0- no

1- yes if yes are they

i) Consulting superiors/supervisors/getting advice in person or via radio contact

ii) Discussing the case with colleagues

iii) Explaining events to other agencies for example security guards, ambulance staff

iv) Having events explained to them by other agencies such as security guards, ambulance staff

v) Debriefing the audience (for example police dialogue to camera explaining the outcome or situation)

\section{Variables 11 Policing visual imagery}

Variable 11 is concerned with the repeated images which are shown on Police Ten 7. In this case imagery refers to the images shown when there is no dialogue or when images are used as an editing tool to break between scenes. Please note here any imagery which is used in this way to serve as an editing tool, to convey meaning or is repeated multiple times.

\section{Variables 12:1-12:3 Offender to police interaction}

Please indicate if the following occurs in relation to the offender acting towards the police

The following variables relate to the presence of various kinds of aggression. Please code whether the verbal and/or physical confrontations occur in the scene

Definition of verbal aggression: Swearing, yelling, making threats of violence, calling others negative names

Definition of physical confrontation: Punching, kicking, hitting, headlocks, pushing, struggling, holds, spitting, close physical intimidation:

V: 12:1- Does the offender challenge the authority of the police?

0 - No

1- Yes (please explain)

V12:2- Does verbal aggression occur in this scene from offender to police officer?

0 - No

1- Yes if yes please indicate

i) Swearing (in general but not directed at the police) for example "Fuck this shit"

ii) Yelling

iii) Making threats of violence

iv) Insulting the police

v) Swearing at police for example "Fuck you"

V12:3- Does physical confrontation occur in this scene from offender to police officer?

0 - No

1- Yes if yes please indicate

i) Punching

ii) Kicking 
iii) Hitting

iv) Headlocks

v) Pushing

vi) Struggling

vii) Holds

viii) Spitting

ix) Close physical intimidation

Variables 13:1- 13:6 Police to offender interaction and language

Please indicate if the following occurs from the police officer towards the offender

\section{13:1 What is the tone/nature of police interactions overall?}

\section{i)Police Officer 1:}

0- Informal + friendly, warm, relaxed (e.g. "Hey guys, what's going on here?")

1- Informal + using slang but not friendly or warm ("What's really going on here, bro. I know what I saw")

2- Formal + friendly/pleasant but professional/detached (e.g.: "Tell me what is wrong, I am here to help")

3- Formal + controlling/authoritative but not negative (e.g. "Settle down, stop being silly")

4- Patronising (e.g. "you're not big, you're not scary")

5- Negative and/or confrontational (e.g"shut your trap")

6- Transition: Interaction goes from to for example "interaction goes from informal and friendly to negative"

\section{ii) Police officer 2}

0- Informal + friendly, warm, relaxed (e.g. "Hey guys, what's going on here?")

1- Informal + using slang but not friendly or warm ("What's really going on here, bro. I know what I saw")

2- Formal + friendly/pleasant but professional/detached (e.g.: "Tell me what is wrong, I am here to help")

3- Formal + controlling/authoritative but not negative (e.g. "Settle down, stop being silly")

4- Patronising (e.g. "you're not big, you're not scary")

5- Negative and/or confrontational (e.g"shut your trap")

6- Transition: Interaction goes from "interaction goes from informal and friendly to negative" for example to 
(iv) making restraint threats (for example "Do what I say or I will take you to the ground")

(v) marking threats of violence (for example "Do what I say or I will punch you")

(vi) insulting the offender

Variable 13:3 Does physical confrontation from police officer to offender occur in this scene?

0 -no

1-yes if yes indicate

(i) Punching

(ii) kicking

(iii) hitting

(iv) headlocks

(v) pushing

(vi) struggling

(vii) holds

(viii) spitting

(ix) close physical intimidation

V13:4: Do police refer to the offender in a negative way?

0 No

1 Yes

If yes what words are used?

V13:5: Do police refer to the offender in a positive way?

0 No

1 Yes:

If yes, what words are used?

V13:6) Do police refer to the job as dangerous?

0 -no

1-yes if yes what words or phrases are used?

Variables 14:1- 14:3 Offender to camera crew/other bystanders interaction

Please indicate if the following occurs from the offender directed towards the camera crew The following variables relate to the presence of various kinds of aggression. Please code whether the verbal and/or physical confrontations occur in the scene

Variable 14: 1 Does verbal aggression from offender to camera crew/others in the vicinity occur in this scene?

Camera crew:

0 -no

1-yes

(i) swearing

(ii) yelling

(iii) making threats of violence 
(iv) insulting the camera crew

\section{Others in the vicinity/bystanders}

0 -no

1 -yes

(i) swearing

(ii) yelling

(iii) making threats of violence

(iv) insulting bystanders

Variable 14:2 Does physical confrontation from offender to camera crew/others in the vicinity occur in this scene?

\section{Camera crew}

0 -no

1-yes if yes indicate

(i) Punching

(ii) kicking

(iii) hitting

(iv) headlocks

(v) pushing

(vi) struggling

(vii) holds

(viii) spitting

(ix) movement towards the camera with design to intimidate (for example pushing the camera away with an arm/attempting to approach the camera in a threatening way)

(x) close physical intimidation

2- Ambiguous: it is unclear who the offender is directing aggression towards

\section{Others in the vicinity}

0 -no

1-yes if yes please indicate
(i) Punching
(ii) kicking
(iii) hitting
(iv) headlocks
(v) pushing
(vi) struggling
(vii) holds
(viii) spitting
(ix) close physical intimidation

V14:3- Does the offender has an aside to the camera?

0 -no

$1-$ yes

If yes what is the nature of the aside?

V14:4- Does the offender have an aside to others in the vicinity? For example, does the offender ask bystanders for help or speak to them?

0 - No 
1- Yes

If yes what is the nature of this aside?

\section{15: Incident resolution}

\section{Variable 15-General resolution features}

0 - Offender is not found/detected/escapes

1- Offender is cautioned but not arrested

2- Offender is told of an intention for future involvement with police but action is postponed (for example, an officer may ask the offender to come to the police station the next day)

3- offender is arrested and released

4- Offender is arrested and charged

5- Offender is given a fine

V16: Discretion: Discretion refers here to the capacity of police to choose whether to uphold the letter of the law or whether to utilise alternative options. Does this occur?

$0-$ No

1- Yes if yes please explain the situation briefly

\section{Variables 17:1- Features of the narrator: language and content}

The following variables relate to the language used by the narrator Graham Bell either as a voice over during the scene or at the end of the scene in a face to face camera interview

V17:1: Does the narrator refer to the offender (s) in a negative way?

0 No

1 Yes

If yes, what words are used?

V 17:2: Does the narrator refer to the offender(s) in a positive way?

0 No

1 Yes

If yes, what words are used?

V17:3: Does the narrator refer to the police in a negative way?

0 No

1 Yes

If yes, what words are used?

V 17:4: Does the narrator refer to the police in a positive way?

0 No

1 Yes

If yes, what words are used?

V 17:5: Does the narrator attempt to justify police aggression or police physical confrontation? 
0 No

1 yes

If yes how? What words are used?

V 17:6: Does the narrator refer to the police job as dangerous?

0 No

1 yes

If yes what words are used?

V 17:7: Does the narrator emphasise the rapid response function of police: are words which denote speed or excitement used?

O No

1 yes

If yes, what words?

V17:8: Does the narrator emphasise the community policing/social work functions of policing?

0 No

1 yes

If yes, how? What words are used?

V17:9: Does the narrator allude to the non-crime fighting aspects of policing?

0 - no

$1-$ yes if yes please explain

\section{Characteristics of the "Wanted" section of Police Ten 7}

Within Police Ten 7 there exists a "wanted" section. This consists of a reconstruction of a crime as well as a 'roll call' where wanted criminals are profiled. Please fill in the following demographic and contextual information for this section.

For each crimeloffender please indicate the following to the best of your ability:

$$
\text { 18:1-Offender } 1 \text { variables }
$$

V18:1 Offender 1: Gender: Please indicate the gender of the offender

0 Male,

1 female

3 unable to determine

V 18:2 Offender 1: Ethnicity: Please select the ethnicity which you feel best matches the offender

0- NZ Maori

1- NZ European

2- Pacific Islander

3- Asian

4- Indian

5- Other

xxv) British/UK 
xxvi) Eastern European

xxvii) (please state)

6- Unsure

i) Maori or pacific islander

ii) Impossible to determine

V 18:3 Offender 1: Age Please indicate the offender's age

$0-0-16$

$1-17-25$

2- 26-40

$0-\quad 41-55$

1- 56 and over

2- Unknown

V18:4 Offence type/crime for offender one: If there is more than one offence mentioned please choose the offence highlighted as most important or serious by police.

Violence $=$ grievous assaults, group assemblies, homicide, intimidation and threats, kidnapping and abduction, minor assaults, robbery, serious assaults

Drugs and anti social= Alcohol, disorder, drugs, family offences, gaming, vagrancy offences

Sexual offences $=$ abnormal sex, immoral behaviour, sexual affronts, sexual attacks

Dishonesty $=$ Burglary, car conversion, fraud, receiving, theft

Property damage $=$ destruction of property, endangering

Property abuse $=$ animals, arms acts offences, littering, postal/rail/service abuses, trespass Administration= against justice, against national interest, births, deaths, marriages, by law breaches, immigration, justice, racial

Driving $=$ all driving offences

0- Violence

1- Drugs and anti social

2- Sexual offences

3- Dishonesty

4- Property Damage

5- Property abuse

6- Administration

V18:5:4-15:6 Offender 1 narrator's comments

V 18:5 Does the narrator refer to offender 1 in a negative way?

0 No

1 yes

If yes what words are used?

$V$ 18:6 Does the narrator refer to offender 1 in a positive way? 0 No 
1 yes

If yes, what words are used?

V 18:7 Please indicate if offender 1 is given a motivation for offending by the narrator?

0 No

1 yes

If yes please explain briefly

18:8) Is a connection to a gang or gangs mentioned?

0 - No

1- Yes if yes which gangs:

V19:1- Offender 2 variables

V 19:1 Offender 2 Gender: Please indicate the gender of the offender

0 Male,

1 female

3 unable to determine

4- not applicable: no such individual present in this scenario

V 19:2 Offender 2 Ethnicity: Please select the ethnicity which you feel best matches the offender

0- NZ Maori

1- NZ European

2- Pacific Islander

3- Asian

4- Indian

5- Other

xxviii) British/UK

xxix) Eastern European

$\mathrm{xxx})$ (please state)

6- Unsure

iii) Maori or pacific islander

iv) Impossible to determine

V 19:3 Offender 2 Age: Please indicate the offender's age

$0-0-16$

$1-17-25$

$2-26-40$

3- $41-55$

4- 56 and over

5- Unknown

V19:4 Offender 2 Offence type/crime: If there is more than one offence mentioned please choose the offence highlighted as most important or serious by police.

Violence $=$ grievous assaults, group assemblies, homicide, intimidation and threats, kidnapping and abduction, minor assaults, robbery, serious assaults 
Drugs and anti social $=$ Alcohol, disorder, drugs, family offences, gaming, vagrancy offences

Sexual offences $=$ abnormal sex, immoral behaviour, sexual affronts, sexual attacks

Dishonesty $=$ Burglary, car conversion, fraud, receiving, theft

Property damage $=$ destruction of property, endangering

Property abuse $=$ animals, arms acts offences, littering, postal/rail/service abuses, trespass

Administration= against justice, against national interest, births, deaths, marriages, by law breaches, immigration, justice, racial

Driving $=$ all driving offences

0- Violence

1- Drugs and anti social

2- Sexual offences

3- Dishonesty

4- Property Damage

5- Property abuse

6- Administration

Offender 2 Narrator comments

V 19:5: Does the narrator refer to offender 2 in a negative way?

0 No

1 yes

If yes what words are used?

V 19:6 Does the narrator refer to offender 2 in a positive way?

0 No

1 yes

If yes, what words are used?

V 19:7: Please indicate if offender 2 is given a motivation for offending by the narrator?

0 No

1 yes

If yes please explain briefly

$\mathrm{V}$ 19:8) Is a connection to a gang or gangs mentioned?

0 - No

1- Yes if yes which gangs:

20:1- Offender 3 Variables

V 20:1 Offender 3 Gender: Please indicate the gender of the offender

0 Male,

1 female

3 unable to determine

4- not applicable: no such individual present in this scenario

V 20:2 Offender 3: Ethnicity: Please select the ethnicity which you feel best matches the offender

0- NZ Maori 
1- NZ European

2- Pacific Islander

3- Asian

4- Indian

5- Other

xxxi) British/UK

xxxii) Eastern European

xxxiii) (please state)

6- Unsure

3- Maori or pacific islander

4- Impossible to determine

V 20:3 Offender 3: Age : Please indicate the offender's age

$0-0-16$

$1-17-25$

2- $26-40$

3- $41-55$

4- 56 and over

5- Unknown

V20:4 Offender 3 Offence type/crime: If there is more than one offence mentioned please choose the offence highlighted as most important or serious by police.

Violence $=$ grievous assaults, group assemblies, homicide, intimidation and threats, kidnapping and abduction, minor assaults, robbery, serious assaults

Drugs and anti social $=$ Alcohol, disorder, drugs, family offences, gaming, vagrancy offences

Sexual offences $=$ abnormal sex, immoral behaviour, sexual affronts, sexual attacks

Dishonesty $=$ Burglary, car conversion, fraud, receiving, theft

Property damage $=$ destruction of property, endangering

Property abuse $=$ animals, arms acts offences, littering, postal/rail/service abuses, trespass Administration= against justice, against national interest, births, deaths, marriages, by law breaches, immigration, justice, racial

Driving $=$ all driving offences

0- Violence

1- Drugs and anti social

2- Sexual offences

3- Dishonesty

4- Property Damage

5- Property abuse

6- Administration

Offender 3 Narrator's comments

V 20:5 Does the narrator refer to offender 3 in a negative way?

$0 \mathrm{No}$

1 yes

If yes what words are used?

V 20:6 Does the narrator refer to offender 3 in a positive way?

0 No 
1 yes

If yes, what words are used?

V 20:7: Please indicate if the offender is given a motivation for offending by the narrator?

0 No

1 yes

If yes please explain briefly

20:8) Is a connection to a gang or gangs mentioned?

0 - No

1- Yes if yes which gangs:

Offender 4 variables

V 21:1 Offender 4 Gender: Please indicate the gender of the offender

0 Male,

1 female

3 unable to determine

4- not applicable: no such individual present in this scenario

V 21:2 Offender 4 Ethnicity: Please select the ethnicity which you feel best matches the offender

0- NZ Maori

1- NZ European

2- Pacific Islander

3- Asian

4- Indian

5- Other

xxxiv) British/UK

xxxv) Eastern European

xxxvi) (please state)

6- Unsure

6- Maori or pacific islander

7- Impossible to determine

V 21:3 Offender 4 Age : Please indicate the offender's age

$0-0-16$

$1-17-25$

2- 26-40

$3-\quad 41-55$

4- 56 and over

5- Unknown

V21:4 Offender 4 Offence type/crime: If there is more than one offence mentioned please choose the offence highlighted as most important or serious by police.

Violence $=$ grievous assaults, group assemblies, homicide, intimidation and threats, kidnapping and abduction, minor assaults, robbery, serious assaults

Drugs and anti social= Alcohol, disorder, drugs, family offences, gaming, vagrancy offences

Sexual offences $=$ abnormal sex, immoral behaviour, sexual affronts, sexual attacks 
Dishonesty $=$ Burglary, car conversion, fraud, receiving, theft

Property damage $=$ destruction of property, endangering

Property abuse $=$ animals, arms acts offences, littering, postal/rail/service abuses, trespass

Administration= against justice, against national interest, births, deaths, marriages, by law breaches, immigration, justice, racial

Driving= all driving offences

0- Violence

1- Drugs and anti social

2- Sexual offences

3- Dishonesty

4- Property Damage

5- Property abuse

6- Administration

Offender 4 Narrator's comments

V 21:5: Does the narrator refer to offender 4 in a negative way?

0 No

1 yes

If yes what words are used?

V 21:6: Does the narrator refer to offender 4 in a positive way?

0 No

1 yes

If yes, what words are used?

V 21:7 Please indicate if offender 4 is given motivation for offending by the narrator?

0 No

1 yes

If yes please explain briefly

21:8) Is a connection to a gang or gangs mentioned?

0 - No

1- Yes if yes which gangs:

Offender 5 variables

V 22:1 Offender 5 Gender: Please indicate the gender of the offender

0 Male,

1 female

3 unable to determine

4- not applicable: no such individual present in this scenario

V 22:2 Offender 5 Ethnicity: Please select the ethnicity which you feel best matches the offender

0- NZ Maori

1- NZ European

2- Pacific Islander

3- Asian

4- Indian

5- Other

xxxvii) British/UK 
xxxviii) Eastern European

xxxix) (please state)

6- Unsure

6- Maori or pacific islander

7- Impossible to determine

\section{22:3 Offender 5 Age : Please indicate the offender's age}

$0-0-16$

$1-17-25$

$2-26-40$

3- 41-55

4- 56 and over

5- Unknown

V22:4 Offender 5 Offence type/crime: If there is more than one offence mentioned please choose the offence highlighted as most important or serious by police.

Violence $=$ grievous assaults, group assemblies, homicide, intimidation and threats, kidnapping and abduction, minor assaults, robbery, serious assaults

Drugs and anti social= Alcohol, disorder, drugs, family offences, gaming, vagrancy offences

Sexual offences $=$ abnormal sex, immoral behaviour, sexual affronts, sexual attacks Dishonesty $=$ Burglary, car conversion, fraud, receiving, theft

Property damage $=$ destruction of property, endangering

Property abuse $=$ animals, arms acts offences, littering, postal/rail/service abuses, trespass Administration= against justice, against national interest, births, deaths, marriages, by law breaches, immigration, justice, racial

Driving $=$ all driving offences

0- Violence

1- Drugs and anti social

2- Sexual offences

3- Dishonesty

4- Property Damage

5- Property abuse

6- Administration

Offender 5 narrator's comments

V22:5 Does the narrator refer to offender 5 in a negative way?

0 No

1 yes

If yes what words are used?

V 22:6: Does the narrator refer to offender 5 in a positive way?

$0 \mathrm{No}$

1 yes

If yes, what words are used?

V 22:7 Please indicate if offender 5 is given motivation for offending by the narrator? $0 \mathrm{No}$ 
1 yes

If yes please explain briefly

22:8) Is a connection to a gang or gangs mentioned?

0 - No

1- Yes if yes which gangs:

V23:

Finally, please note any important/salient information from your viewing of this episode of Police Ten 7. 


\section{Appendix 2}

TE WHARE WĀNANGA O TE UPOKO O TE IKA A MĀUI

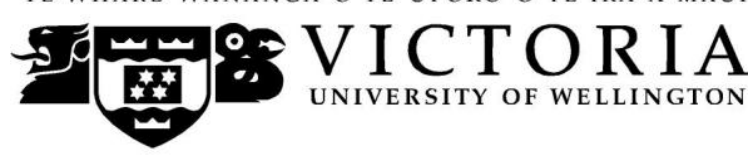

MEMORANDUM

Phone $\quad 04-4636134$

Fax 04-4635064

EmailＲhonda.Shaw@vuw.ac.nz

\begin{tabular}{l|l}
\hline TO & Gabrielle Podvoiskis \\
\hline COPY TO & \\
\hline FROM & Dr. Rhonda Shaw \\
\hline
\end{tabular}

\begin{tabular}{l|l}
\hline DATE & 24 September 2010 \\
\hline PAGES & 1 \\
\hline SUBJECT & $\begin{array}{l}\text { Ethics Approval: No. 17996 } \\
\text { Title: Reel Cops: Exploring the representation of policing on } \\
\text { New Zealand Reality Television }\end{array}$ \\
\hline
\end{tabular}

Thank you for your request for ethical approval, which has been considered by the Social and Cultural Studies Human Ethics Sub-Committee.

Your application has been approved and this approval continues until the end of June 2011. If your data collection is not completed by this date you should apply to the Human Ethics Committee for an extension to this approval.

Best wishes with the research.

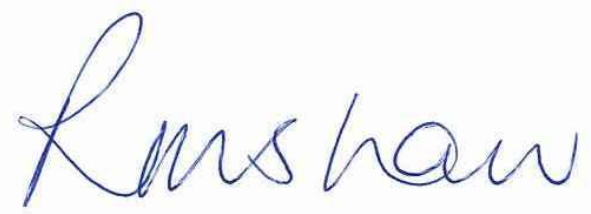

Dr Rhonda Shaw

Convener, SACS Human Ethics Committee 